Cherreux, \& $\quad 1913$

961

CRUSTACEA IIBRARY SMITHSONIAN INST. RETURN TO $W-119$ 

OUVRAGE PUBLIÉ SOUS LES AUSPICES DU MINISTÉRE DE L'TNSTRUCTION PUBLIQUE SOUS LA DIRECTION DE L. JOUBIN PROFESSEUR AU MUSEUM D'HISTOIRE NATURELLE

\title{
DEUXIEMME EXPÉDITION
}

\section{ANTARCTIQUE FRANÇAISE}

\author{
$(1908-1910)$ \\ - COMMANDEE PAR LE \\ D JEAN CHARCOT
}

i)

OWISTACSA DISRARX

SWITGSONIAR IUSI.

RQTURN TO W-119

SCIENCES NATURELLES : DOCUMENTS SCIENTIFIQUES

CRUSTACES ISOPODES PAR

HARRIET RICHARDSON

CRUSTACES PARASITES PAR

CH. GRAVIER

Assistant au Museum d'Histoire Naturelle.

(1)...

\section{COLLEMBOLES}

AMPHIPODES

ED. CHEVREUX

Correspondant du Muséum d'Histoiro Naturelle.

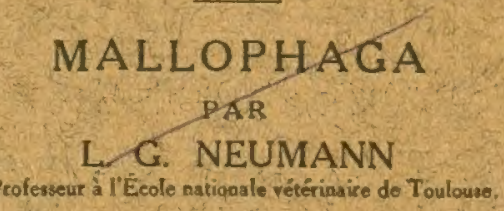

Proferseur à l'École nationale vétérinaire de Toulouso

PAR

IV ANOF

MASSON ET CIE, EDITEURS

120. Bd SAINT-GERMAIN, PARIS (VI') 


\section{COMMISSION CHARGÉE PAR L'A CADÉmIE dES SCIENCES d'élaborer le programme scientifique de l'Expédition}

MM. les Membres de l'Institut :

\begin{tabular}{|c|c|c|c|}
\hline $\begin{array}{l}\text { BOU QUET DE LA GRYE. } \\
\text { BORNET. } \\
\text { BOUVIER. }\end{array}$ & $\begin{array}{l}\text { GaRD. } \\
\text { GuYou. } \\
\text { LACRoIX. }\end{array}$ & $\begin{array}{l}\text { DE LAPPARENT. } \\
\text { MANGIN. } \\
\text { MASCART. }\end{array}$ & $\begin{array}{l}\text { MuNT. PERRIER. } \\
\text { Roux. }\end{array}$ \\
\hline
\end{tabular}

Commission nommee par le Ministère de l'Instruction Publique pour examiner les résultats scientifiques de l'Expédition

MM. Eo. Perrier......... Membre de l'Institut, Directeur du Muséum d'Histoire naturrelle, Président.

Vice-Amiral Fournier, Membre du Bureau des Longitudes, Vice-Président.

Angor............ Directeur du Bureau central météorologique.

BAYET ............. Correspondant de l'Institut, Directeur de l'Enseignement supérieur.

Bigourdan .......... Membre de l'Institut, Astronome à l'Observatoire de Paris.

Colonel Bourgeors... Directeur du Service géographique de l'Armée.

Bouvier .......... Membre de l'Institut, Professeur au Muséum d'Histoire naturelle.

Gravier .......... Assistant au Muséum d'Histoire naturelle.

Commandant Gurov.. Membre de l'Institut, Membre du Bureau des Longitudes.

Hanusse .......... Directeur du Service hydrographique au Ministère de la Marine:

Joubin............ Professeur au Muséum d'Histoire naturelle et à l'Institut Océanographique.

Lacroix............ Membre de l'Instifut, Professeur au Muséum d'Histoire naturelle.

Lallemand.......... Membre de l'Institut, Membre du Bureau des Longitudes, Inspecteur général des mines.

Lippanann .......... Membre de l'Institut, Professeur à la Faculté des Sciences de l'Université de Paris.

Müntz ........... Membre de l'Institut, Professeur à I'Institut agronomique.

RABOT............. Membre de la Commission des Voyages et Missions scientifiques et littéraires:

Roux ... ......... Membre de l'Institut, Directeur de l'Institut Pasteur.

Vélsin ............ Professeur à la Faculté des Sciences de l'Untversité de Paris. 


\section{AMPIIIPODES}

Par Ed. CHEVREUX

CORRESPONDAXT UL MLSELM NATIOMAL DHATURE NATUELLE
CRUSTACEA IIBRARY

SMITHSONIAN INST.

RETURN TO W-119

Les Amphipodes recueillis par la deuxième Expédition Antarctique Française, et dont M. le P'Bouvier a bien voulu me confier l'étude, sont représentés par quarante-quatre espèces, parmi lesquelles se trouvent dix-sept formes nouvelles. La plupart de ces Amphipodes proviennent d'une série de dragages effectués par des profondeurs comprises entre 40 et 420 mètres. Quelques autres ont été recueillis à marée basse, ou dans des touffes d'Algues provenant d'une profondeur de quelques mètres. Il m’a été possible d'indiquer la couleur de presque tous ces animaux gràce aux notes soigneusement prises au moment de leur capture par MM. Louis Gain et Liouville, naturalistes attachés à l'Expédition ; je leur en exprime ici tous mes remerciements.

Il n’est pas sans intérèt de comparer la faune antarctique proprement dite, limitée au $60^{\circ}$ de latitude sud, avec la faune arctique, bien qu'elles diffèrent beaucoup l'une de l'autre par la quantité de leurs espèces connues, le nombre des formes antarctiques d'Amphipodes n’atteignant qu'un peu plus du quart de celui des formes aretiques.

Les especes communes aux deux faunes sont au nombre de six :

Andaniexis abyssi (Boeck). Ampelisca Eschrichli Kröyer.

- macrocephala Lillj.
Harpinia plumosa (Kröyer).

Leucothoe spinicarpa (Abildg.).

Eusirus propinquus G. O. Sars.

Les seize familles suivantes, appartenant à la faune arctique, ne sont pas représentées dans l'Antarctique: 
Haustoriidæ.

Cressidx

Stenothoidr.

Laphystiopsida.

Pardaliscidæ.

Pleustidx.

Alylidx.

Aoridæ.

Amphithoidr.

Corophiidæ.

Podocerida.

Caprellidæ.

Scinidx.

Lanceolidx.

Mimoneclidx.

Tryphrenide.

Par contre, il n'existe pas de Colomastixide, de Cyllopidie et de Phrosinida dans les mers arctiques, bien que ces familles soient représentées dans les eaux de l'hémisphère nord.

Le tableau qui suit résume l'état actuel de nos connaissances sur les distributions géographique et bathymétrique des Amphipodes antarctiques et subantaretiques. 


\section{LISTE DES AMPHIPODES ANTARCTIQUES ET SUBANTARCTIQUES}

\section{(Les noms des espèces recueillies par les deux expéditions du $\mathrm{D}^{\mathrm{r}}$ Charcot sont imprimés en caractères gras.)}

\begin{tabular}{|c|c|c|c|c|c|c|c|c|}
\hline & \multicolumn{6}{|c|}{ PROVINCE } & \multirow[b]{2}{*}{$\begin{array}{l}\text { Profosoletr } \\
\text { ent } \\
\text { metres. }\end{array}$} & \multirow[b]{2}{*}{$\begin{array}{l}\text { AUTRES HABITATS } \\
\text { ET } \\
\text { OBSERVATIONS. }\end{array}$} \\
\hline & de Iras & follan. & 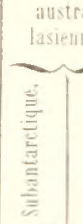 & 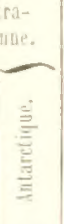 & $\mid$ & L & & \\
\hline 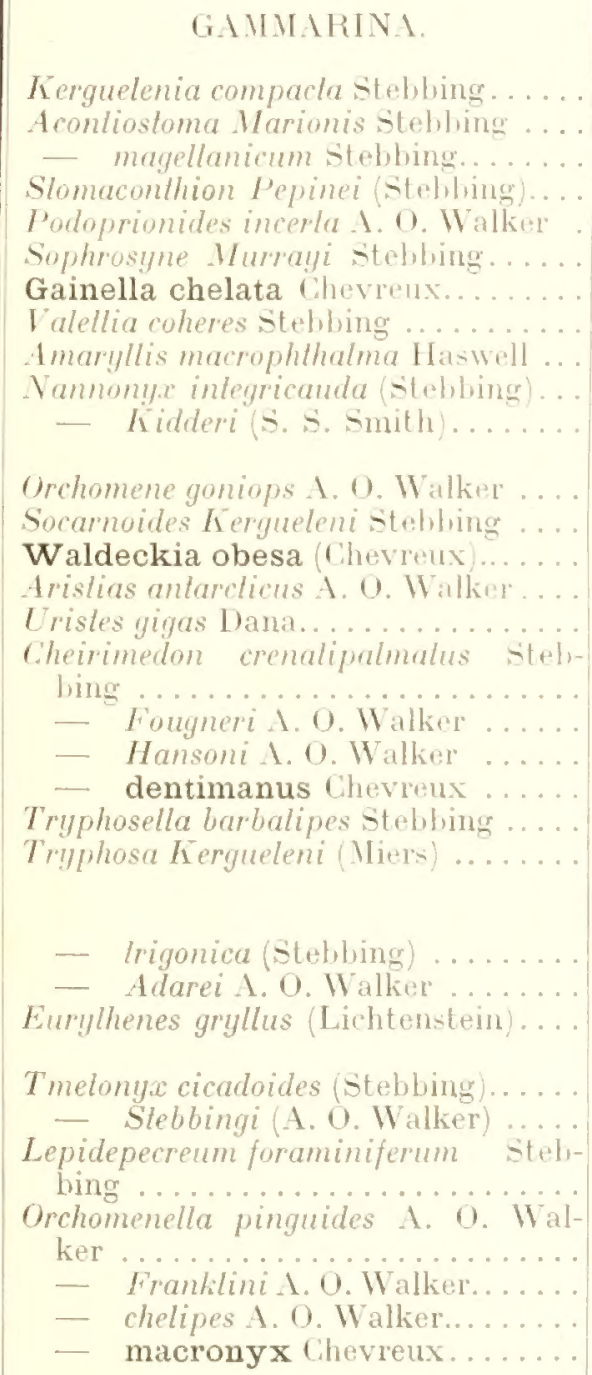 & $\begin{array}{l}+ \\
+ \\
+\end{array}$ & + & + & $\begin{array}{l}+ \\
+ \\
+ \\
+\end{array}$ & $\begin{array}{l}+ \\
+ \\
+ \\
+ \\
+\end{array}$ & 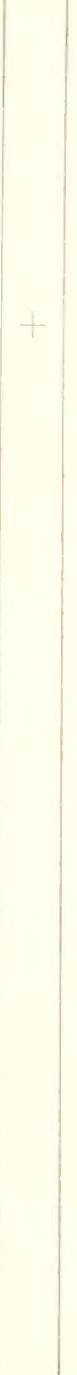 & $\begin{array}{c}230 \\
90-135 \\
100 \\
20 \\
0 \\
297 \\
3612 \\
18-100 \\
50 \\
0 \\
\\
51-230 \\
98-200 \\
37 \\
274 \\
230 \\
0-7 \\
13-37 \\
0-25 \\
228 \\
15-385 \\
\\
\\
47 \\
0-5310 \\
36-228 \\
47 \\
230 \\
18-27 \\
18-44 \\
18 \\
40\end{array}$ & $\begin{array}{l}\text { Nouvelle-Zélande. Deut- } \\
\text { che Südpolar-Expedi- } \\
\text { lion. } \\
\text { Atlantique, océan Are } \\
\text { tique. }\end{array}$ \\
\hline
\end{tabular}




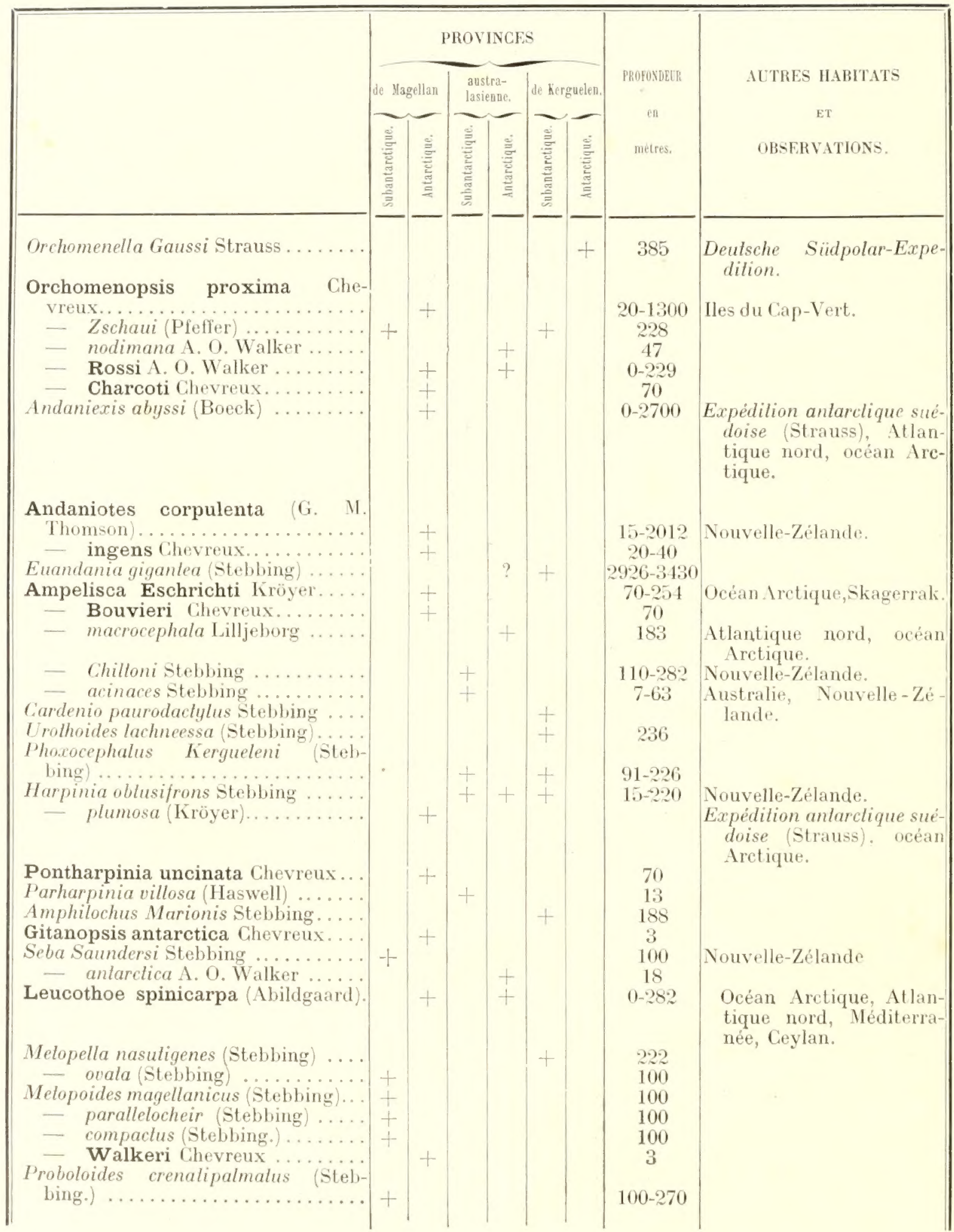




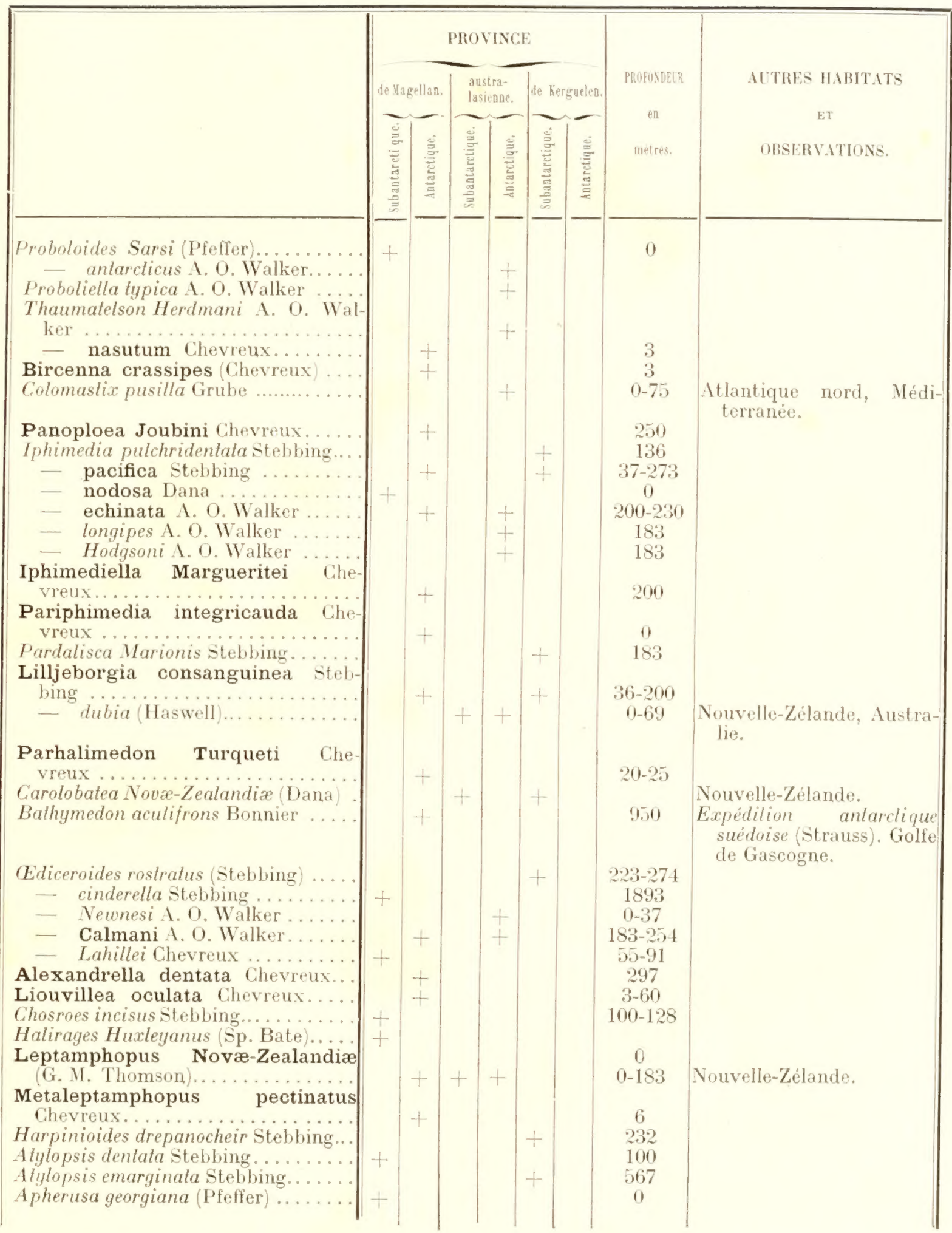




\begin{tabular}{|c|c|c|c|c|c|c|c|}
\hline & de Nage & 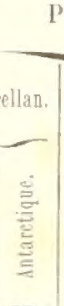 & 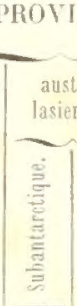 & 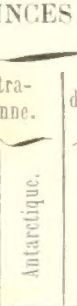 & do herguelen. & $\begin{array}{l}\text { PRopoveder } \\
\text { ent } \\
\text { mètres. }\end{array}$ & $\begin{array}{l}\text { AUTRES HABITATS } \\
\text { ET } \\
\text { OBSER VATIONS. }\end{array}$ \\
\hline 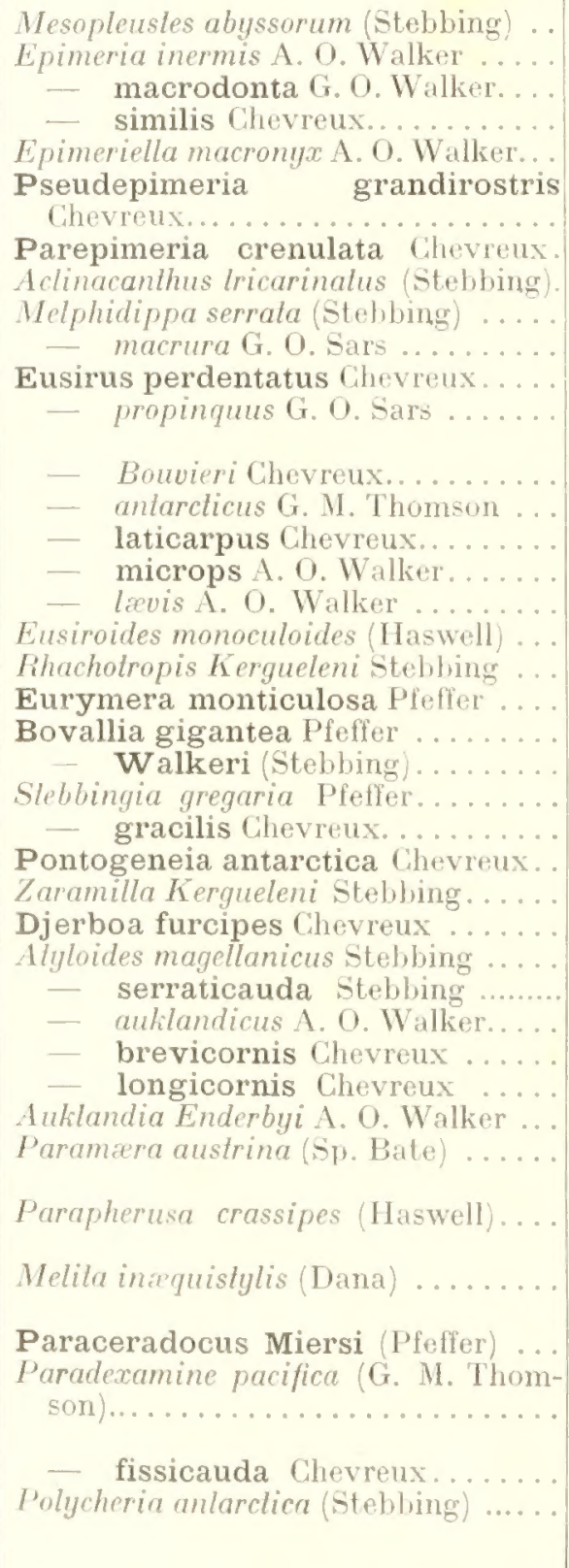 & $\begin{array}{l} \\
+ \\
+ \\
+ \\
+ \\
+ \\
+ \\
+\end{array}$ & $\begin{array}{l}+ \\
+ \\
+ \\
+ \\
+\end{array}$ & $\begin{array}{l}+ \\
+ \\
+ \\
+ \\
+ \\
+\end{array}$ & $\begin{array}{l}+ \\
+ \\
+\end{array}$ & + & $\begin{array}{c}3013 \\
196-914 \\
70-914 \\
420 \\
9-18 \\
254 \\
129 \\
282 \\
239 \\
549 \\
60-70 \\
11-282 \\
55-91 \\
282 \\
40 \\
18 \\
\\
\\
0 \\
0-5 \\
0-18 \\
0 \\
5-254 \\
0 \\
0 \\
3-5 \\
0-100 \\
0-129 \\
50-91 \\
25-129 \\
0-45\end{array}$ & $\begin{array}{l}\text { Cap des Aiguilles, Sydney: } \\
\text { Port-Jackson. } \\
\text { Australie, Nouvelle- } \\
\text { Zélande } \\
\text { Nouvelle-Zélande, océan } \\
\text { Indien. } \\
\text { Australie, } \\
\text { Zélande. } \\
\begin{array}{l}\text { Australie, } \\
\text { Zélande. }\end{array}\end{array}$ \\
\hline
\end{tabular}




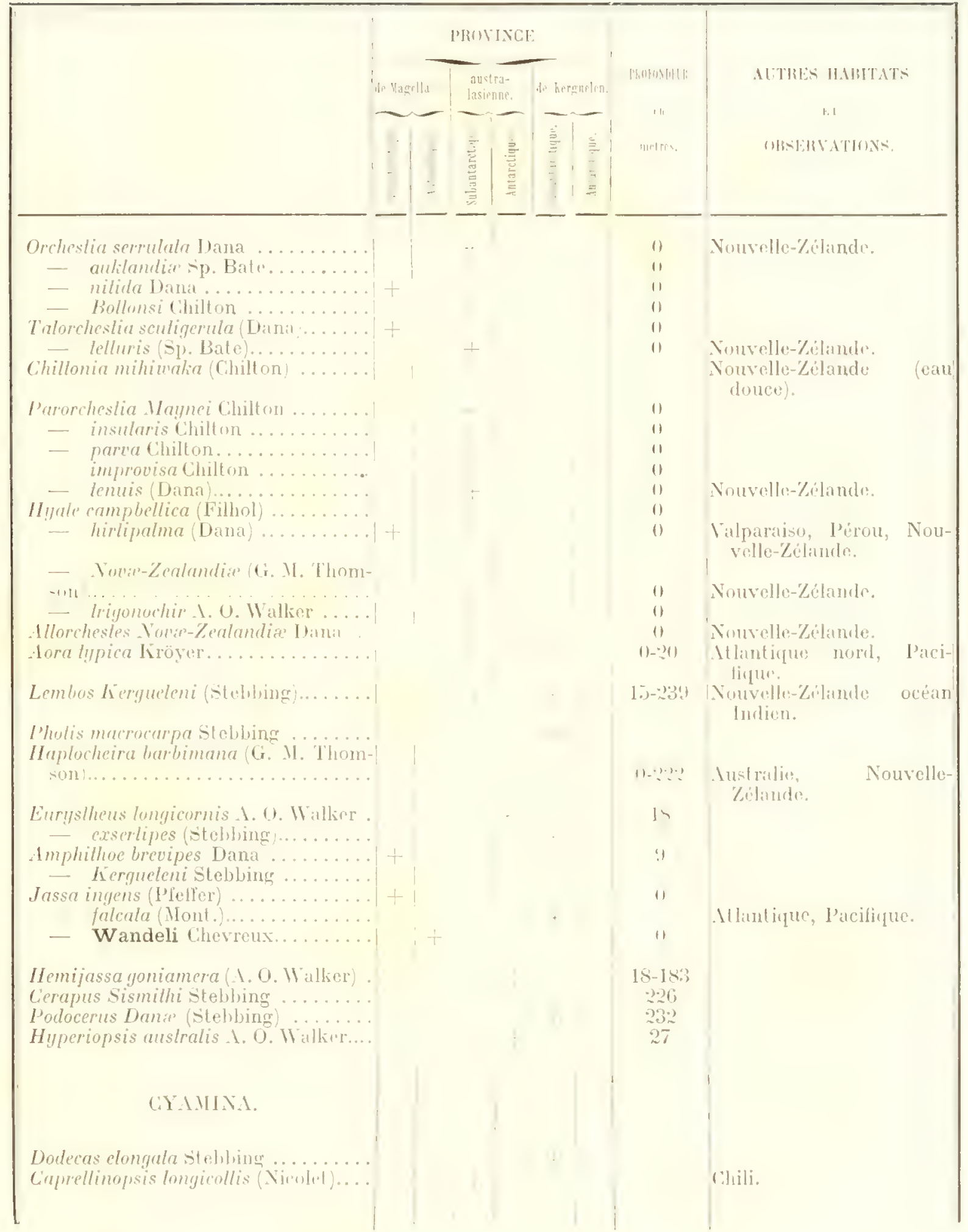




\begin{tabular}{|c|c|c|c|c|c|c|c|c|}
\hline & de thag & cellan. & 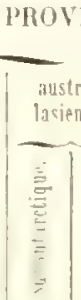 & - & 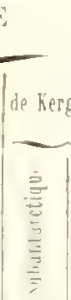 & guten. & $\begin{array}{l}\text { PROFUNIEL R } \\
\text { metres, }\end{array}$ & $\begin{array}{l}\text { AUTRES HABITATS } \\
\text { ET } \\
\text { OBSERVATIONS }\end{array}$ \\
\hline 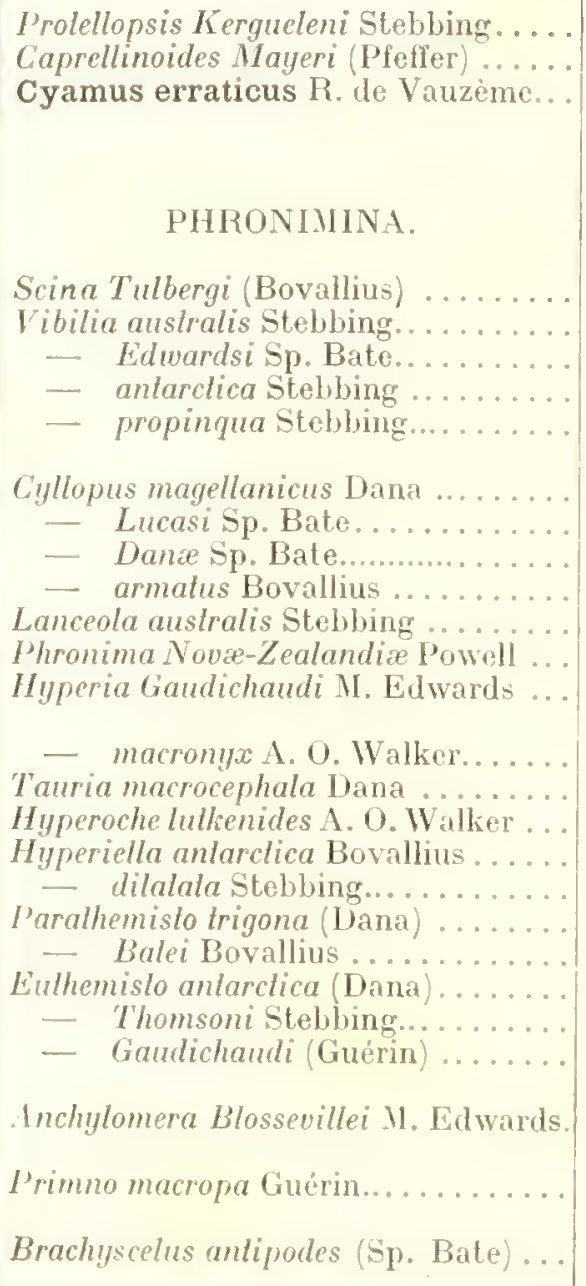 & $\begin{array}{l}+ \\
+ \\
+ \\
+ \\
+ \\
+\end{array}$ & $\frac{t}{+}$ & $\begin{array}{l}+ \\
+ \\
+\end{array}$ & $\begin{array}{l}+ \\
+ \\
+ \\
+ \\
+\end{array}$ & + & + & $9-18$ & $\begin{array}{l}\text { Pacifique nord, golfe de } \\
\text { Gascogne. } \\
\begin{array}{c}\text { Régions tempérées du } \\
\text { Pacifique. }\end{array}\end{array}$ \\
\hline
\end{tabular}




\section{GAMUARIJA.}

\section{LYS/AISS/DE.}

\section{G.THELLA Chereux.}

1!11. Gainella Chevreux (3), p. 116\%.

Corps obese, téguments épais of consistants, plaques cosales tres hautes. Antennes courtes, subégales. Promirra article du pédoncule des antennes superienres cábiné. Wernier article du pédoneule des antennes inférieures plus court que chatun des deux articles précédents. Epistome ne débordant pas sur la live antéricure. Processus molare des mandibules bien développé, palpe dixé en aróiere du processus molaire. Prolonsoments postrieurs de la leve postéreme non divergents. Lobe interno des maxilles anteriemes ne portant qu'une spinule au bord distal; lobe rxtorne armé de dix epines simples; palpo trés devoloppé. Lobo des maxilles posterieures d'égale longueme. Lobe interne des maxillipides triss long, acomine; lobe externe plus court que le lobe interne; palpe remarquablement développé, gualriome article non dactyliforme. Propode des suathopodes ahéliforme, celui des snathopodes posteriens étant de beaucoup le phus etroit. Perciopodes pobustes et tries courts. leopodes de la dernière pare tres léduits. branche externe mniaticulé, branche interne rudimentaire. Telson profondément fendu.

Ce nouvea sente de Lysianassides a été dédié à M. Lonis Gain, naturaliste attaché it l'Expédition du " Pourquoi l'as"? ".

\section{Gainella chelata Chevreux.}

1912. Gainella chelala Chevreux (4).

Dragage 1. 22 janvier 1909, pres de la Teres Alexandre-ler; profonden, 297 metres. Dans l'interieur d'me Eponge. Un exemplaire, dont le copps était d'un jaune pale.

Le corps, tres obese, mesurail ; millimetres de longueur, dans la position ou il est figuré ici. Les téguments sont épais et consistants. Lit tête, un peu plus longue au bord dorsal que le premier segment du 
mésosome, ne posside pas de rostere Les lobes lateraux, trés prolongés cu avant, sont subaigus. Les plaques coxales des quatre premières paires atfeignent à peu press lo double do la inauteur des segments corres-

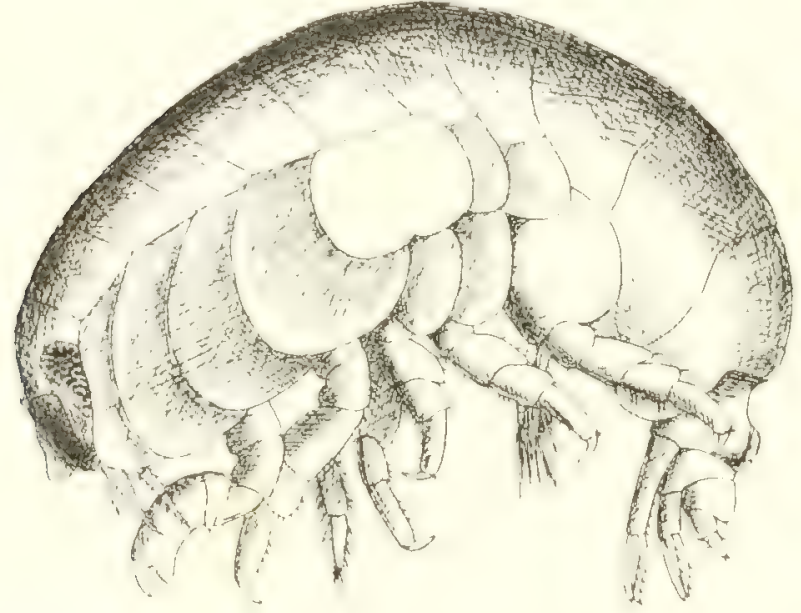

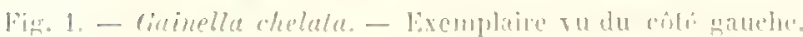
pondants du mésosomr" Les plaques coxales de la premiere palpe sont irregulierenent erénelées an hord inférieur. Les plaques coxales de la cinquiome paipe sont plus larges que haules. Los plarques épiméralos dos deux derniers sogments du mótasome, un peu prolongives en arriere, sont rignliemenent arrondies. I, fremior segment de l'urosome présente mo profonde dépression dopale, suivio d'une catrone anondie.

Les yeux, fris seands, roniformes, compremment de nombroux ocelles. los antemnes suporiomes soml aussi longues quo lonsemble de la

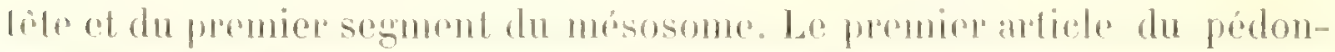

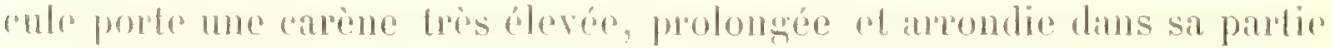

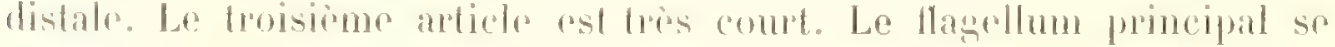

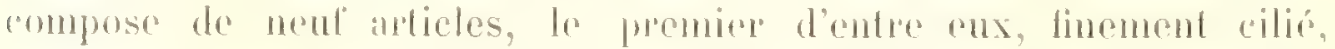
depassant un peu en longueur l'onsemble des deux articles suivants. Ido llagellum accessoine ost frianticule.

Les antennes infréperos dépassent a peine on longueur les antomnes supérienres. Le cinquiome article du pédoncule n’attrint pas tout in lail la longuene du troisibme anticle, qui lui-mome est beancoup moins long fuo le quatriome. Le flagellum se compose do dix articles fincment ailiós.

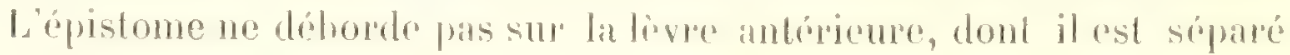
par un léger sinus.

Les mandibules sont peu developpeses. Le. bord tranchant porte une

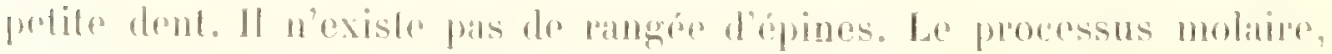


bien conformé, est très saillant. Le palpe, court et robuste, est fixé beancoup plus loin du bord tranchant que le processus molaire; son dernier article, beaucoup plus court que l'article précédent, porte une rangée d'épines au bord interne.

La lèvre postérienre, peu développée, présente des lobes externes

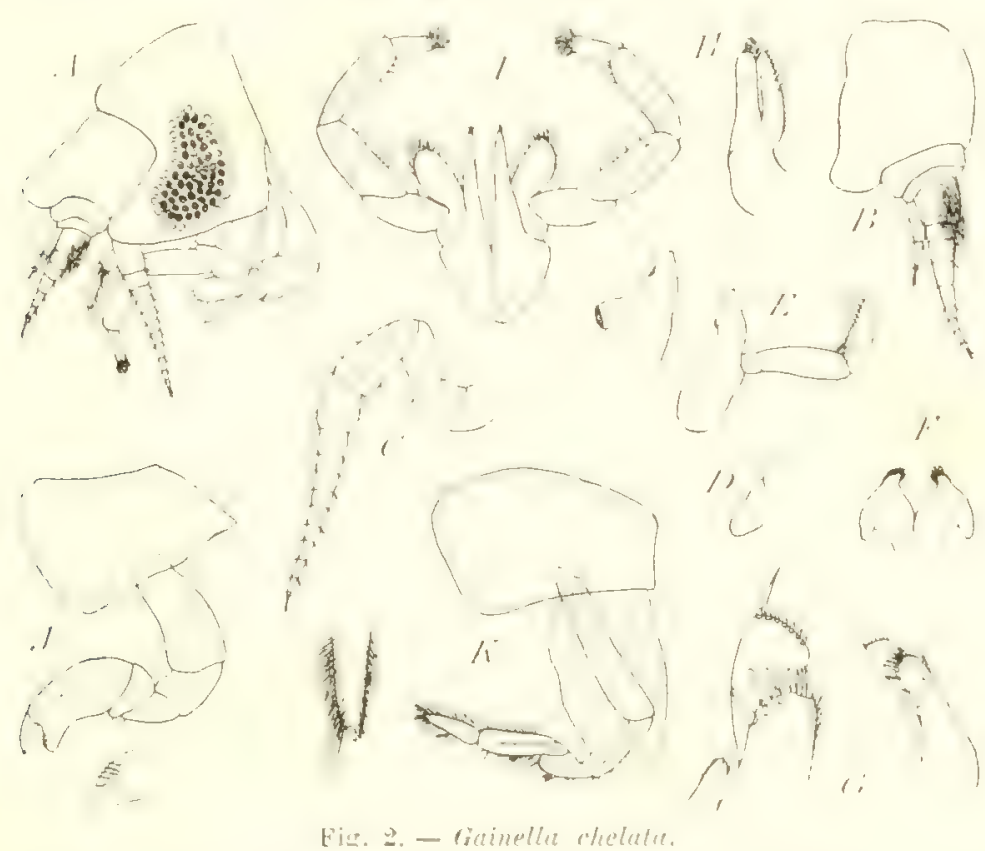

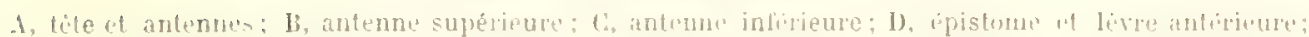

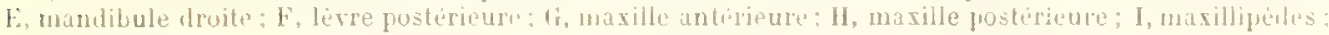

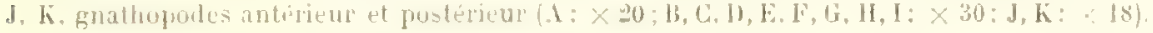

brusquement rétréeis dans leur partie distale. Les prolongements postérieurs ne sont pas divergents.

Le fole interne des maxilles antérieures, finement cilié sur ses deux bords, ne porte qu'une petite épine à son extrémité. Le lobe externe esl armé de dix épines simples. Le palpe, très robuste, biarticulé, est dilaté dans sa partie distale, qui porte sept épines, grosses et courtes, et nue longue soie spiniforme.

Les lobes des maxilles pustérieures sont d'égale longueur. Le lobe externe porte une rangée d'épines au bord distal. Le lobe interne, plus étroit, acuminé, porte sept épines au bord interne.

Les maxillipides sont tres remarquables. Le lobe interne, tress etroit, acuminé, se termine par trois petites fpines. Le lobe externe, petit.

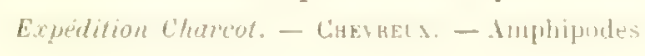

CRUSTACEA IIBRARY SMITHSONIAN INST. RETURN TO W-119 
ovalaire, un peu phus court que le lobe interne, porte des epines au bord interne; son bord externe est finement cilié. Le palpe est extrème ment développé. Lies deuxieme ef troisième articles, très robustes, sont it peu près de même longueur. Le quatrième article atteint la moitié de la longueur de l'article précédent: son bord distal, arrondi, porte une épaisse touffe de soies.

Les gnathopodes antérieurs sont robustes. L'article basal, gros et court, s'élargit dans sa partie distale. L'article ischial est aussi long que l'ensemble de l'article méral et du carpe. Ce dernier article, très court, présente un prolongement lobiforme peu accentué. Le propode, deux lois mssi long que large, oftre un bord antérieur fortement convexe. Le bord postérieur, concare, se prolonge inférieurement pour former. aver le bord palmaire, un angle subaigu sur lequel l'extrémité du dacfyle peut s'appuyer.

Les gnathopodes posterieurs, tres grêters, sont un peu plus longs yur les gnathopodes antérieurs. Le carpe, cilie sur ses deux bords, atteint la longueur de l'article ischial. Le propode, très étroit, se prolonge infélieurement pour former une petite pince aree le dactyle.

Tous les péréiopodes sont très courts et très robustes. Liarticle basal dés péréiopodes des deux premieres paires s'élargit dans sa partie distale. Larticle méral est très volumineux. Le propode atteint le donble de la longueur du carpe. Ces deux derniers articles portent de petites épines au bord postérieur. Le dactỵle est robuste et courbé.

Les péréiopodes des trois dernières paires augmentent progressivement de longueur. de la troisième a la cinquième paire. Larticle basal, un peu plus longr que large, ne présente pas de crénelures au bord postérieur. Le carpe et le propode portent des épines au bord antérieur. Le dactyle est moins robuste ot moins courbé que dans les péréiopodes des deux premières paires.

Les uropodes des deux premières paires sont très robustes. Les branches des uropodes de la première paire sont plus courtes que le pédoncule. Les branches des mopodes de la deuxième paire alteignent à peu frès la longueur du pédoncule. Les uropodes de la demière paire sont lrès compts. Le pédoncule est un peu plus large que long. La branche 
externe, uniarticulée, un peu phs longue que le pédoneule, se termine par deux épines d’inégale taille. La branchto interne, rudimentaire, est stpuamitorme.

Le telson, plus large que long, est curent sur presque toute sa lon-

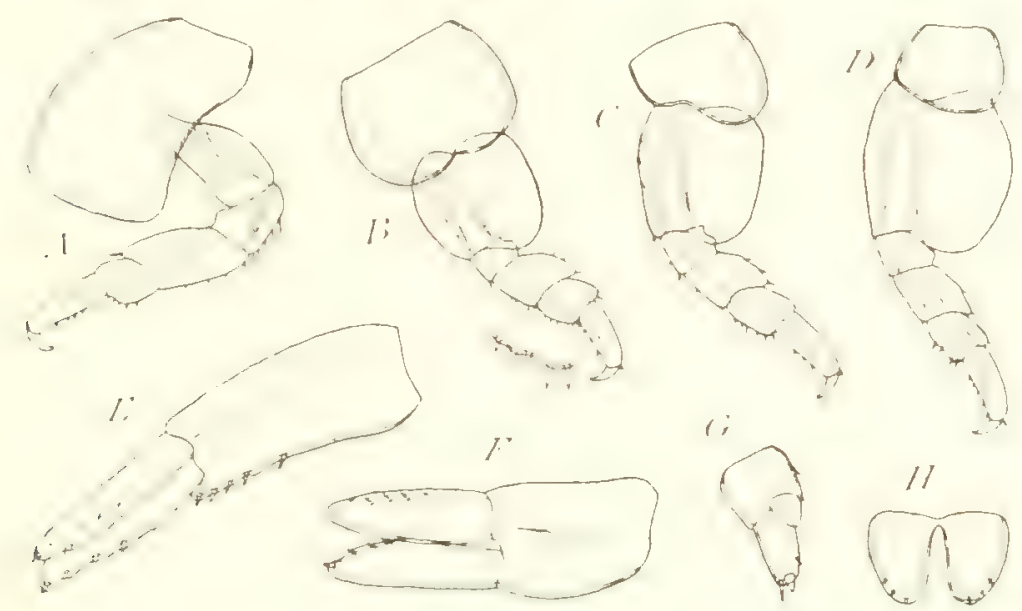

Fig. 3. - Gainella chelata.

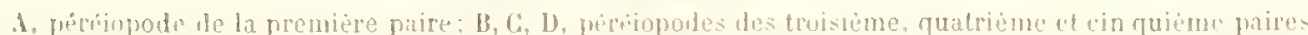
E, F, G, uroporles des première, deuxime et troisieme paires: H, telson $(\mathrm{A}, \mathrm{B}, \mathrm{C}, \mathrm{I}): \times 18: \mathrm{E}, \mathrm{F}, \mathrm{G}, \mathrm{II}$ : $\times 421$.

sueur. Ses lobes, largement arondis à leur extrémité, portent chacun trois petites épines.

Le nom spécifique de cette espèce fait allusion ì la forme du propode des gruathopodes antérieurs.

\section{Waldekia obesa Chevreux).}

1905. Charcolia obesa Chevreux (1), p. 163, fig. 3.

1906. Charcolia obesa 1. O. Walker (16), p. 454.

1906. Charcolia obesa Stebbing (11), p. 718.

1906. Waldectia obesa Chevreux (2), p. 15, fig. 8 à 10 .

1907. Waldectia obesa A. 0. Walker (17), P. 10, P1. II, fig. 4.

1910. Waldeckia obesa Stebbing (12), p. 572.

Dragage V, 2! décembre 1908, chenal l'ellier, entre l'ilot Goetschy ot lîle Doumer; profondeur, "2) mètres. Deux femelles, dont la plus srande mesurait 18 millimetres de longueur. Le corps de ces femelles était d'un jaune orangé.

Dragage VIII, 20 janvier 1909, baie Marguerite; profondeur, 200 mòtros. Dowzo exemplaires : un mall adulte, six femelles et cinq jeunes. Ise 
corps. d'un jaune orangé chez les adultes, était rose chez un jeune exemplaire, long de 6 millimetres, et jaunatre chez un exemplaire de 3 , 3 i de longueur.

\section{Cheirimedon dentimanus Cherreux.}

1905. Cheirimedon dentimanus Chevreux (1), p. 159 , figr. 1.

1906. Cheirimedon dentimanus stebbing (11), p. 7:0.

1906. Cheirimedon denlimams Chevreux (2). p. "., fig. 1 à 4 .

He Déception, Pendulum-Cove, 2̇i décembre 1908. littoral. Tombreux exemplaires. 1I. Gain a trouvé beaucoup de ces Amphipodes " tués par la forte température de leau le long du rivage, température qui atteinl jusqu à $+70^{\circ}$. Il y a en cet endroit, au niveau de la mer, des sources chandes".

Orchomenopsis Rossi A. O. Walker.

1903. Orchomenopsis Rossi A. O. Walker (15), p. 45, Pl. VII, fig. 18 à 23.

1306. Orchomenopsis Rossi Stebling (11), p. 721.

1907. Orchomenopsis Rossi 1. 0. Walker (17), p. 14.

Ile Petermann, 2: juillet 1909, dans l'estomac d'un màle de Pygoscelis Alliz. In mâle de 21 millimetres de longueur.

\section{Orchomenopsis Charcoti Chevreux.}

1912. Orchnmenopsis Charcoli Cherreux (4).

Dragage XY, 26 novembre 1909, chenal de Roosen, devant PortLockroy: profondeur, 60 i 70 mètres. Ln màle, une femelle.

Le corps de ces Amphipodes était blane, passant au rougeatre dans la partie dorsale: les yeux étaient bruns.

Yile. - Le corps, assez obèse, atteignait 11 millimètres de longueur dans la position où il est figuré ici. Les téguments sont épais et consistants. Le bord supérieur de la tête est un peu plus court que le premier segment du mésosome. La tête ne porte pas de rostre; ses lobes latéraux. tres saillants. sont largement arrondis au bord distal. Les plaques coxales dos quatre premières paires dépassent de heaucoup en hauteur les segments correspondants du mesosome. Les platpues coxales de lat ein- 
quieme paire, m peu plus larges que hautes, sont à peine ichancrés au bord inférieur, le lobe antérieur étant plus petit que le lobe postérieur. Les plaques épinérales du derniè segment dumétasome, peu prolongées. sont largement arrondies en arrière. Le premier segment de l'urosome

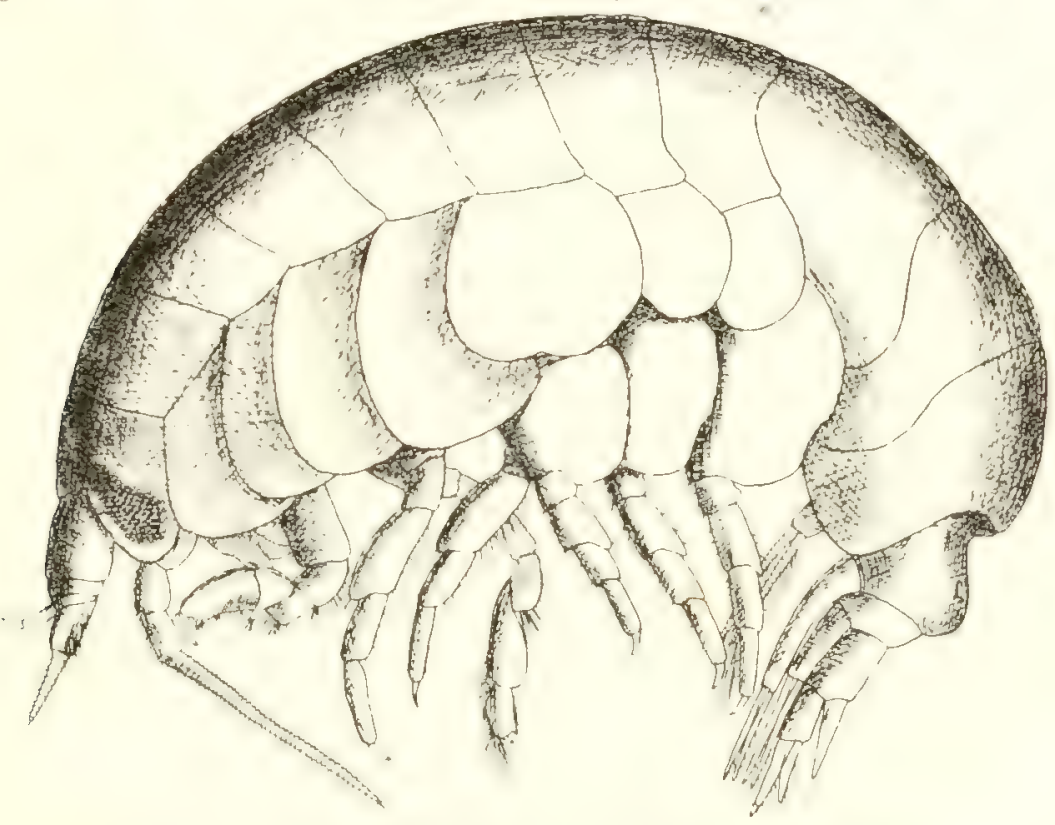

Fig. \&. - Orchomenopsis charenti. - Mile, vu lu coté gauche

présente une profonde dépression dorsale, suivic d'un renflement arrondi.

Les yeux, tres grands, lagreniformes, possident un grand nombre d'ocelles.

Les antennes supérieures dépassent id prine en longrurur l'ensenble de la tête et du premier segment du mésosome. Le premier arlicle du pédoncule, un peu plus long que large, natteint pas la longueur du bord supérieur de la tete. Le tlagallum principal, un peu plus long que lo pédoncule, se compose d'un premier arlicle trés allongé, garni d'uno dizaine de rangées de soies, suivi de treize articles beaucoup moins longs que larges. Le flagellum accessoire comprend un article lamellilomme, un peu dilaté dans sa partie médiane, suivi de cing articles très courts.

Les antennes inferieures atteignent lo doublo de la longuenr des antennes supérieures. Les troisicme ef cinquieme articles du pédoncule. d'égalo laille, sont un pou plus courts que le quatriome aticle. Le bord 
antérieur des deux derniers articles porte une épaisse rangée de soles. Le flagellum, plus long que le pédoneule, comprend quarante-six articles très courts.

L'épistome ne déborde pas sur la lère antérieure:

Le processus molaire des mandibules est garni d'épines et de soies.

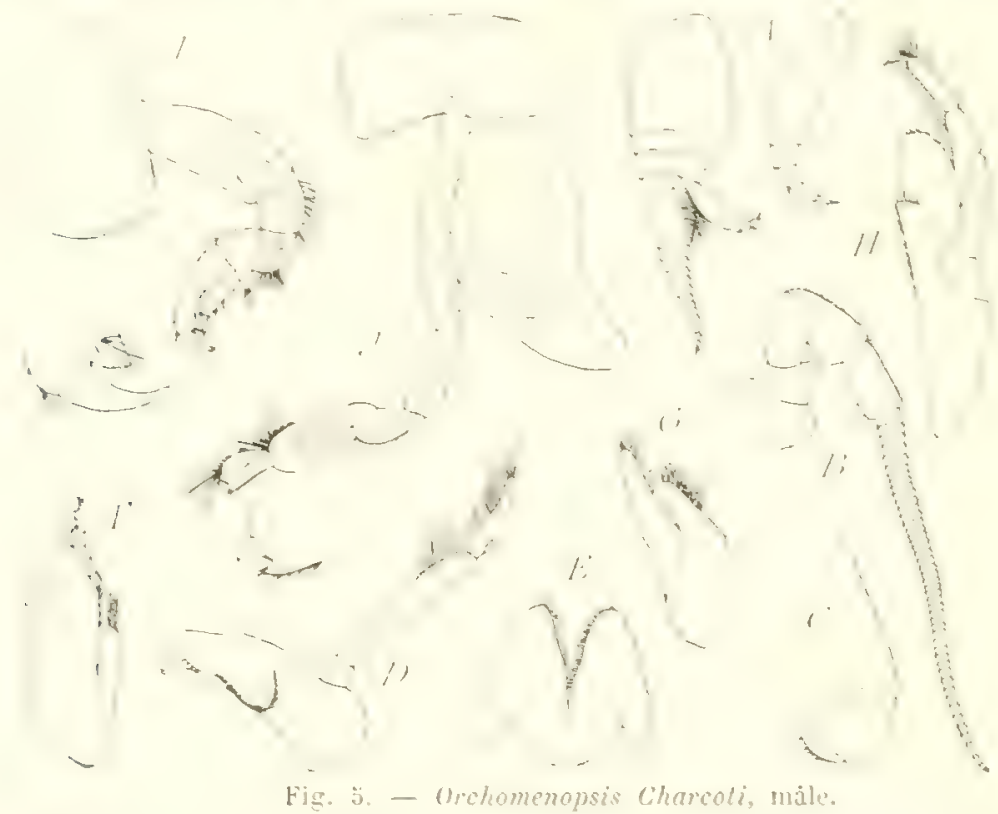

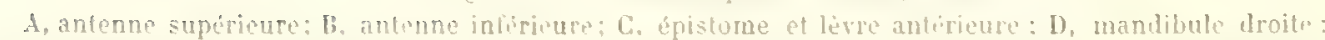

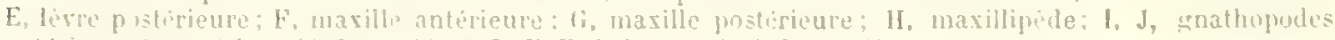

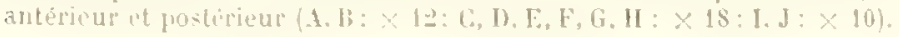

Le palpe est tixé près de la base de la mandibule; son dernier article niatteint que la moitié de la longueur de l'article précedent.

Le tobe interne des maxilles antérieures porte, au bord distal, ume épine ot deux soies ciliées. Le lobe externe, très large, est obliquement trongué. Le palpe porte une rangée de petites épines au bord distal.

Les lobes des maxilles postérieures sont de taille trìs inégale, le lobe externe dépassant de beaucoup le lobe interne. Tous deux portent des ipines au bord distal ot au bord interne.

Le lobe externe des maxillipèdes, crénelé au bord interne, n'atteint pas lout à fait l'extrémité du deuxieme article du palpe. Le troisième article du palpe, très grête, est plus de deux fois aussi long que le quatrième article.

Les gnathopodes antéricurs sont robustes. Larticle basal, un peu plus 
court que l'ensemble des quatre artirolns suivants, présente un bord antérieur droit, un bord postérieur un pen convexe. Le carpe porte un prolongement lobiforme ebroit ot anguleux. Le propode, quadoangulaire. heancoup plus long que large, ofle un bord posterieur concave, se prolongeant inforieurement pour lormer un angle aigu avee le bord palmaire.

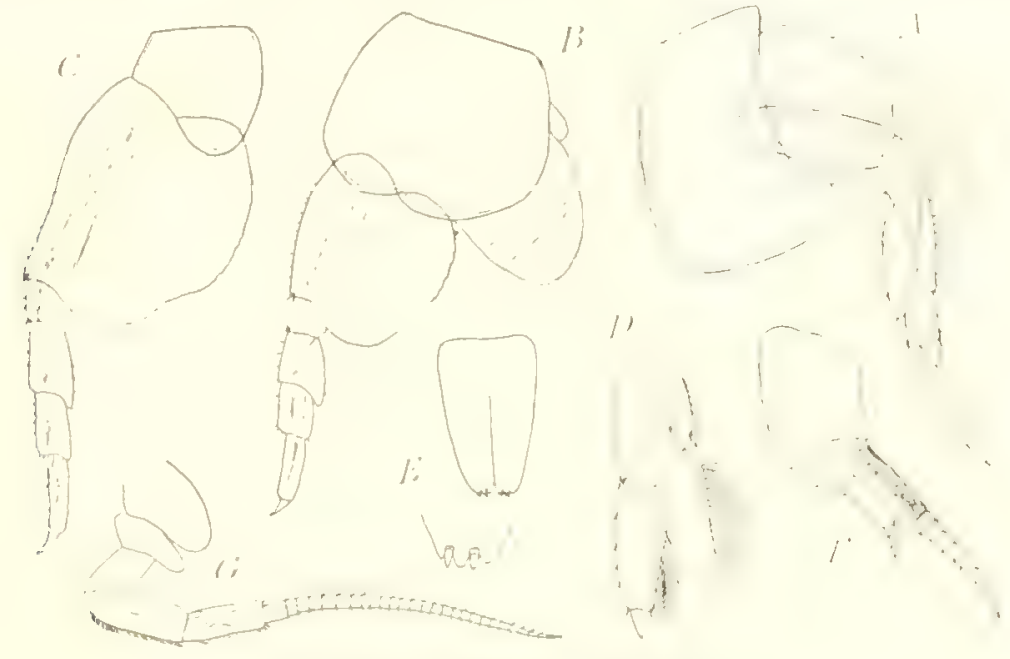

Figr. Ai. - Urchomenopsis Chureuli.

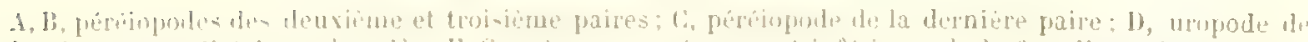

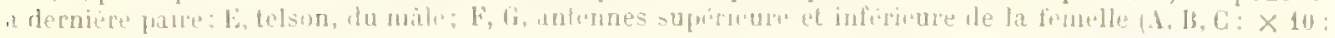

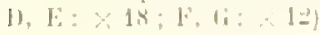

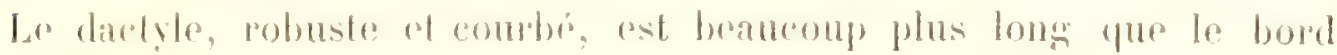
palmaine.

Lor carpe des guathopodes postionirurs, modérement large, atteint lo double de la longurur du propode. Ce dernirr artich se prolonge infísrieurement pour former une petite pince avec le dactyle.

Les peréiopodes des trois dernieres paires, tris courts, angmentent progeresivement de longueur, de la troisieme ì la cinquiome paire. L'illicho basal est tros large. Dans les probiopodes des deux dernieres paires, le lored postérieur de cet article porte quelques crénelures. suivies d'une légère concavité. Les quatre articles suivants sont courts it robustes.

Les lobes branchianx sont plissés des deux cótés.

Les uropodes de la derniere paire dépassent l'extrémité des deux paires précédentes. Les branches, largement lancéolées, sont assez inégrales. la branche interne, a peine plus lonşue que lo pédoneule, nattergnant 
pas tout à fait l'extrémité du premier article de la branche externe. Le bord interne de chacune des branches porte une rangée de soies ciliées.

Le telson, beaucoup plus long que large, atteint à peu près le milieu des branches des uropodes do la derniere paire. Il est fendu sur les deux tiers de sa longueur. Chacun de ses lobes présente, au bord distal, deux petites échancrures garnies chacune d'une épine. Deux paires de spimules latérales ne sont visibles qu'à l'aide d'un fort grossissement.

Femelle. - La femelle atteignait 15 millimètres de longueur. Les antemnes sont un peu plus courtes que celles du male, le llagellum des antennes supérieures possédant seutement treize articles et celui des antennes inférieures, vingt-sept articles. Les autres appendices ressemblent a ceux du mile, et l'article basal des péréiopodes des deux dernières pares présente également une échancrure au bord postérieur.

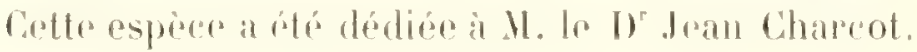

\section{AHIELSTHIIE.}

\section{Ampelisca Eschrichti Liriyer,}

1906. Ampelisca Eschrichli Stebbing (11), p. 100.

1906. Ampelisca Eschrichli Chevreux (2), p. 20, fig. 11.

I) ragage VIII, 20 janvier 1909, baie Harguerite; profondeur, 200 mitres. Un màle, de 1 b̈ millimetres de longueur, ne diftérant de la femelle que par ses antennes inférieures aussi longues que le corps.

Le corps de cet exemplaire était brun, les appendices roses, les yeux d'un rouge vil.

Dragage XV, 26 novembre 1909, devant Port-Lockroy, chenal de Roosen; profondeur, 60 a 70 mètres. In exemplaire de 13 millimètres de longueur.

Lecorps de cet exemplaire blait d'un janne légèrement rosé; les yeux étaient rouges.

\section{Ampelisca Bouvieri nor. sp.}

Dragage XV, (inovembre 1909. Devant Port-Lockroy, chenal de Roosen; profondeur, 60 s 70 metres. Une femelle, dont le corps était d'un jaune légèrement rosé et les yeux rouges. 
Le corps, assez fortement comprimé, mesurait 12 millimetres de longueur dans la position ou il est figuré ici. La tête, un peu plus courte que l'ensemble des trois premiers segments du mésosome, présente un bord dorsal légèrement concave, sa partie distale étant fortement courbée en

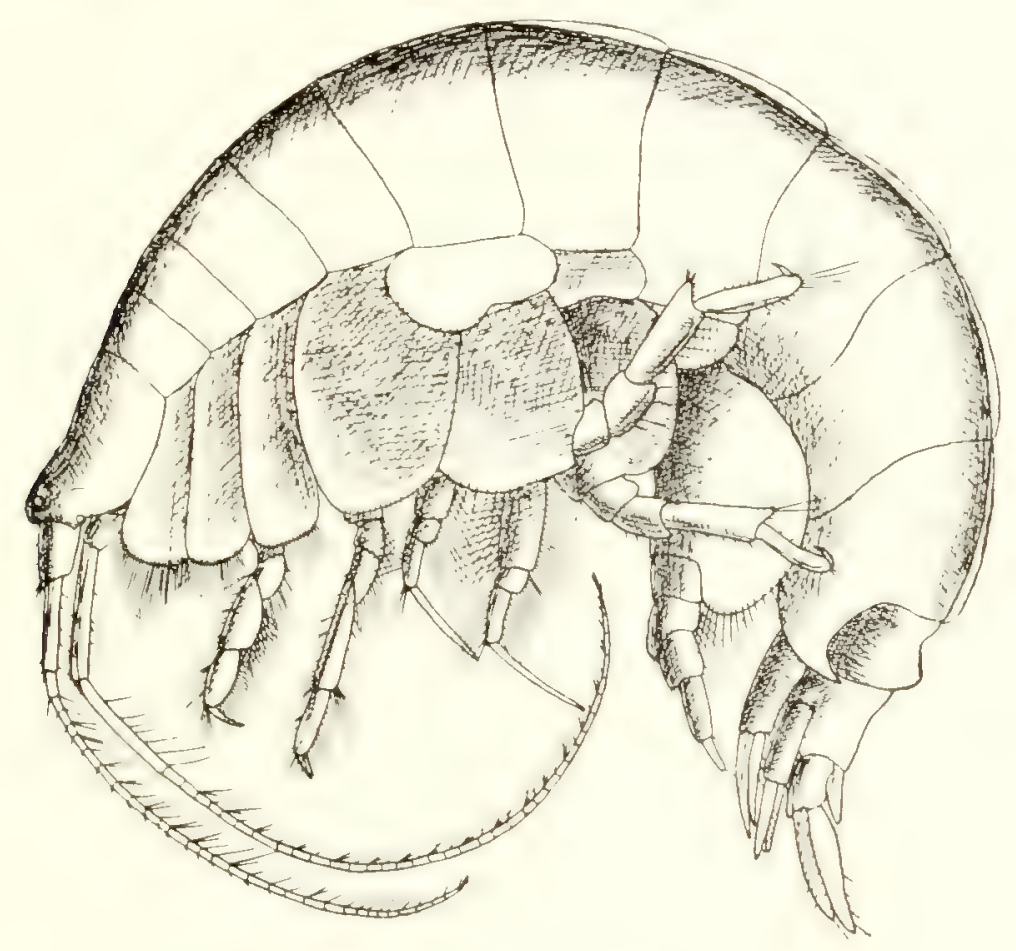

Fig. 7. - Ampelisca Bourieri. - Femelle vue du còté gauche

avant, puis un peu obliquement tronquée. Les plaques coxales de la première paire s'élargissent quelque peu dans leur partie distale. Les plaques coxales de la quatrieme paire sont beaucoup plus hautes que larges, leur bord inférieur étant plus court que leur bord postérieur. Les deux derniers segments du mésosome et le métasome portent une carène dorsale bien nettement distincte. Les plaques épimérales du dernier segment du métasome, fortement prolongées en arrière, se terminent par une dent longue et aiguë. Le premier segment dr: l'urosome porte une carène dorsale arrondie.

Les yeux sont bien distincts; la paire inférieure, située à quelque distance du bord antérieur de la tète, déborde un peu sur le bord inférieur.

Expédilion Charcot. - Cheveetx. - Amphipodes. 
Les antennes supérieures sont aussi longues que l'ensemble de la tête et des cing premier's segments du mésosome, leur extrémité atteignant à peu près le milieu du flagellum des antemnes inférieures. Le premier article du pédoncule est gros et court. Le deuxième article, beaucoup plus spểle et plus allongé que le premier, atteint plus du triple de la longueur

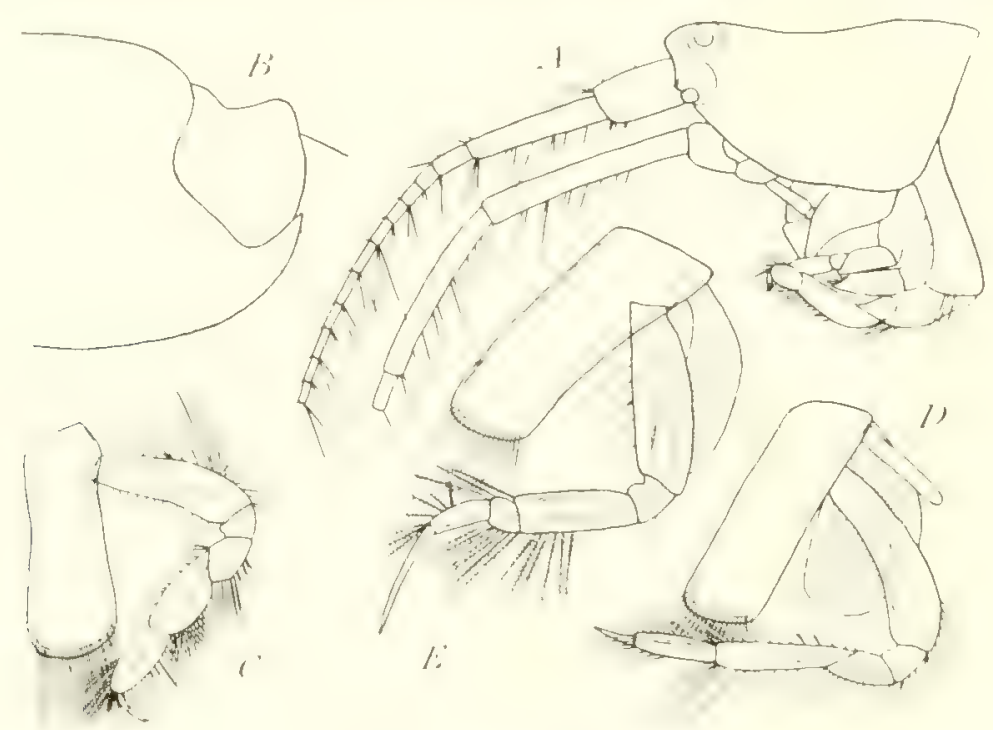

Fig. 8. - Ampelisca Bouvieri.

A. tète el partie des antennes; B, dernier segment du metasame et premier segment de l'urosome: C, D. gnathopodes antérieur et postírieur; E, péćcopode de la premiere paire $(\mathbf{A}, \mathbf{B}: \times 12 ; \mathbf{C}, \mathbf{D}, \mathbf{E}: \times \mathbf{1 0})$.

du troisieme article. Le llagellum, qui comprend trente articles, est à peu près trois lois aussi lonğ que le pédoncule.

Les antemes inférieures sont beaucoup plus longues que les antennes supérieures. Le dernier article du pédoncule est un peu plus court que l'article précédent. Le flagellum, composé de trente-six articles, atteint a peu près le double de la longueur du pédoncule.

Le propode des gnathopodes antérieurs, ovale allongé, est plus étroit et un peu plus court que le carpe.

Le propode des gnathopodes postérieurs, très grêle, atteint à peu près les deux tiers de la longueur du carpe.

Le dactyle des péréiopodes des deux premières paires, assez robuste el remarquablement grand, atteint le double de la longueur du propode.

Le propode des péréiopodes de la troisième paire est un peu pro- 
longé au bord distal. Le propode des péréiopodes de la quatrième paire ne présente pas de prolongement.

L'article basal des péréiopodes de la derniore paire dépasse de beaucoup' en longueur l'ensemble des articles suivants. Le lobe postérieur, régu-

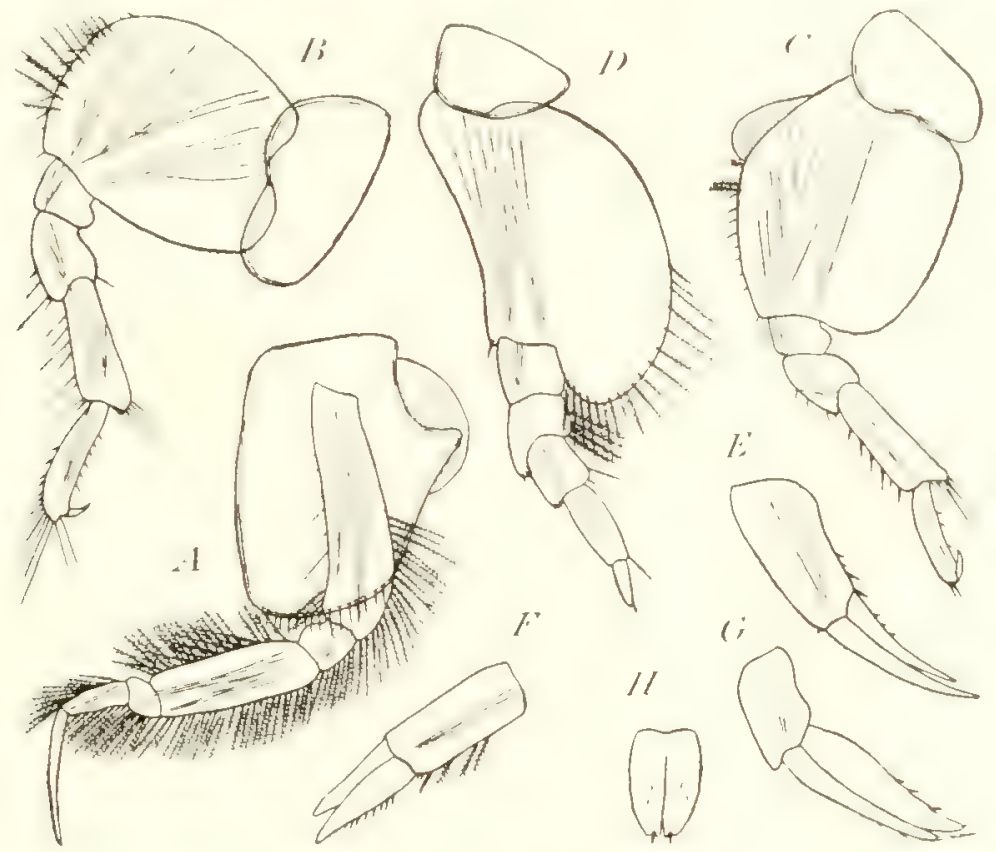

Fig. 9. - Ampelisca Bouvieri.

A, B, C, D. péréiopodes des deuxieme, troisième, quatrieme et cinquiène paires: L, F, G, uropodes des premiere, deusiene el troisième paires; $\mathbf{H}$, telson $(\mathbf{A}, \mathbf{B}, \mathbf{C}, \mathbf{U}: \times 10 ; \mathbf{E}, \mathbf{F}, \mathbf{G}, \mathbf{H}: \times \mathbf{I})$.

lièrement arrondi, se prolonge inférieurement au delà de l'article ischial. L’article méral se prolonge le lonğ du bord antérieur du carpe. Le propode est un peu plus court que l'eusemble des deux articles précédents. Le dactyle atteint un peu plus de la moitié de la Inngueur du propode.

Les uropodes de la dernière paire dépassent de beaucoup les uropodes précédents. Les branches, de taille un peu inégale, sont armées de quelques épines, mais ne portent pas de soies ciliées.

Le telson, ovale allongé, une fois et demie aussi long que large, porte une paire d'épines distales et deux paires de spinules dorsales.

Cette espèce a été dédiée à M. le Pr Bouvier. 


\section{PIOYOCEPIALIDE.}

Pontharpinia uncinata Chevreux.

1912. Pontharpinia uncinala Chevreux (4).

Dragage $\mathrm{XV}, 26$ novembre 1909, devant Port-Lockroy, chenal de Roosen; profondeur, 60 à 70 metres. Une femelle ovigère, dont le corps était teinté de jaunâtre et les yeux noirs.

Gette femelle, qui portait vingt-deux oufs dans sa poche incubatrice,

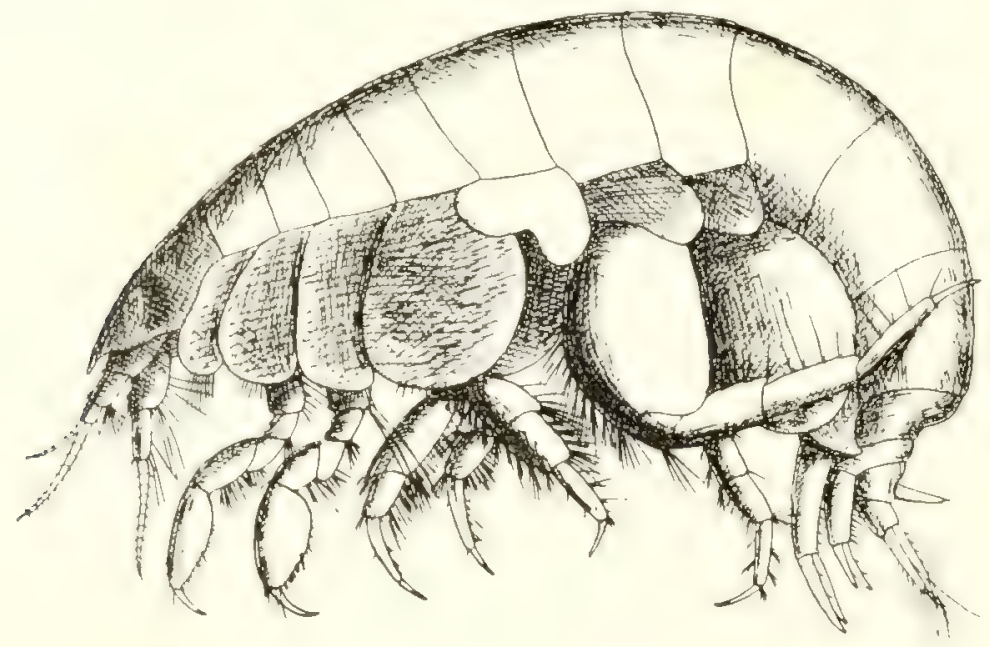

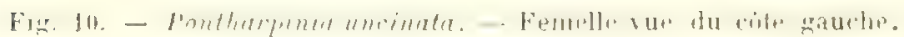

mesurait 6 millimetres de longueur dans la position où elle est figurée ici.

Le corps est assez fortement comprimé. La tète dépasse un peu en longueur l'ensemble des trois premiers segments du mésosome. Le capuchon, quisemble très aigu quand on licxamine par côté, esten réalité largement arrondi au bord distal; son extrémité atteint à peu près le milieu du deuxième article du pédoncule des antennes supérieures. Les plaques coxales des ruatre premieres paires, beaucoup plus hautes que les segments correspondants du mésosome, portent une rangée de soies au bord inférieur. Le lobe postérieur des plaques coxales de la cinquieme paire atteint le double de la hauteur du lobe antérieur. Les plaques épimérales du dernier segment du métasome, fortement pro- 
longées en arrière, se terminent par un crochet modérément aigu; leur bord inférieur est armé de quatre épines.

Les yeux, bien conformés, très grands, réniformes, comprennent de nombreux ocelles.

Les antennes supérieures sont un peu plus longues que la tête. Le premier article du pédoncule, presque aussi large que long, dépasse lémirement en longueur l'ensemble des deux articles suivants ; son bord

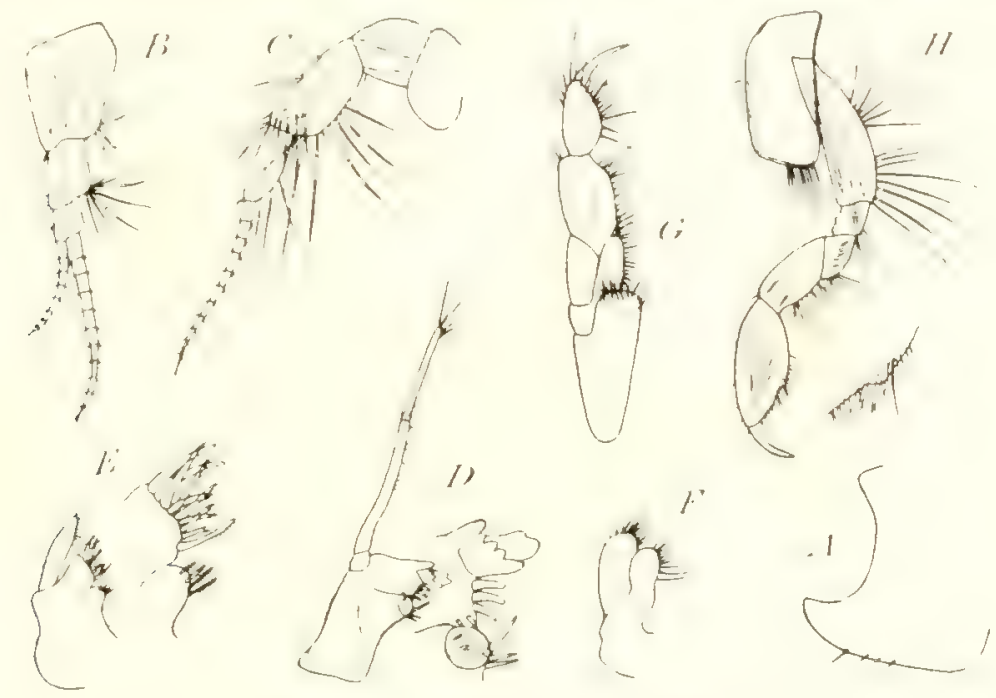

Fig. 11. - Pontharpinia uncinata.

A. plarue épimérale du dernier segment du métasome; B. antenne supérieure: $\mathbf{C}$, antenne infírieure; D, mandibule ganche; E, maxille antérieure; F, maxille postérieure; G, maxillipède; H, gnathopode antérieur $\{1,11: \times 18: B, C: \times 24: D, E, F, F: \times 30\}$.

postérieur, fortement convexe dans sa partie proximale, porte quatre soies ciliées. Le bord postérieur du deuxième article se termine par une toufle de sept grandes soies spiniformes. Le flagellum principal, un peu plus court que le pédoncule, se compose de onze articles. Le flagellum accessoire, qui comprend huit articles, atteint à peu près la moitié de la longueur du flagellum principal.

Les antennes inférieures sont un peu plus longues que les antennes supérieures. L'avant-dernier article du pédoncule, très large, porte de nombreuses soies spiniformes. Le dernier article est plus court et beaucoup plus étroit que l'article précédent; son bord postérieur porte trois soirs spiniformes. Le flagellum, aussi long que l'ensemble des deux derniers articles du pédoncule, comprend onze articles finement ciliés. 
Le lobe tranchant des mandibules porte trois dents arrondies. Il est suivi d'une rangée de cing épines. Le processus molaire, assez saillant, porte trois épines. Le lobe accessoire de la mandibule gauche est armé de quatre dents. Le palpe, très grèle et très allongé, atteint le double de la longueur de la mandibule; il est fixé à peu près au niveau du processus molaire; son dernier article, beaucoup plus court que l'article précédent, se termine par une touffe d'épines.

Le lobe interne des maxilles antéricures porte quatre grosses soies ciliées. Le lobe externe, obliquement tronqué, est armé de dix épines. Le palpe n'est pas biarticulé; bien qu’un fort grossissement montre deux petites encoches vis-à-vis l'une de l'autre, près de sa base, la ligne de séparation n'est pas distincte.

Le lobe externe des maxilles postérieures est un peu plus long et beaucoup plus large que le lobe interne. Ce dernier porte une rangée de dix épines au bord interne.

Le lobe interne des maxillipèdes, très court et très large, porte de nombreuses épines au bord distal. Le lobe externe, également très court, ne dépasse pas l'extrémité du premier article du palpe; il est bordé d'une quinzane d'épines. Le palpe est très robuste. Ses deuxième et troisième articles portent de nombreuses épines au bord interne. Le troisième article ne se prolonge pas au delà de l'insertion de l'article suivant. Ce dernier, dactyliforme, n'atteint pas tout à fait la longueur du troisieme article.

Les gnathopodes antérieurs sont assez grêles. L'article basal, un peu courbé, porte, au bord postérieur, de longues et nombreuses soies spiniformes. Le carpe, quadrangulaire, est beaucoup plus court que le propode. Cie dernier article allecte une forme étroitement ovale, sa longueur alteignant beacoup plus du double de sa largeur. Le bord palmaire n’est séparé du hord postérieur que par une légère saillie, armée d'une épine. Le dactyle est grèle et courbé.

Les gnathopodes postérieurs, plus robustes que les gnathopodes antérieurs, sont à peu près de même forme, bien que leur carpe, beaucoup plus court, n'atteigne guère que la moitié de la longueur du propode. Ce demier article est à peu près deux fois aussi long que large. La 
saillie qui sépare le bord postérieur du bord palmaire est un peu plus accentuée que dans les gnathopodes antérieurs.

Dans les péréiopodes des deux premières paires, l'article méral est très robuste; son bord postérieur ainsi que celui du carpe portent de nombreuses soies spiniformes. Le propode, très grêle, beaucoup plus

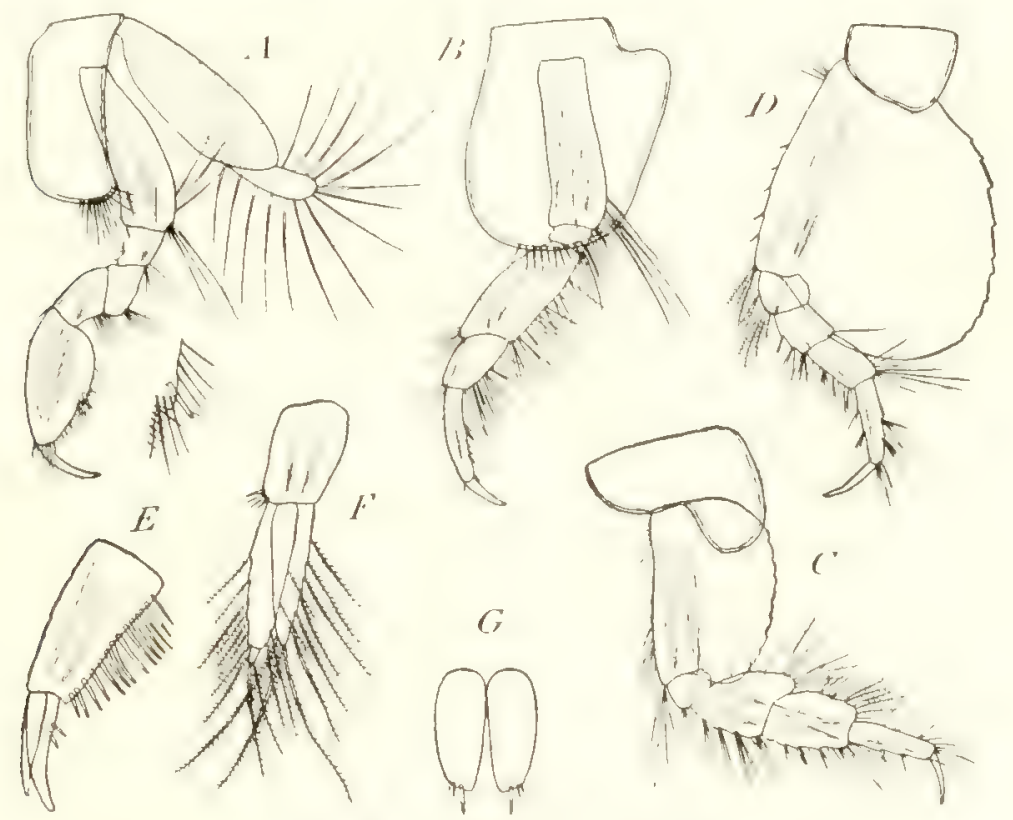

Fig. 12. - Pontharpinia uncinalu.

A, gnathopode posterieur; $\mathbf{B}, \mathbf{C}$, fríréiopodes des deuxiène et troisieme pairés; $\mathbf{b}$, péréiopode de la derniêre paire: $\mathbf{E}, \mathbf{F}$, uropodes des deuxiène et troisieme paires; G, telson $(\mathbf{A}, \mathbf{B}, \mathbf{C}, \mathbf{D}: \times 18 ; \mathbf{E}, \mathbf{F}$, $\mathrm{G}: \times 301$.

long que le carpe, est un peu plus court que l'article méral. Le dactyle est à peine courbé.

L'article basal des péréiopodes de la troisième paire, plus long que large, est crénelé au bord postérieur. L'article méral et le carpe, très robustes, portent de nombreuses soies, accompagnées de quelques épines. Cinq soies ciliées sont fixées vers l'extrémité du bord postérieur du carpe. Le propode, très étroit, n'est pas plus long que le carpe.

Les péréiopodes de la quatrième paire sont beaucoup plus longs que les péréiopodes précédents et suivants. Leur article basal, plus long que large, n'est pas crénelé au bord postérieur. Son bord antérieur porte de longues soies, dont quelques-unes sont ciliées. Les soies du bord antérieur de l'article ischial sont également ciliées. L'article méral el le 
carpe présentent un aspect moins robuste que dans les gnathopodes précédents. Le propode n'est pas plus long que le carpe.

L'article basal des péréiopodes de la dernière paire, très dilaté en arrière, crénelé au bord postérieur, se prolonge inférieurement au delà de l'extrémité de l'article ischial. L'article méral et le carpe sont modérément robustes. Le propode est beaucoup plus long que le carpe. Le dactyle atteint plus des deux tiers de la longueur du propode.

Le bord postérieur du pédoncule des uropodes de la première paire porte une rangée de petites épines. Les branches, un peu plus courtes que le pédoncule, sont d'égale taille. Le pédoncule des uropodes de la deuxième paire, très robuste, porte, au bord postérieur, une rangée de quatorze grandes épines. La branche externe des uropodes de la dernière paire possède un petit article terminal. La branche interne est aussi longue que le premier article de la branche externe. Les deux branches sont garnies de longues soies ciliées.

Le telson, entièrement fendu, est plus long que large. Ses lobes sont obliquement tronqués à leur extrémitá, qui porte trois épines d'inézale taille.

Cette espèce, assez voisine de Pontharpinia rostrata (Dana), en diffère surtout par la forme des plaques épimérales du dernier segment du métasome, caractère auquel le nom spécifique fait allusion, par le peu de longueur du carpe des gnathopodes postérieurs et par les proportions des branches des uropodes de la dernière paire.

\section{AMPHILOCHIDE.}

\section{Gitanopsis antarctica Chevreux.}

Ile Petermann, \& octobre 1909. Dans une toufle de Desmorestic ramenée de 3 mètres de profondeur. Nombieux exemplaires.

L'exemplaire dont la description suit était une femelle dont la poche incubatrice contenait onze oufs. Elle mesurait $3^{\text {mm }}, \ddot{y}$ de longueur, dans la position où elle est figurée ici.

Le corps, assez obèse, présente des téguments minces et peu conisistants. La tète, un peu plus longue que l'ensemble des deux premiers 
segments du mésosome, porte un rostre fortement courbé, dont l'extrémité, très aiguë, dépasse un peu le premier article des antennes supérieures. Les lobes latéraus, à peine saillants, largement arondis, portent une petite dent située un peu au-dessus dr l'espace interantennal. Les plagues coxales de la premiere paire, quadrangulaires, à moilié cachées par les plaques suivantes, sont prolongées inférieurement dans leur

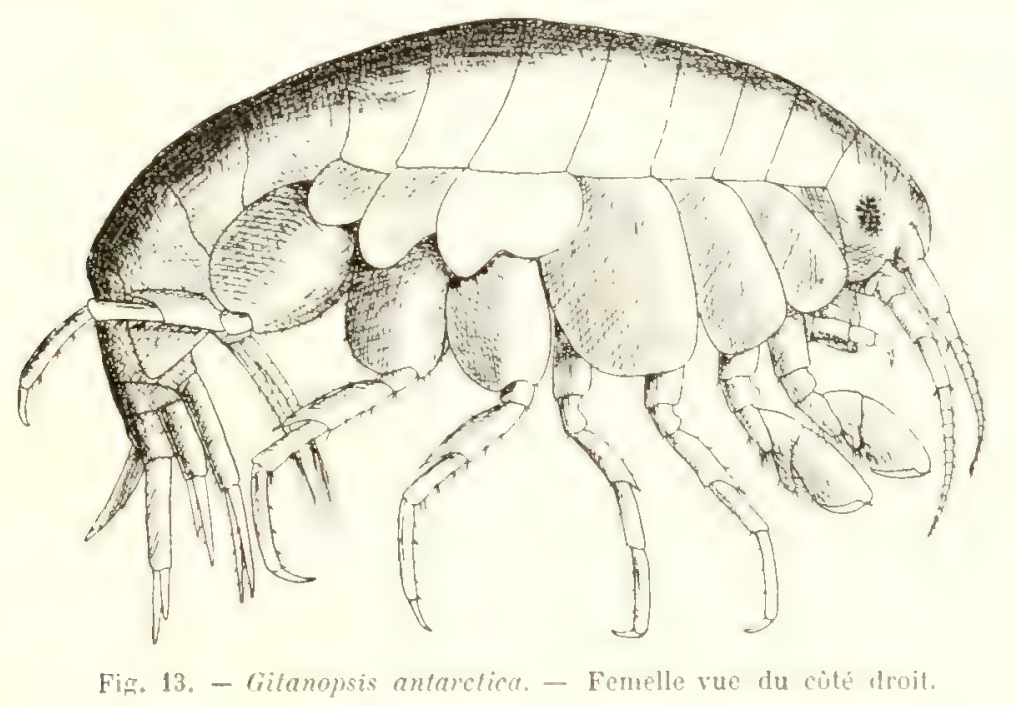

partie antérieure. Les plaques coxales de la denxieme paire, beancoup plus grandes que les plaques précédentes, portent quelques potites crénelures au bord inférienr. Ces platues coxales, ainsi que celles des deux paires suivantes, sont un peu plus hautes que les segments correspondants du mésosome. Le lobe antérieur des plaques coxales de la cinquieme paire est beaucoup moins haut que le lobe postérieur. Les plaques épimérales du dernier segment du mólasome, légèrement prolongées en arrière, se terminent par un angle un peu arrondi; leur bord inférienr est armé de cinq petites épines.

Les yeux, de grandeur moyenne, présentent un contour ovoïde.

Les antemnes supérieures sont aussi longues que l'ensemble de la tête et des trois premiers segments du métasome. Le premier article du pédoncule, très volumineux, est à peine aussi long que large. Le deuxième article, presque aussi robuste, est plus allongé. Le troisieme article, beaucoup plus grêle, n'atteint que la moitié de la longueur de l'article précédent. Le flagellum, un peuplus long gue le pédoncule, 
comprend dix articles dont le bord antérieur porte de longues soies smotives. Il wistr un petit flagellum accessoire uniarticulé, qui atteint la moitié de la longueur du premier article du flagellum principal.

Les antemes inférieures sont un peu plus longues que les antennes supérieures. Les deux derniers articles du pédoncule sont d'égale taille.

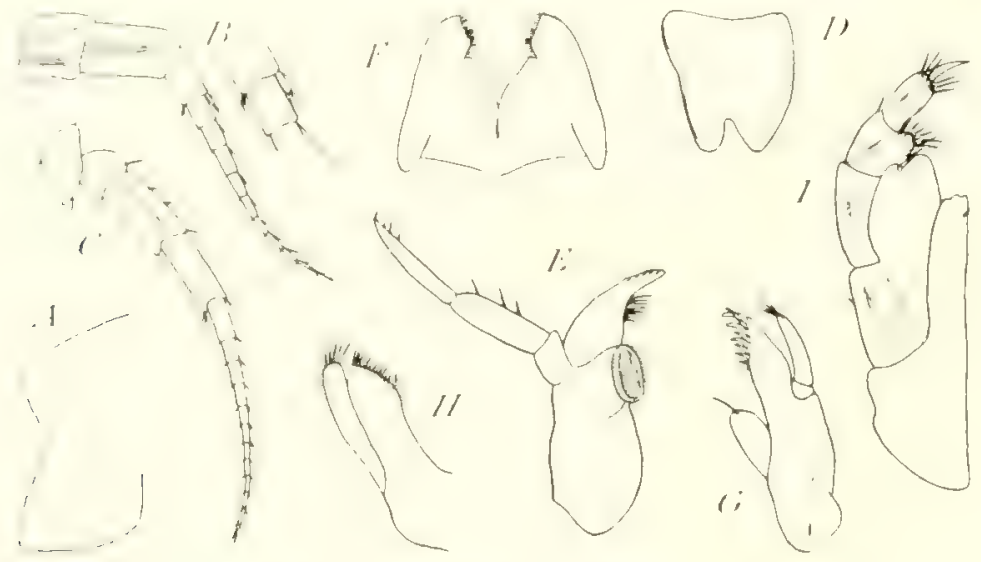

Fig. 14.- Gilanopsis anlarctica.

1, plaque épinérale du denier segment du métasorae: B, antenne supérieure; C, antenne inférieure: 1). lév'e antérieure: $\mathrm{E}$, mandibule; $\mathrm{F}$, lère postérieure; $\mathrm{G}$, maxille antérieure; H, maxille postérjeure : I. maxillipede $(\mathbf{A}: \times 30 ; \mathbf{B}, \mathbf{C}: \times \mathbf{4} ; \mathbf{H}, \mathbf{F}, \mathbf{F}, \mathbf{G}, \mathbf{H}, \mathbf{I}: \times 7 \mathbf{2})$.

Le flagellum, aussi long que le pédoncule, comprend douze articles.

La lère antérieure porte, au bord distal, une profonde échancrure, qui la sépare en deux lobes d’inégale taille.

Les mandibules, bien développées, présentent un lobe tranchant long et élroit, armé de nombreuses petites dents. La mandibule gauche porte un lobe accessoire. Le rang d'épines en comprend huit dans la mandibule droite et neuf dans la mandibule gauche. Le processus molaire est très grand et très saillant. Le palpe, court et robuste, porte quelques epines au bord interne; son troisieme article est un peu plus long que l'article précédent.

Les lobes de la lère postérieure, obliquement tronqués, portent deux petites dents, suivies d'une échancrure anguleuse.

Le lobe interne des maxilles antérieures, bien développé, porte une soie au bord distal. Le lobe externe, obliquement tronqué, est armé de huit épines. Le palpe, biarticulé, ne dépasse pas l'extrémité du lobe externe; il porte quatre longues épines au bord distal. 
Le lobe interne des maxilles postérieures, très large, obliguement tronqué, porte treize épines au bord distal. Le lobe externe, trè étroit, s'arrondit au bord distal, qui est armé de cinq épines.

Le lobe interne des maxillipèdes, bien développé, ne porte ni soies ni épines; son bord distal présente deux petites crénelures. Le lobe externe, très large, dépasse à peine l'extrémité du premier article du

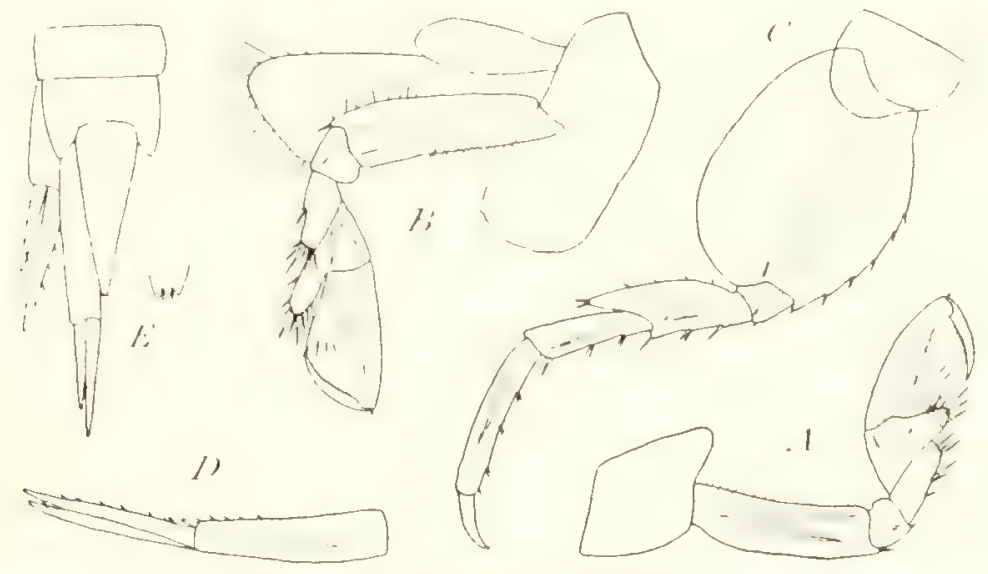

Fig. 15. - Gilanopsis antarctica.

A, B, gnathopodes antérieur et postérieur; $\mathbf{C}$, péréiopode de la dernière paire; $\mathbf{D}$, uropult de la première paire; $\mathbf{L}$, uropodes des deux dernières paires et telson (toutes les figures: $x+2$ \}.

palpe; il ne porte ni soies ni épines au bord interne; son bord distal présente une échancrure garnie d'une forte épine. Le palpe, très robuste, est armé de nombreuses épines; son premier article atteint prós du double de la longueur de chacun des articles suivants.

Les gnathopodes, robustes, bien développés, à peu près d'égale taille, different surtout entre eux par la forme du carpe, dont le lobe est beaucoup plus allongé dans les gnathopodes postérieurs que dans les gnathopodes antérieurs. L'article méral et le carpe portent de nombreuses épines. Le propode, quadrangulaire, s'élitrgit beaucoup dans sa partie distale; son bord palmaire est denticulé. Le dactyle, très grête, aussi long que le bord palmaire, est denticulé au bord interne.

Les péréiopodes des deux premières paires sont grêles et allongés; le bord antérieur de leur article méral se prolonge un peu le long du carpe.

Les péréiopodes des trois dernières paires, d'égale longueur, sont à peu près de même forme. L'article basal, un peu plus large dans les 
péréiopodes de la dernière paire que dans ceux des deux paires précédentes, est ovalaire. L'article méral, assez dilaté, se prolonge inférieurement le long du bord postérieur du carpe. Le dactyle est robuste.

Les branches des uropodes de la première paire, d'ézale taille, sont presque aussi longues que le pédoncule; elles portent une rangée d'épines au bord postérieur. Dans les uropodes de la deuxième paire, la branche interne est beaucoup plus longue que la branche externe. Les branches des uropodes de la demiere paire sont aussi d'inégale taille, la branche interne dépassant d'un quart la longueur de la branche externe; les deux branches sont completement glabres.

Le telson, étroitement triangulaire, trois fois aussi long que large à sa base, n’atteint pas l'extrémité du pédoncule des uropodes de la dernière paire; son extrémité porte deux petites crénelures garnies d'un cil.

Cietle espèce s'écarte un peu de la diagnose du genre Gitcmopsis par la forme du lobe interne de ses maxilles antérieures. Ce lobe, bien développé chez G. antartica, est très petit, presque rudimentaire, chez les antres espèces connues de Gitanopsis. Très voisine de G. arctica G.-O. Sars, l'espèce antarctique en diflère par son rostre long et aign, par ses smathopodes plus robustes et parles proportions relatives du pédoncule de ses uropodes de la derniere paire et de son telson. La famille des Amphilorhida n'élait représentée jusqu'ici, dans les mers antaretiques, que par Amphilochus llarionis Stobbing, dragué par le "Challenger" au voisinage des iles Harion.

\section{LEUCOTHOIDE.}

Leucothoe spinicarpa (Abildgaard).

1906. Lencolhoe spinicarpa Stebling (11), p. 165.

1907. Lencothoe spinicarpa A. O. Walker (17), p. 18.

Dragage VIII, 20 janvier 1909, baie Varguerite; profondeur, 200 mètres. Un exemplaire de 7 millimètres de longueur. La couleur du corps était blanchatre.

Dragage XIV, 18 novembre 1909, chenal de Lemaire, Je long de la côte nord-est de l'île Petermann; profondeur, 60 à 40 mètres. Deux 


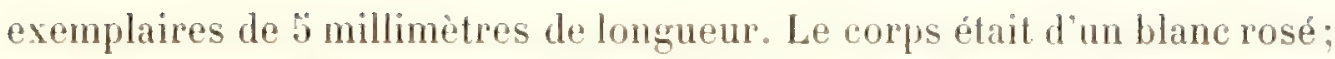
les yeux, d'un rouge-brique.

Dragage XV, 26 novembre 1909, chenal de Roosen, devant PortLockroy; profondeur, 60 à 70 mètres. Un màte et une femelle de 15 millimètres de longueur, la femelle portant 3 í aufs dans sa poche incubatrice. Le corps de ces exemplaires était jamâtre; les yeux, d'un brun rougeàtre; les oufs, d'un vert pàle.

\section{IIETOPIDE.}

\section{Metopoides Walkeri Chevreux.}

1906. Metopoides Walkeri Chevreux (2), p. 28, fig. 15 is 17.

He Petermann, 4 octobre 1909 , dans une toufle de Desmarestia ramenée de 3 mètres de profondeur, le long de la còte de l'île. Deux jeunes exemplaires, dont le plus grand mesurait 2 millimetres de longueur.

\section{Thaumatelson nasutum Chevreux.}

1912. Thaumatelson nasutum Chevreux (4).

Ile Petermann, i octobre 1909. Dans une toutte de Desmarestin ramenée de 3 mètres de profondeur. Une femelle, un jeune exemplaire.

La femelle mesurait à peine '2 millimetres de longueur, dans la position oủ elle est ligurée ici. Sa poche incubatrice contenait onze aufs. L'autre exemplaire, beaucoup plus petit, n'atteint que 1 millimètre de long.

Le corps, très obèse, est lisse. Le mésosome, excessivement déreloppé, atteint le double de la longueur de l'ensemble du métasome et de l'urosome. Le quatrième segment du mésosome dépasse un peu en longueur l'ensemble des trois segments précédents. Le premier segment de l'urosome présente un prolongement dorsal qui atteint la base du telson. Les deux segments suivants, extrêmement courts, sont soudés entre eux dans leur partie dorsale.

La tête, aussi longue que l'ensemble des deux premiers segments du mésosome, porte un petit rostre. Les lobes latéraux, assez saillants, sont 
étroitement arrondis au bord distal. Les plaques coxales de la première paire, très petites, sont presque entièrement cachées par les plaques suivantes. Ces dernières, très développées, se prolongent en avant bien an delà des lobes latéraux de la tête. Les plaques coxales de la quatrième

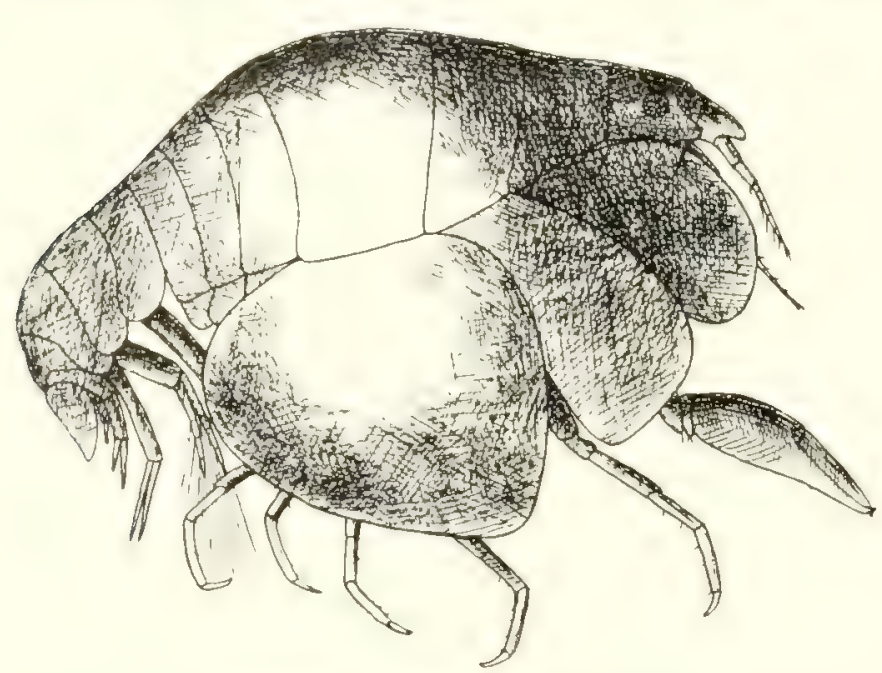

Fig. 16. - Thaumatelson nasutum. - Femelle vue du còté droit. paire, excessivement grandes, un peu plus longues que hautes, se prolongent en arrière jusqu'au niveau du bord postérieur des plaques de la dernière paire. Les plaques épimérales du métasome sont arrondies au bord distal, le bord postérieur de celles du dernier seg-

ment se terminant inférieurement par une petite dent obtuse.

Les yeux, de petite taille, sont arrondis.

Les antennes supérieures atteignent à peu près la longueur de l'ensemble de la tête et des deux premiers segments du mésosome. Le premier article du pridoncule, tress volumineux, aussi long que l'ensemble des deux articles suivants, se prolonge antérieurement pour former une sorte de capuchon, arrondi dans sa partie distale, et pouvant envelopper le deuxième article. Ce dernier et le troisième article sont d'égale longueur. Le flagellum, un peu plus court que le pédoncule, comprend sept articles; son bord postérieur porte quelques longues tigelles sensitives.

Les antennes inférieures dépassent un peu en longueur les antennes supérieures. Les deux derniers articles du pédoncule sont d'égale taille. Le flagellum, un peu plus long que le dernier article du pédoncule, se compose de six articles faiblement ciliés.

Le lobe tranchant des mandibules, très large, porte sept dents arrondies. Le lobe accessoire, qui existe dans les deux mandibules, est 
finement crénelé. Une rangée de trois épines se trouve entre lui et le processus molaire, qui est peu développé. I.e palpe, très court, uniarticulé, porte deux longues soies au bord distal. Dans l'une des mandibules (fig. 17, D), il existe un rétrécissement du palpe, près de sa base, qui
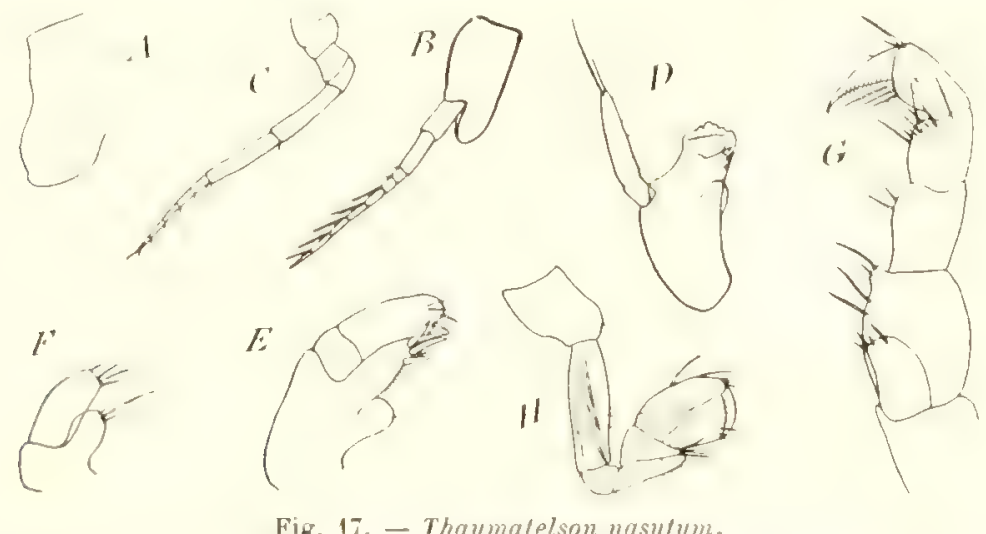

A, plaçue épimtrale du dernier segment du métasome; $B$, antenne supérieure; $C$, antenne inférieure: D, mandibule; E, naxile anterieure; F, maxille postérieure; G, masillipede: $\mathbf{H}$, gnathopote antérieur $(\mathrm{A}, \mathrm{B}, \mathrm{C}, \mathrm{II}: \times 56 ; \mathrm{U}, \mathrm{L}, \mathrm{F}, \mathrm{G}: \times 14 \overline{7})$.

semble être un rudiment d'articulation; le palpe de l'autre mandibule ne présente rien de semblable.

Le lobe interne des maxilles antérieures, tris court, porte une petite épine au boed distal. Le lobe externe, obliquement tronqué, est armé de six grandes épines. Le palpe, très volumineux, biarticulé, porte quelques epines et soies au bord distal.

Le lobe interne des maxilles postérieures est beaucoup plus court que le lobe externe. Les deux lobes portent seulement quelques soies au bord distal.

Les lobes internes des maxillipèdes sont séparés jusqu'à la base. Il n'existe qu'un petit rudiment de lobe externe. Le palpe est très volumineux. Son dernier article, dactyliforme, plus long que l'article précédent, porte une rangée d'épines au voisinaz̧e du bord interne.

Les gnathopodes antérieurs, très courts, sont néammoins asse\% robustes. L’article méral se prolonge un peu au delà de l'extrémité du carpe, qui aflecte une forme triangulaire. Le propode, quadrangulaire, n'est pas beaucoup plus long que large. Le dactyle est de la longueur du bord palmaire. 
Les suathopodes posterieurs atleignent plus du double de la longueur drs gnathopodes antripurs. Lanticle ischial, l'article méral et le carpe sont très courts. Le propode, aussi long que l'article basal, se prolonge inférieurement pour former, avec le dactyle, un robuste organe chéliforme. Ce prolongement et le dactyle sont tous deux crochus à leur
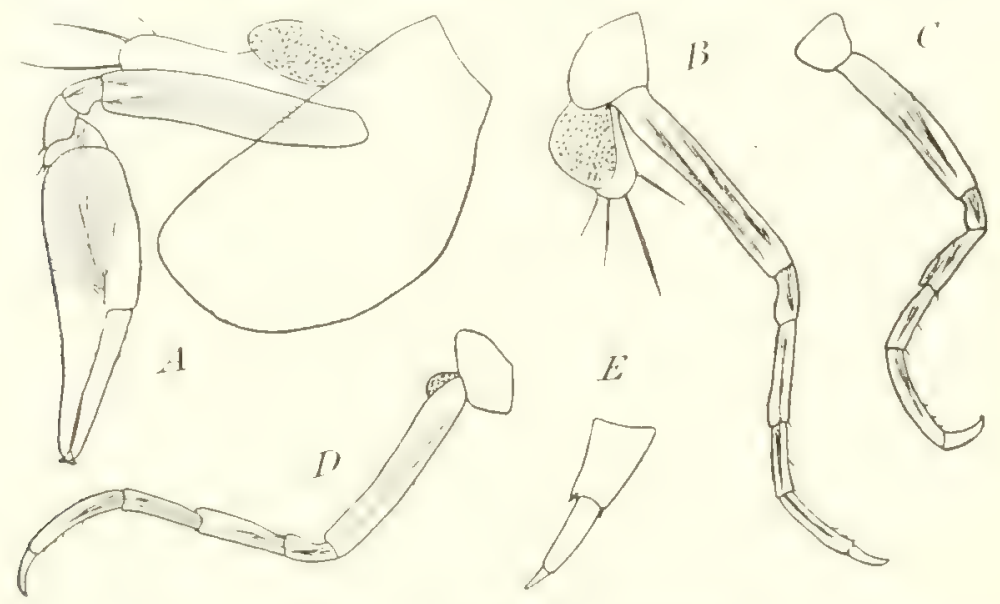

Fig. 18. - Thanmatelson nasutum.

A, gnathopode postérieur: B, C. D, pérétopodes des troisieme, quatrième et cinquième paires: E, uropode de la derniere paire $(\mathbf{A}, \mathbf{B}, \mathbf{C}, \mathbf{D}: \times 56: \mathbf{B}: \times 14 \bar{\imath})$.

extrémité, et les deux crochets, tournés en sens inverse, peuvent se croiser. Le dactyle atteint la moitié de la longueur du propode.

Les péréiopodes, trìs grêles, sont tous de même forme, et l'article basal de ceux des trois dernières paires n'est pas plus dilaté que celui des deux paires antéricures. L'article méral et le carpe, d'égale longueur, sont plus courts que le propode, qui présente une légère courbure. Les péréiopodes de la troisième paire sont plus longs que ceux de la quatrième paire, et ces derniers dépassent eux-mêmes en longueur les péréiopodes de la dernière paire.

Les uropodes de la première paire, longs et grêles, possèdent des branches d'égale taille, beancoup plus courtes que le pédoncule. La branche interne des uropodes de la deuxième paire, aussi longue que le pédoncule, dépasse de beaucoup la branche externe. Les uropodes de la dernifre paire, tris courts, atteignent à peine l'extrémité du pédoneule des uropodes précédents; leur branche unique, biarticulée, est un peu plus longue que le pédoncule. 
Le lelsom, beancoup plus long que larosome, consiste en mone lame lramgulaire, située dans le pan vertical de la longueur du comps. II dépasse de beaucoup l'rextrimilé des uropodes posténicurs.

Cielte forme dithire de l'unique aspece comnue dusenre Thanmalelsun par le prolongement du premier article du pédoncule des antemnes superieures, caractere auquel to nom specilique fait allusion, par l'etal rudimentaine du palpe des mandibulos, par la forme trós spriciale des ginathopodes posterieurs et par la bricreté des uropoders de

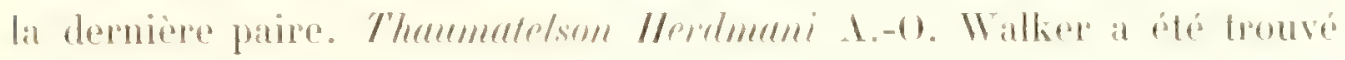
dans l'Antanctique par l'expódition de la "Biscovery.

\section{PI/L/AS/IIE.}

\section{Bircenna crassipes (Chevreux).}

1906. Wandelia crassipes Chevreux (2), p. 45, fig. 24 à 26 du texte.

1909. Bircenna crassipes Chilton (5), p. (i) ot 6\%.

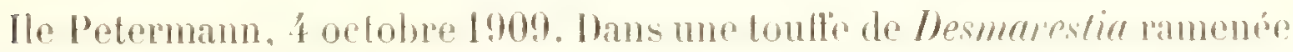
de 3 metres de profondeur. Une grande femelle ovigre, alteignant í millimotres de longueur.

Dans ma diagnose de H'muleliu, javais mentionné que ce nourean senre, très voisin de Bircemme Chilton, en diflúnit par la forme des appendices de l'urosome. En dehors des moprodes des deux promiores paires, dont les branches, subégales chez Wramblia, sont de tres inégale

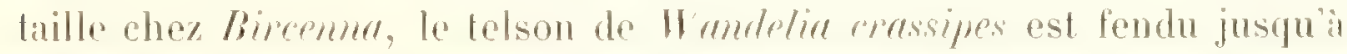
la base, tandis que la diagnose primitive du genpe Bircema porte: telson simple, non divided.

L'importance de ce demier caractère m'arait conduit à créer un nouveau sene pour l'Amphipode de l'ile Wendel.

Depuis la publication de mon travail sur les Amphipodes du "Francais", II. Chilton, ayant eu oceasion de retrouver un exemplaire de lirecum fulev, a reconnu pue sa diagnose de Bircennu était eronée, le lolson du type du genre étant formé de deux pièces séparées. Hindelin doit done disparaitre de la nomenchature, et jadmets, avee $\mathbf{~ I}$. Chilton, que? 
l'Amphipode pour lequel javais créé ce nouveau genre doive prendre le nom de Bircema cressiprs.

\section{ACANTHONOTOSOMIDE. \\ Panoploea Joubini Chevreux.}

1912. Panoploea Jonbini Chevreux (4).

Dragage IX, 21 janvier 1909. Au sud de l'ile Jenny; profondeur,

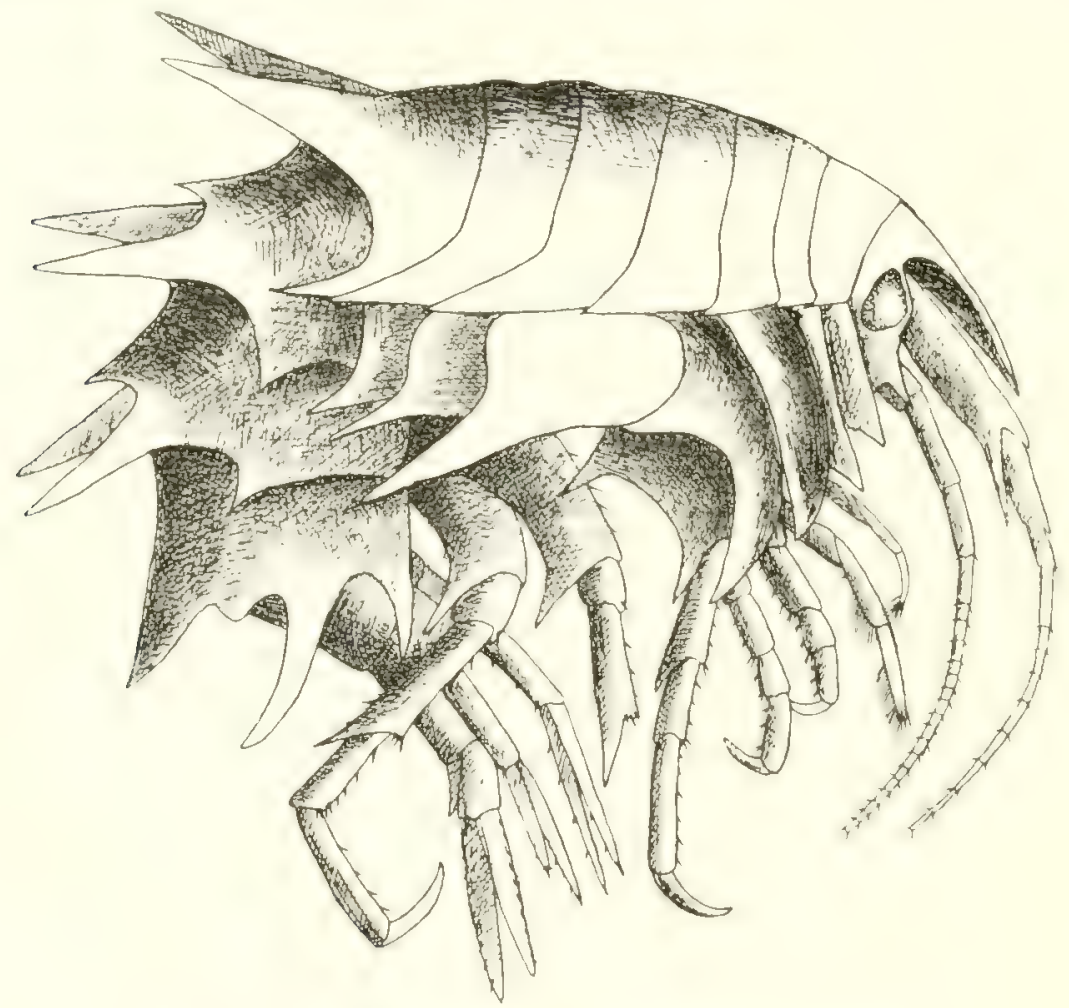

Fir. 19. - Panoploea Joubini. - Femelle vur du cóté droit.

250 mètres. The femelle portant dix aufs dans sa poche incubatrice. Cette femelle était colorée en rouge orangé.

Le corps, très obèse, mesurait 7 millimètres de longueur dans la position où il est figuré ici. Le dernier segnent du mésosome et chacun des deux premiers segments du métasome se terminent par deux dents dorsales, très longues el très aiguës. Tous les segments du métasome portent une carène dorsale terminée, dans les deux premiers segments, par une 
petite dent siture ontro les deux grandes dents dorsales, ot par une dent longue ot aigue, dans te troisibme segment. Dans fous les segments du mésosone, les angles latéraux postérieurs se prolonģent en arriope pour former une dent aiguë, particulierement longue dans les trois deniers segments.

La tite, tries courte, porte un rostre bien développé, légèrement conmé, atteignant presque l'extrémité du premier article du pédoncule des antennes supérieures. Les lobres lateraux, à peine saillants, arrondis, sont suivis d'une dent aigue.

Les plaques coxales des trois premieres paires, à peu pres aussi liautes que les segments correspondants du mésosome, sont éfroites el se terminent inférieurement par une pointe aigne: ; la partie distale de leurs bords antérieur et postérieur porte quelques petites crénelures. Les plaques coxales de la quatième paire portent une forte dent a bord postérieur. Les plaques coxales dos trois demières paires se prolongent en arriere pour former une dent aigur, particulierement longue dans les plapues de la cincuième paire. Les plaques épimérales des deux premiers segments du métasome portent une dent aiguë au bord postérieur. Les plagues épimérales du dernior segment se terminent en arriere pardeux fortes dents superposées, la dont supérieure étant debeaucoup la plus longue; une petite dent obtuse existe entre cette dent et la dent dorsale.

Les youx, très proéminents, sonl ovalaires.

Le premier article du pédoncule des antennes supérioures, tròs robuste et très allongé, porte, an bord distal, une dent antéreure modérément longue et une dent latérale très aiguö, qui atteint presque l'extrémité du deuxiome article. Cet article atteint la moitié de la longueur de l'articte précédent; il est un peu prolongé le long du bordantéricur du troisieme athele, yui atteint un peu plus de la moitio de la longueur du deuxieme article. Le premier article du flagellum est plus long que le dernier article du pédoncule. Les huit articles suivants sont plus longs que larges. Le reste du flagellum avait disparu.

Le dernier article du pédoncule des antennes inférieures n'alteint qur los deux lieps de la longueur de lauticho précédent. Le flagellum était. inutilé. 
La levre antérieure, très longue, subtriangulaire, présente un bord distal étroitement arrondi, sans traces d'échancrure.

Les mandibules, longues et étroites, présentent un lobe tranchant très aign, faiblement crénelé. Aucune des deux mandibules ne porte de lobe accessoire. Le processus molaire est bien développé. Le palpe n’atteint

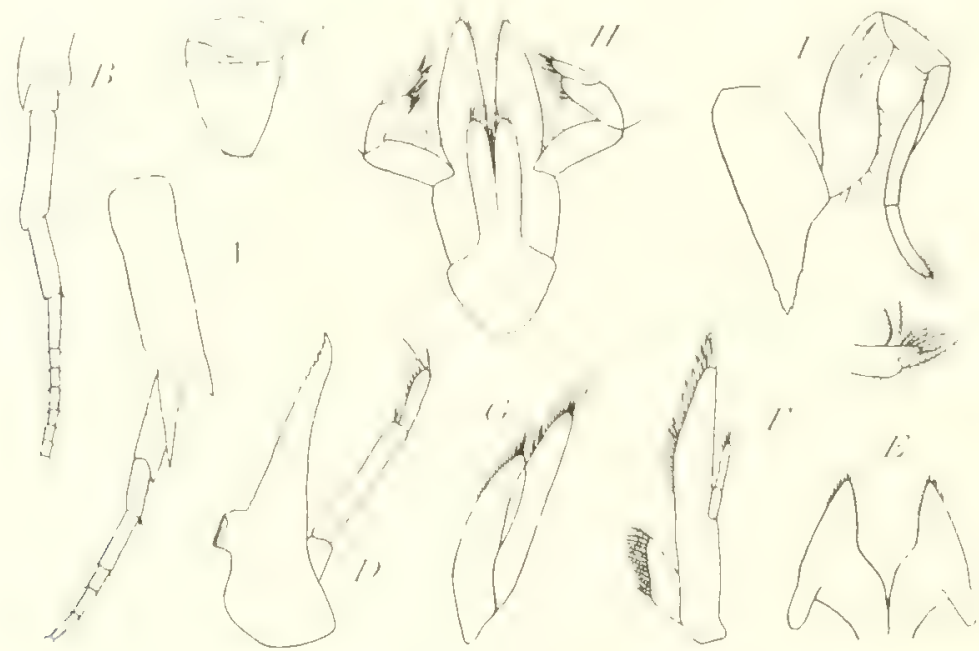

[ï. - o. - P'anoplostr Joubini.

1. B. priloneule et partie du flagellum des antennes superieure et inférieure: C, lére antéricure:

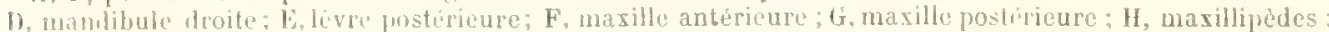

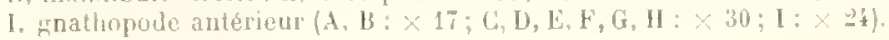

pas tout à fait l'extrémité du lobe tranchant; son troisième article, garni de fortes épines, n’atteint pas la moitié de la longueur de l'article préreslent.

Les lobes latéraux de la lèvre postérieure, très aigus dans leur partie distale, ne sont que faiblement échancrés au bord interne.

Le lobe interne des maxilles antérienres, très large, est bordé de douze soies ciliées. Le lobe externe, altongé, obliquement tronqué, porte ueuf́ épines pectinées. Le palpe est très court; son deuxième article, un peu plus long que le premier, se termine par une toutle de cinq épines.

Le lobe externe des maxilles postérieures est beaucoup plus long que In lobe interne. Tous deux portent des soies au bord distal et au bord interne.

Les lobes exteme ot interne des maxillipèdes sont longrs et étroits. Le palpe, assez court, alteint it peine l'extrémité du lobe externe. 
Les snathopodes anterinurs sont tries grètes et tres courts. Leur article basal, fortement dilaté, attoint presque la longueur de l'ensemble des trois articles suivants. Les articles ischial et méral sont d'égale taillr. Le propode, mo peu phus court que le carpe, se termins par une petite pince zarnie de soies ciliers.

Les gnathopodes postérieur's sont heaucoup plus longs que les gnathopodes antérieurs. Leur article basal n’est pas dilaté. L'article ischial, le

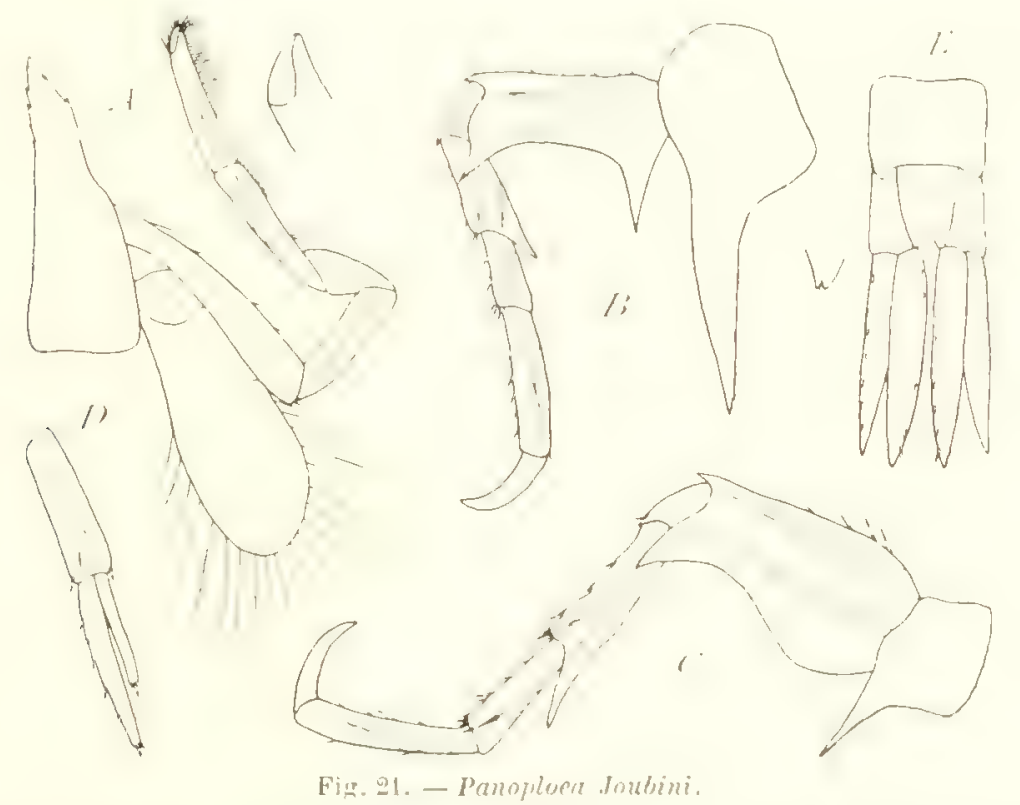

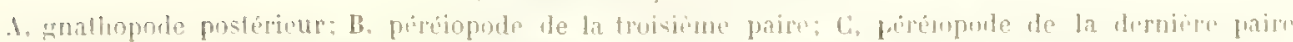

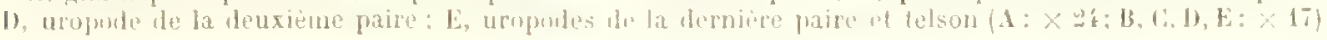

carpe of le propode sont d'égale longueur. Le prolongement du propode, très aigu, atteint l'extrémité du diretyle.

Dans les péréiopodes de la troisieme paire, l'article basal présente un bord postérieur concave, limité en haut el on bas par une dent longue et aiquë. Le bord postérieur de l'articte méral se prolonge en pointe aigü le long du carpe. Le propode atteint le double de la longueur du carpe. Le dactyle, très rohuste, fortement couble, atteint les deux liers de la longueur du propode.

Le bord posterieur de l'article basal des paltes des deux dernirres paires, d'abord fortement convexe, devient concave dans sa partie distate "I se termine par une dent aiguä. La dent qui prolonge l'article méral est 
beaucoup plus longue que dans les péréiopodes de la troisième paire. Le carpe des péréiopodes de la derniere paire atteint les deux liers de la longueur du propode. Le dactyle est remarquablement robuste.

Les branches des uropodes de la première paire, subégales, atteignent la longueur du pédoncule. La branche externe des uropodes de la deuxième paire est beaucoup plus courte que la branche interne. Les branches des uropodes de la dernière paire, étroitement lancéolées, sont presque d'ésale taille, la branche externe étant de très peu la plus courte.

Le telson, un peu plus long que large, atteint l'extrémité du pédoncule des uropodes de la dernirre paire. Il est ouvert, sur à peu près le quart de sa longueur, et chacun de ses lobes se termine par une petile échancrure garnie d'une soie.

Ciette espece a été dédiér à 11 . Ie $P^{\mathrm{r}}$ Joubin.

\section{Iphimedia pacifica Stebbing:}

1906. Iphimedia pacifica Stebbing (11), p. 215.

Dragage VIII, 20janvier 1904, baie Harguerite; profondeur, 200 metres. Un exemplaire de 8 millimètres de longueur et de couleur jaune.

Chez cet exemplaire, la grande dent du premier article du pédoncule des antemnes supérieures est aussi Jongue que chez lphimedia nodosa, c'est-à-dire beaucoup plus grande qu'elle n'est représentée par Stebbing $(10$, p. 890, Pl. LXXI $)$. Les exemplaires d'lphimedia preifica de la "biscovery ", examinés par M. A. O. Walker $(\mathbf{1 7}$, p. 27), présentent le mome catactipe. Ces exemplaires atteignaient 30 millimetres de longueur.

Dragage XIII r, 17 novembre 1909, le long de la còte nord-est de l'ile Petermann; profondeur, 80 a 50 mètres. In exemplaire mutilé, dont la tate manquait el qui devait atteindre à peu près la longueur de l'exempaire du dragage VIII.

Le corpset les appendices de cet Amphipode étaient d'un blane jaunitre, ponclué de brun violacé.

Iphimedia nodosa Dana.

1306. Iphimedia nodosa Stebbing (11), p. 216. 
Defroit de Magellan, Terre Désolation, baie Tuesday, 3 lóvrier 1910, sur une Etoile de Mer. [n exemplaire de li millimètres de longueur, coloré en brun foncí.

Iphimedia echinata A. O. Walker.

1907. Iphimedia echinala 1. O. Walker (17), p. 28, Pl. X.

Dragage VIII, 20janvier 1909, baie Larguenite; profondeur, 200 metres. Un exemplaire de couleu jaune pite, atteignant 12 millimètres do longueur.

Dragage $I X, 21$ janvier 1909, au sud de l'ile Jenny; profondenr. 230 metres. I'n exemplaire de 18 millimetres de longueur, trouvé sur me Ilolothurie, ef un pefit exemplaire de 8 millimetres de longuenr. Le grand exemplaire avait le corps d'un jaume orangé; les yeux étaient blanes et leur partie rentrale, d'un rougrearmin. Lo corps du petit exemplaire était rose.

Le srand exemplaire du dragage IX diflere quelque peu du type décrit par Walker. Le rostre est plus long que le reste de la tête, ef l'extrémité du prolongement du deuxiemen articlo du pédoncule des antennes supérieures atteint le quatrieme article du flagellum.

Chez l'exemplaire du dragage VIII, le prolongement du deuxibme article du pédoncule des antenues supérieures n'est pas plus long que chez le type, mais les dents du métasome sont plus nombreuses.

\section{IPHIMEIIELLA ChevreuX.}

1911. Iphimediella Chevreux (3), p. 1167.

Semblable à Panoplope ot à Iphimediu par la torme du corps et de la tête. Plaques coxales des deux promières paires tridentées à leur extrémité. Lève antérieure régulierenent arondie au bord distal. Mandibules frosses et courtes, sans rangée d'épines; processus molaire petit, mais assez saillant; lobe accessoire dans la mandibule gauche seulement; fremier article du palpe très développé. Lère postérieure ne possédanl pas de lobes internes; lobes cxternes réguliorement arrondis, sans traces d'échancrure. Maxilles antérieures semblables à celles des fphimedin. 
Lobe externe des maxilles postérienes subacuminé au bord distal. Deuxieme arlicle du palpe des maxillipèdes non prolongé le long de l'article suivant. Ginathopodes, uropodes ef telson semblables it ceux des deux genres voisins.

Ce nouveatu genre diflère de P'onophert par Jes dimensions du palpe des maxilles antérienres, d'Tphimedie par ses plaques coxales des deux premieres paires tridentées, des deux genres par les lobes externes non incisés de sa levre postérieure et par la forme de son deuxieme article du palpe des maxillipedes, qui n'rest pas prolongé le long de l'article snivant.

\section{Iphimediella Margueritei Chevreux.}

1912. Iphimediella Marqueritei Chevreux (4).

Uragage VIII, 20 janvier 1909, baie Marguerile; profondeur, 200mines.

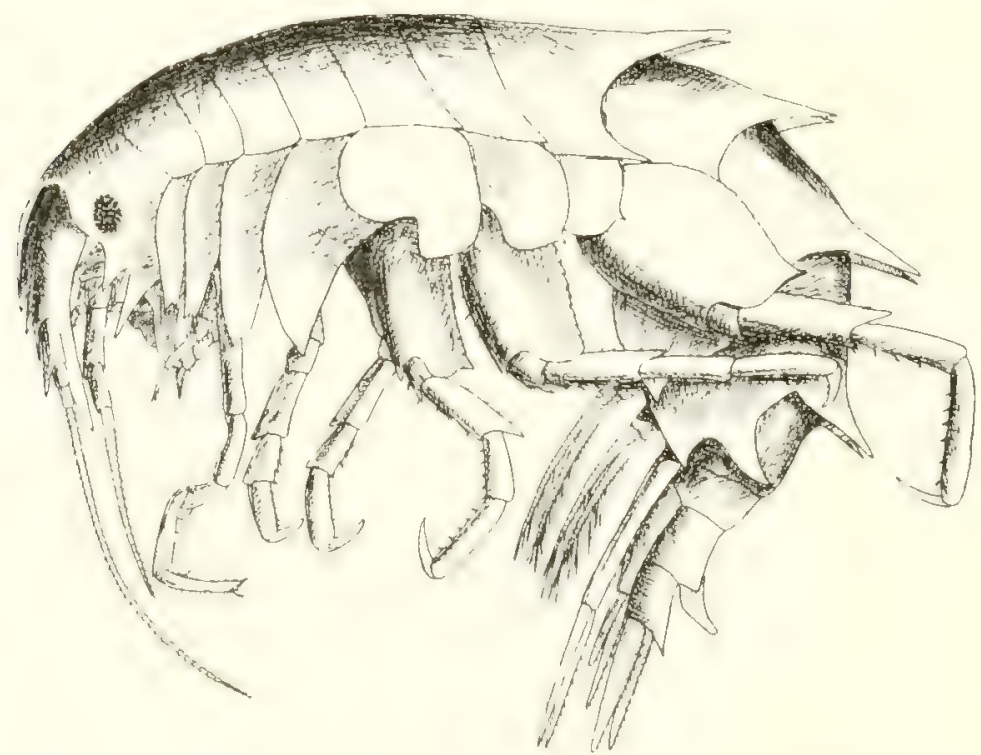

Hig. - Iphomediella Margueritei. - Femells vue du coté gauche.

İn mâle, une lemollo. Le corps de la femelle élait rose; le male bail coloré en jaune orangés.

Femelle. - Le corps, frès obese, mesurait 19 millimintes de longueme dans la position où il est fignué iei. Le dernier segnent du mésosome el chacun des segmonts du mótasome portent donx dents, longues et aigues. 
an bord dorsal posterieur. Les angles lateraux posterieurs des segmomts du mésosome, arrondis dans les quaterepremiors segments, se prolongent en arpiere, dans les segments suivants, pour former une dent aiguö. particulierement longue dans le dernier segment.

Lil tete, non compris le rostre, ast deux fois aussi haute que longue. Le rostre, beaucoup plus long que le reste de la tête, n'atteint pas tout a lait l'extrémité du premier artiele du pédoncule desantennes supérienros. Les lobes latérax se probongent pour fomer doux dents agruës, la denl inférieure étant beancoup plus longue que la dent supépienro.

Le bord antérieur des planpes coxales des denx premireres paires se

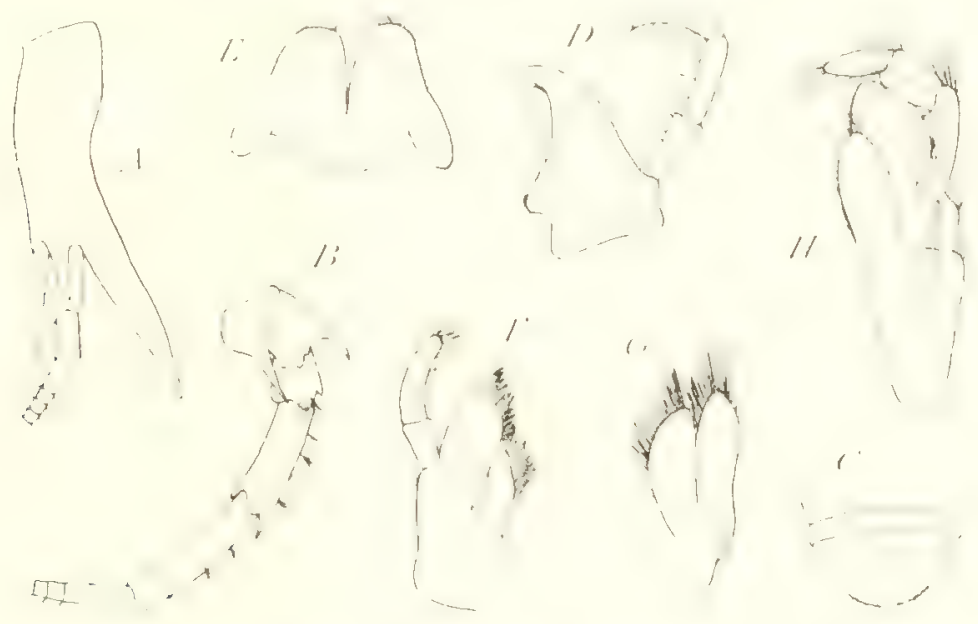

Fig. 23. - Iphimenliellu Wargueritei.

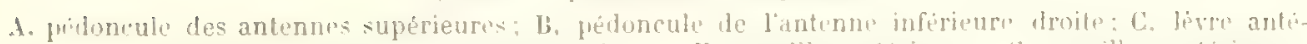

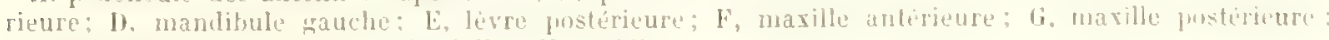

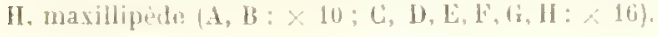

prolonge inférieurement pour former unc dent aigui, suivio de deux dents plus petites. Les plaques coxales de la troishome paire. donticulées dans la partie distale de leur bord antérieur, se terminent inlériemement par une dent aigue. Le bord postéreur des plaques coxales de la cinquieme paime est lisse. Co bord porte une dent aigue dans les platques coxales des deux derniores paires. Les plaques épimerales du dernier segment du metasome, fortement prolongees en arriere, se terminent par denx dents aiguess, la dent suprobieme etant beaucoup plus longur que la dent interienre.

Les yeux, assez petils, ovales, sonl proéminents.

Expédition Charcut. - Guevrelx. - Amphipodles. 
Les antennes supérieures atteignent à peu pris la moitié de la longueur du rorps. Le premier article du pédoneule, très développé, se prolonge inférieurement pour former trois dents : une petite dent, au bord antérieur, est suivie d'une dent aiguë n'atteignant pas tout ì fait l'extrémité du denxime article du pédoncule, puis d'une dent trìs longue et tres robuste, qui s'étend jusqu'au niveau de l'extrémité du quatrième article du flagellum. Le deuxième article du pédoncule se prolonge inférieurement pour former une dent aiguë, aussi longue que le troisieme article. Le flagellum comprend une quarantaine d'articles, le premier d'entre eux étant aussi long que l'ensemble des trois articles suivants.

Les antemes inferieures sont notablement plus courtes que les antennes supérieures. Les deux premiers articles du pédoncule portent chacun une dent longue et aiguí. Le quatrième article se prolonge inférieurement en avant et en arrière, la dent antérieure étant plus longue et plus aigué que la dent postérieure. Ciet article, un peu plus court que l'article suivant, dans l'antenne droite, était plus longe dans l'antenne sauche. Le flagellum se compose d'une vingtaine d'articles, le premier d'entre eux atteignant la longueur de l'ensemble des cinq articles suivants.

La lève antéricure est régulièrement arrondie au bord distal.

Les mandibules sont larges et courtes. Le lobe tranchant est légìrement bidenté an bord distal. La mandibule gauche présente seule un lobe accessoire, également bidenté. Le processus molaire, assez saillant, est garni de petites épines. Il n'existe pas de rangée d'épines entre le lobe tranchant ef le processus molaire. Le palpe, à peine plus long que le corps de la mandibule, se compose d'un premier article relativement allongé, suivi de deux articles un peu plus loness et d'égale taille.

Les lobes externes de la lèvre postérieure sont régulièrement arrondis et ne présentent pas d'échancrure au bord interne. Il n’y a pas traces de lobes internes.

Le lobe interne des maxilles antérieures, très développé, porte une rangée de soies ciliées, au nombre de quinze dans la maxille droite et de douze dans la maxille gauche. Le lobe externe, obliquement tronqué, rst armé de onzo ípines accompannées de nombreuses soies. Le palpe dépasse de beaucoup le lobe externe; son premier alticle, très développé, 


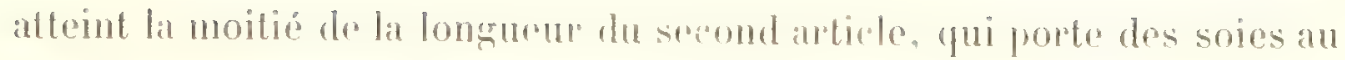
bord distal of an bord interno.

Le lobe externo dos maxilles postérieures, un peu plus long que le lobe interne, se réstrecit à sonextrémitr. Les deux lobes portent de nombreuses epines au bord distal el au bord interme.

Le lobe interne des maxillipedes, hien développé, porte de nombreuses epines. Le loberiterne, assez large, n’atteint pas lextrémité du deuxieme

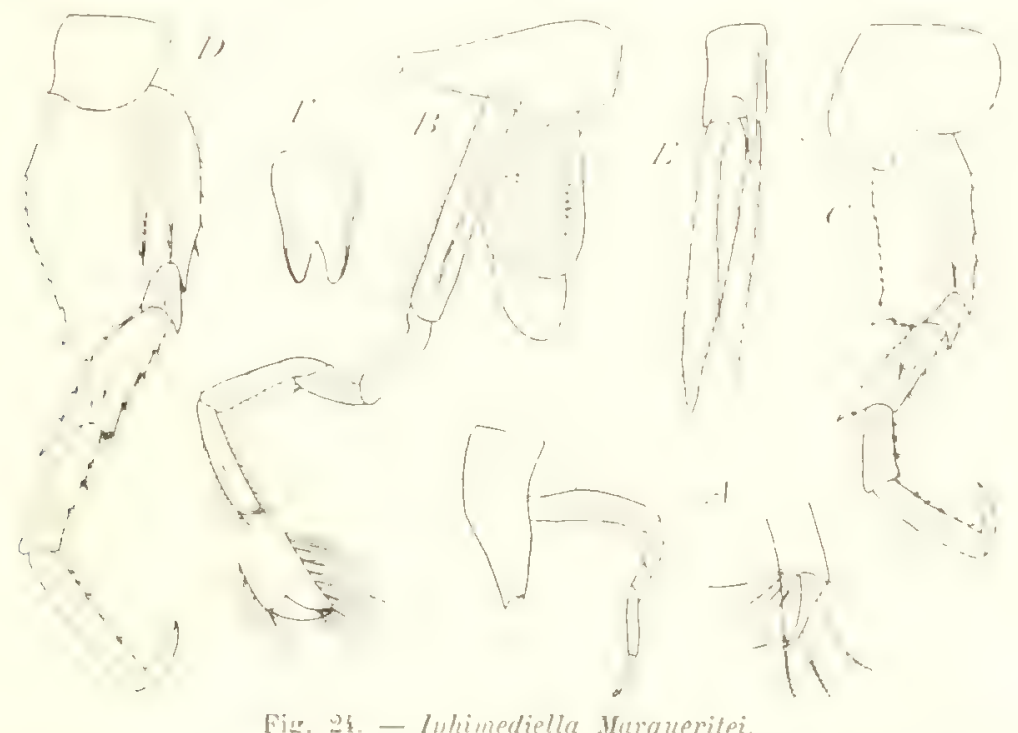

Fig. ㅁ․ - I phimediella Marqueritei.

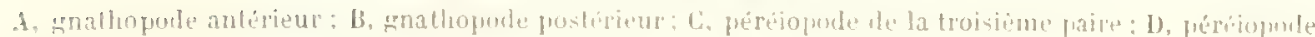

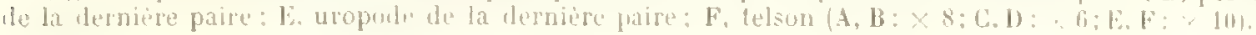

artiele du palpe; il porte une langéc de petites épines au bord interne. Le palpe ne comprend que trois articles. Le premier d'entre oux esl presque aussi long que l'ensemble des deux suivants. La deuxibmo articto ne se prolonge pas le long du bord interme du troisieme.

Les anathopodes anterieurs, tris courts at tres grèles, prespue rudimentaires, sont tordus comme chez les l'mmploen el les Iphimedire. L'article basal est aussi long que l'onsemble des trois articles suivants. Liarticle ischial, plus court que le carpe, est un peu plus longen que le propode, yui se termine par une petite pince garnie de puelpues soies, dont trois sont ciliées.

Les znathopodes postériours, tries dévoloppés, beatcoup plus longs

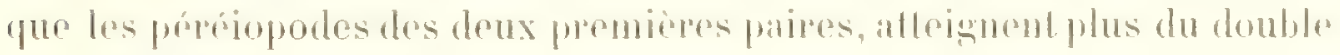


de la longueur des gmathopodes antérieurs. Larticle ischial atteint les frois quarts de la longueur du carpe. Le propode, aussi long que le carpe, est ehélifirme.

Les péréiopodes des deux premieres paires sont assez robustes. Le propode est un peu plus long que le carpe. Tous deux portent de protites fpines au bord antérieur.

L'arlicle basal des péréiopodes de la troisieme paire, deux fois aussi longr que largé, présente un bord postérieur crénelé, légèrement concave, lerminé inférieurement par une forte dent, suivie de quelques crénelures. L'article ischial se termine antérieurement par une dent robuste. L'article méral présente, en arrière, un prolongement aigu, accompagné d'une petite dent. Le propode, beancoup plus long que le carpe, porte, comme lui, des toufles de petites épines an bord antériemr.

Les pérélopodes de la quatrieme paire, un peu plus longs que les péréiopodes précédents, n'en diffèrent que par la forme de leur artich basal, qui est un peu plus large el dont le lobe postérieur est arrondi inférieurement.

Les péréiopodes de la dernière paire, un peu plus longs que les péréiopodes précédents, présentent un article basal plus large et dont le bord postérieur, convexe et crénclé, se prolonge inférieurement pour former, avec le bord inférieur, une dent aiguë s'étendant bien au delà de l'extrémité de l'article ischial.

Les uropodes de la première paire sont grêles et allongés; leur's branches, subégales, n’atteignent pas tout à fait la longueur du pédoncule. Les uropodes de la deuxieme paire sont beancoup plus courts que les uropodes précédents. La branche interne est un peu plus longue que le pédoncule; Ia branche externe atteint à peine les deux tiers de la longueur de la branche interne. Le pédoncule des uropodes de la dernière paire porte une carène qui se prolonge distalement pour former une dent aiguë. Les branches, garnies de petites épines, sont trois fois aussi longues que le pédoncule.

Le telson, plus long que large, un peu rétréci dans sa partie médiane et profondément échancré sur le tiers de sa longueur, ne porte ni soies ni épines. 
Whe - Bearoup plus petil que la femelle, le male mesurait sentement 9 millimètres de longueur. Les yeux, très grands, ovales, oceupent presque toute la largeur de la tête. Les intemnes inférieures sont plus longues que les antennes supérieures, et le dernier article de leur pédoncule n’atteint pas tout à fait la longueur de l'article précédent.

Le nom spécificue se rapporte au lien de la capture.

\section{LILU,EROR(IIII) E.}

Lilljeborgia consanguinea Stebbing.

1906. Liljeborgia consanguinea Stebbing (11), p. 23:2 (1).

1909. Liljeborgia consanguinea strauss (14), p. 13, fig. 18 A, 18 B du texte, et I'l. V. fig. 29.

1910. Liljeborgia consanguinea Stebbing (13), p. 454.

Dragage VIII, 20 janvier 1909, baie Marguerite; profondeur, 200 mètres. Un màle, coloré en jaune orangé.

Le corps, très comprimé, mesurait 7 millimetres de longueur dans la

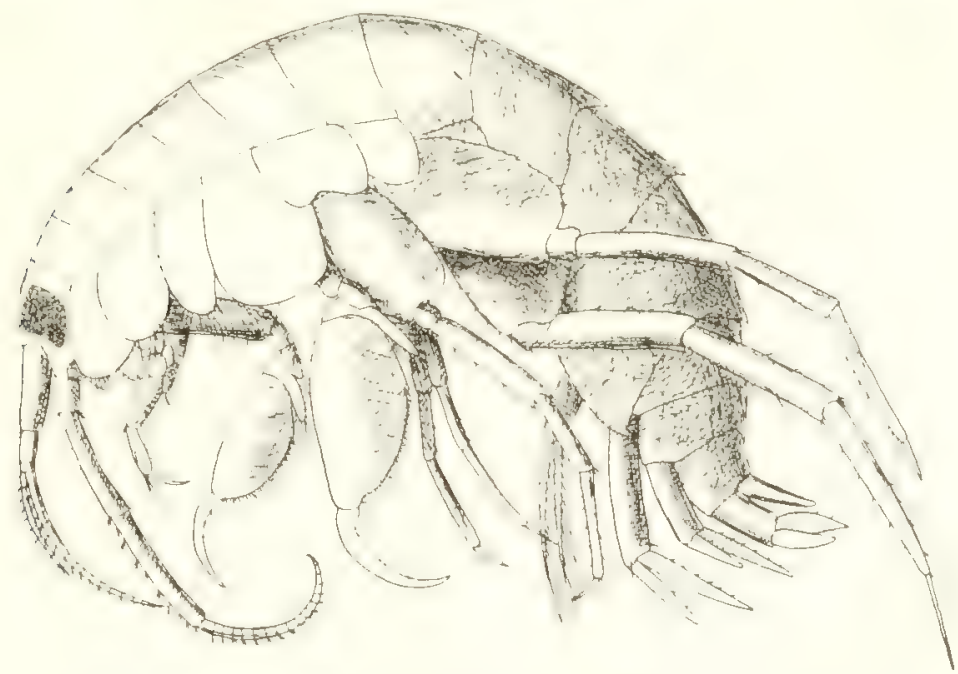

Fig. 25. - Lilljeboring consangrinea. - Màle vu du coté gauche.

position où il est figuré ici. Le mésosome est lisse. Chacun des trois segments du métasome et des deux premiers segments de l'urosome porte une dent à l'extrémité postérieure du hord dorsal. La dent du dernier segment du métasome est plus petite que celle des deux segments

1) On trunsera dans l'ouvage de Stebbing la synonymie antérieure à 1906. 
próndents. La dent du prenier segment de liurosome, frès allongée, alteint presque l'extrémité du segment suivant. La dent du deuxième segment est beaucoup plus courte. Ces deux dents sont couchées sur le segment qui les snit.

Le bord supérieur de la tête atteint le double de la longueur du premier segment du mósosome. Le rostre est à peine distinct. Les lobes latéraux, tris prolongés, étroitement arrondis, sont courbés à leur extrémité. Les plaques coxales de la première paire, fortement prolongées en avant, sont régulièrement arrondies. Le lobe antérieur des plaques coxales de la cinquieme paire est moins haut que le lobe postérieur. L'angle postérieur des plaques ipimérales du demier segment du métasome, fortement prolongé en arriore, se termine par une dent aiguë, surmontée d'une petile échancrure.

Les yeux, tres grands, alfectent une forme puadrangulaire, leur bord antérieur étant un pen concave. Ils oceupent la plus grande partie de la licte et comprement un tres grand nombre d'ocelles.

Les antennes superieures atteignent ì peu près la longueur de l'ensemble

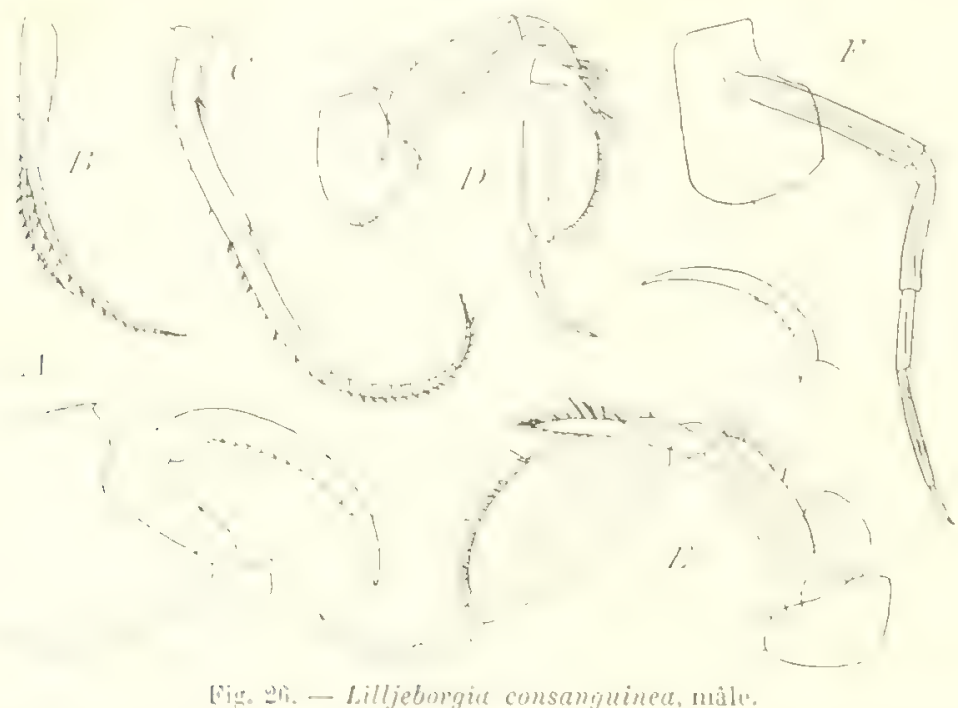

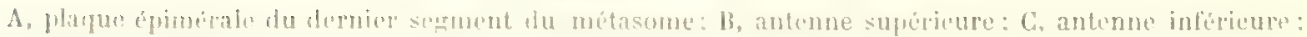

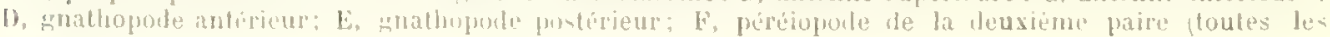
ligures: $\times 16$.

de la tète el des quatre premier's segments du mésosome. Le premier anticle du pédoncule est aussi long que le bord supérieur de la lète. Le 
second article natteint que le tiers de la longuene du premior. Le tlagellum principal, beaucoup plus long que lo predoncule, atteint l'astré-

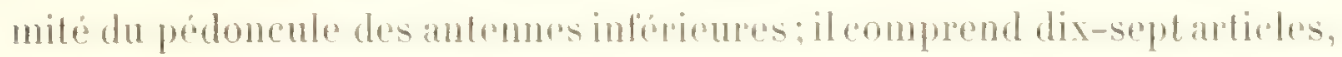
swanis de toutles de soies an bord anlérieur. Lo Hagellum aceessoire, qui se compose de onze articles, attrint un peu plus de la moitié de la longueur du llagellum principal.

Les antemnes inférioures attergnent la lonsurur de l'ansemble de la lote et des sis premiers segments du mésosome. Le dernicre artich du pédoncule est un peu plus long pue l'articho précédent. Le fligrallum, aussi long que le demier article du peidoncule, comprend vingl et un articles finement ciliés au bord anterionr.

Le bord postérieur de l'artich basal des gnathopodes antrépems ast lortement comvexe. Le propode, ovalabe, deux fois aussi long gur large. presente un bord palmaire reguliorement convexe, à peine distinct du bord posterieur. Le dietyle, grêle ot couble, porte six dents peu accenluees in bord interne.

Les guathopodes postéricurs sont heaucoup plus grands que les gnathopodes antérieurs. La plus grande largour du propode égale les deux tiers de sa longueur. Le bord palmaire est séparó du bord postérieur par un petit ressaut, sarui d'une epine. Le dactyle porte quatorze dents, modérément saillantes, an bord interme.

Les péréiopodes des deux premieres paires sonl tres grètes. fae pro-

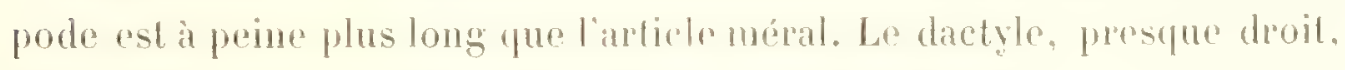
natteint guere plus du tiers de la longurur du propodr.

Dans les péréiopodes des troisiemes et quatriène paires, l'article basal est ovale allongé, sa lapupur n"alloignant que les deux liers de sa longueur; son bord postérieur porter des dents trés aceentuérs, acconpagnées de longs cils. Liaticlo mónal est beancoup plus long que le propode. Le dactyle est court.

Les péréiopodes de la derniere parre, heaucoup plus longs que les péréiopodes précédents, présentent un apticle basal largement ovalo. fortement crénelé au bord postépionr. La canpe, un pen plus long que

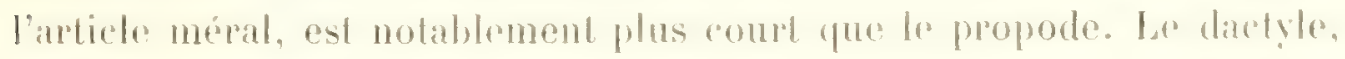
styliforme, atteint la moitié de la longueur du propode. 
Le pédoneule des uropodes de la première paire porte trois longues soies. Dans les uropodes des deux premieres paires, la branche externe ast notablement plus courte que la branche interne. Les branches des uropodes de la derniere paire sont lancéolées. La branche externe est

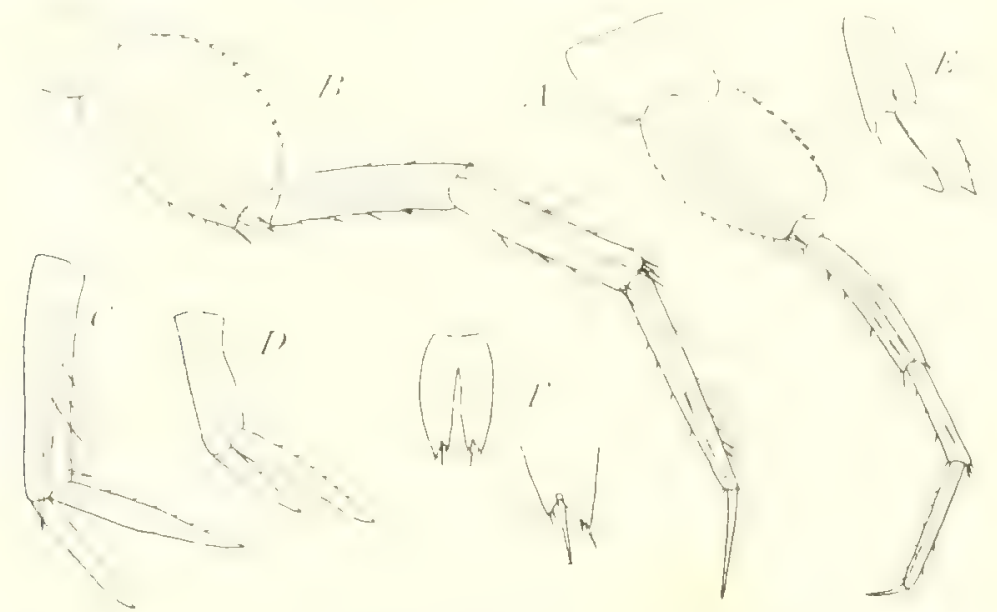

Fir. 27. - Lilljeborgia consanguinea, mâle.

1. péréiopode de la troisième paire: B, pécéioprode de la dernière paire: C, D, E, uroporles des promière, deuxime et troisieme pares: $\mathbf{F}$, fulson $(A, B: \times 16: C,[),[2, F: \times 20)$.

aussi longue que le pédoncule. La branche interne, plus longue et plus large que la branche externe, porte deux petites épines au bord interne.

Le telson, beancoup plus long que large, présente des bords latéraux convexes. Il est fendu sur les trois quarts de sa longueur. Ses lobes se terminent par une échancrure anguleuse, qui forme deux dents d'inégale taille. Chacune de ces dents porte deux spinules, et une épine, modérément longue, est fixée dans l'échancrure.

\section{(NEITIEROSIDE.}

Ediceroides Calmani A. (). Walker.

1907. Ediceroides Calmani A. O. Walker (17), p. 22, P'. VI, fig. 12.

Dragage VI, Iti janvier 190!, entrée de la baie Marguerite; profondeur, $2: 3$ motres. Une femelle de 27 millimetres de longueur. Le corps était d'mu, jame brumatere, tacheté de rouge-bricpue.

Dragage VIII, 20 janvier 1909, baie Marguerite; profondeur, 200 metres. 


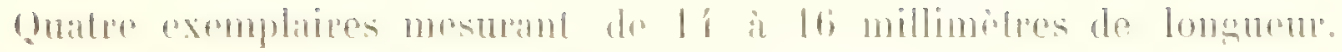

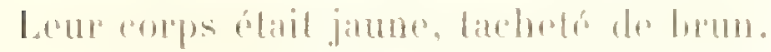

Latemelle dont la deseription suit mesment 16 millimetres de longueur. Le corps est tris obrise. Chacun des segments du mesosome prosente 111 sillon transversal, assoz profond au bord dorsal ot s'attemuant progressivement sur les cotós du sogment. Les trois premiers segments du mésosone sont d'égale longrueur. Les lrois segunents suivants, un peu plus longs, sont aussi d'énale taille. Le dronier segment atteint lo double

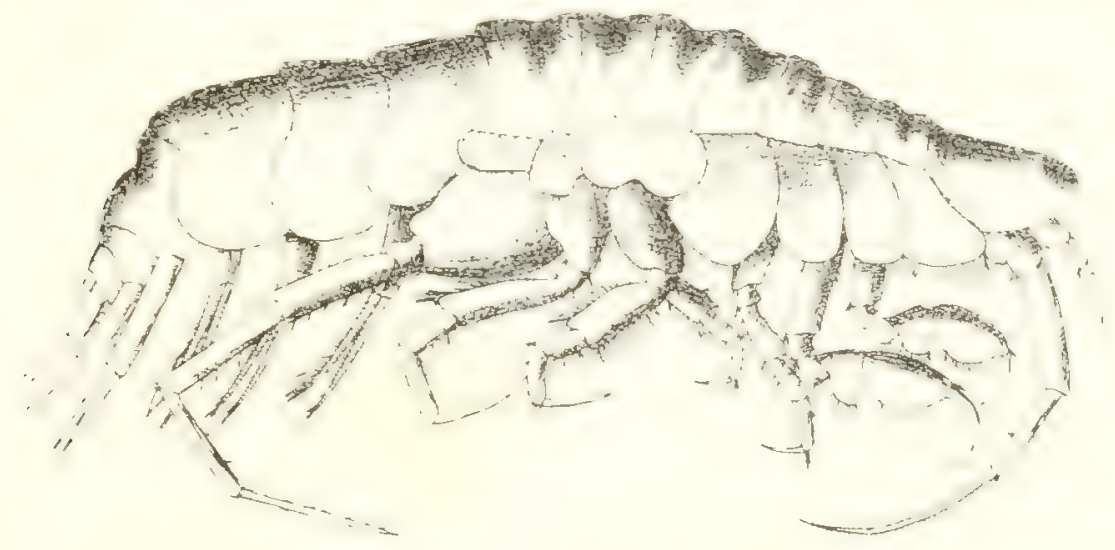

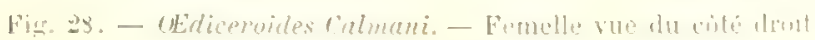

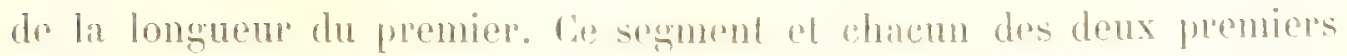
sergments du mélasome délordent fortemment, all bord dorsal, sur le segmont suivant. Le premier sregment de lanosome présente une dépression dorsale assozacentuce.

Lil tête, aussi longue que lonsemble des loois premiers somonents du anesosomr. presente, dans sa parlie postrirure, un sillon analogute i ceux

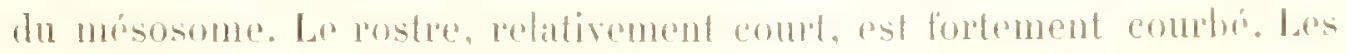
lobes latroux sunt largement arrondis.

Les plaques coxales des six premieres paibes sont borderes de sobre spiniformes, principalement longues ed robustes dems los plapuescoxales dro la prentièe paire. qui se prolongent beanconp enavant. Les platpurs

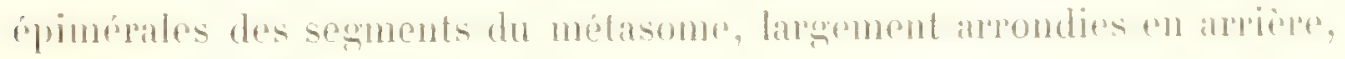
sont borderes de petites épines.

Les yeux, assez grands, ovales, alleignent presque l'extrémite du rostre al solouchent a soul sommed. 
Lens antemmes suprefieures, extremement courtes, sont moins longues yur la tête, leur extrémité atteignant a peine an dela du milieu de l'avantdernier article du pédoncule des antennes inférieures. Chez la grande femelle du dragage VI, ces antenues, encore plus courtes, n'atteignent yu'au premier tiers de la longueur de l'avant-dernier article du pédoncule des antenmes inférienres. Le premier article du pédoneule est fortement dilaté dans sa partie distale, son bord antériour formant une sorte de bourrelel, sarni de soies ciliées, qui déborde sur l'article suivant. Cé article est un peu plus court et beaucoup phus étroit que le premior arlicle. Le troisieme article n'atteint que le liers de la longueur de l'arlicle précédent. Le flagellum, beaucoup plus court que le pédonenle, comprend sept articles fincment ciliés, mais ne portant pas de calcóoles.

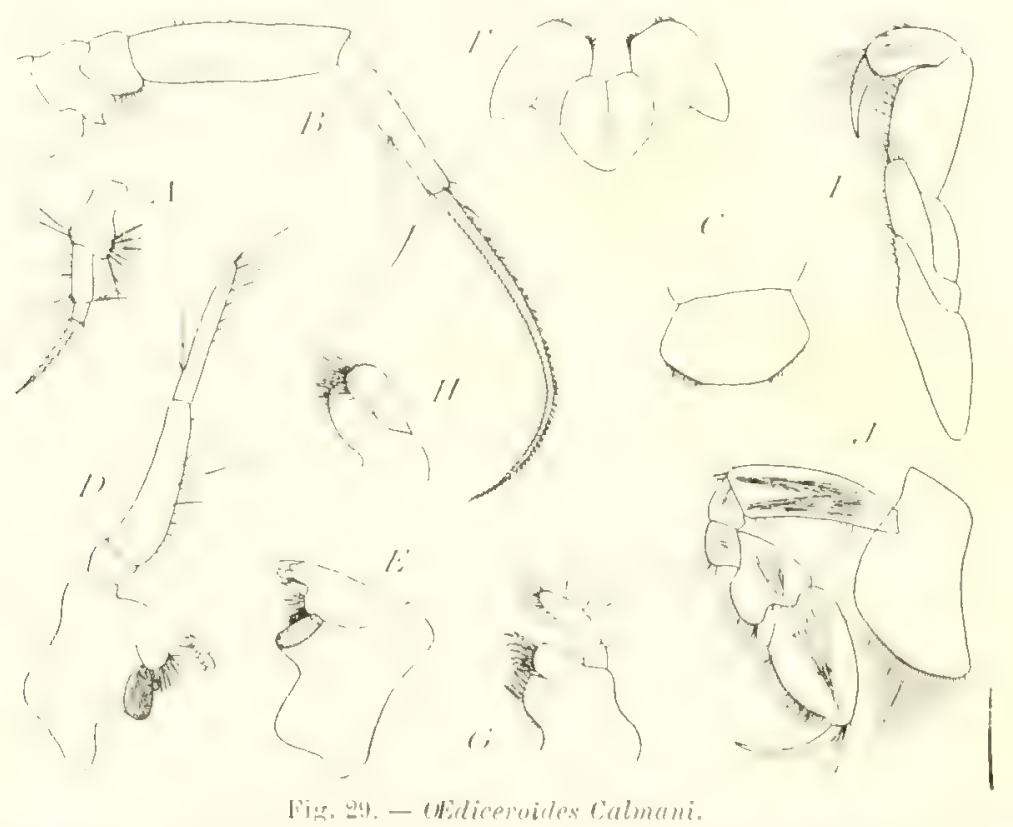

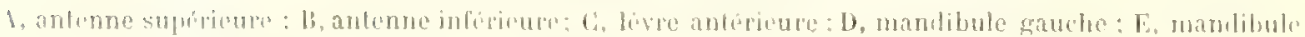

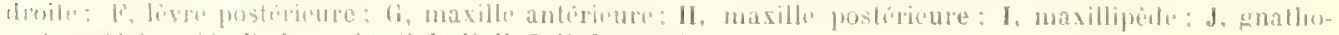

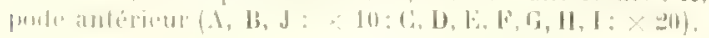

Les antemes inferiemresatteignent à peu priss la longueur de l'ensemble de lat lober des six premiers segments du mésosome. Le quatrieme atticle du pridoncule, tries robuste, est aussi long ì lui seul que las antemnes suprobures. Le cinquieme atticle atteint les trois quarts de la longueur de l'articte précedent. Il porte, ì l'extrémilé du bord postérieur, une soie 


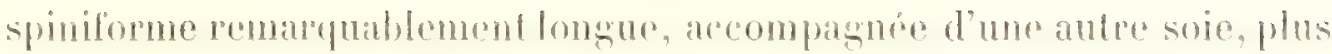
courledemoitie. Le flagellum, anssi longrye l'ensemble des deux derniers articles du pédoncule, comprend une soixantaine d'articles. Il porle des calcéoles at bord antériour.

Le bord distal de la lievere anteriene ast laree ed droil.

Le lobe tranchant des mandibules est constitue par un groupe de qualue dents. Le lobe accessoiro, bidenté dans la mandibulo droite, ost quadridonte dans la mandibule gatehe. Le processus molaine rest tres volumineux. Le palpe alteint pres du double de la longueur du corps de la

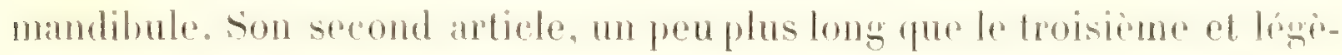
rement courbor, est assez fortement dibité dans sa parlie prosimale. Tous deux portent de nombrenses cpines au bord interne.

Les lobes latérax de la leve postérieure sont un peu trongués au bond distil.

Le lobe intene des maxiltes antrienures porte six soies ciliées. Le lobe externe est armé do neuf épines. Le palpe est mani de longues soirs spiniformes.

Les lohes des maxilles posterieures sont d'ógale taillo.

Les lobes des maxillipedes sont btroits. Le lobe extrme niatteint qu'un peu au dela du premier article du palpe. lo deuxiome article du palpe. lemarquablement large, depasse en longueur l'ensemble des doux arlicles suivants. Le quatrime anticle, dactyliforme, est un peu pus court que l'articlepróédent.

Le carpe" des guathopodes antéremes atteint les deux lieps do la longuenr du propode; son lobe est très dilate dans sa partie distale. Le propode. ovalaire, préspute un boted palmaire deux fois aussi long que le bord postérieur, dont il "st séparé par un petit angle obtus. Le dactyle, lo's greble, est aussi long que le bord palmaire.

Le carpe des gnathopodes posterieurs n'alleint que la moitie do la Inngueur du propode; il est un peu plus larege que long, ot son lobe est phus botroit que dans les gnathopodes antérieurs. Le propode, ovale allongr, pst deux fois aussi long que large; son bord palmaine so confond avere le

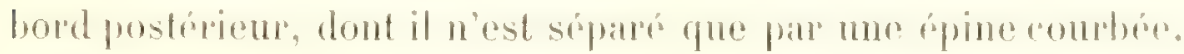

Larticle méral des péréiopodes des deux premieres paires porter, alu 
bord postérieur, deux longues soies ciliées, acompagnées de nombreuses soies simples. Le carpe, le propode et le dactyle sont d'égale longueur.

Les articles basal ot ischial des prónopodes do la troisiome paire portent chacm drux soies ciliées. Larticle méral est garni, sur ses deux

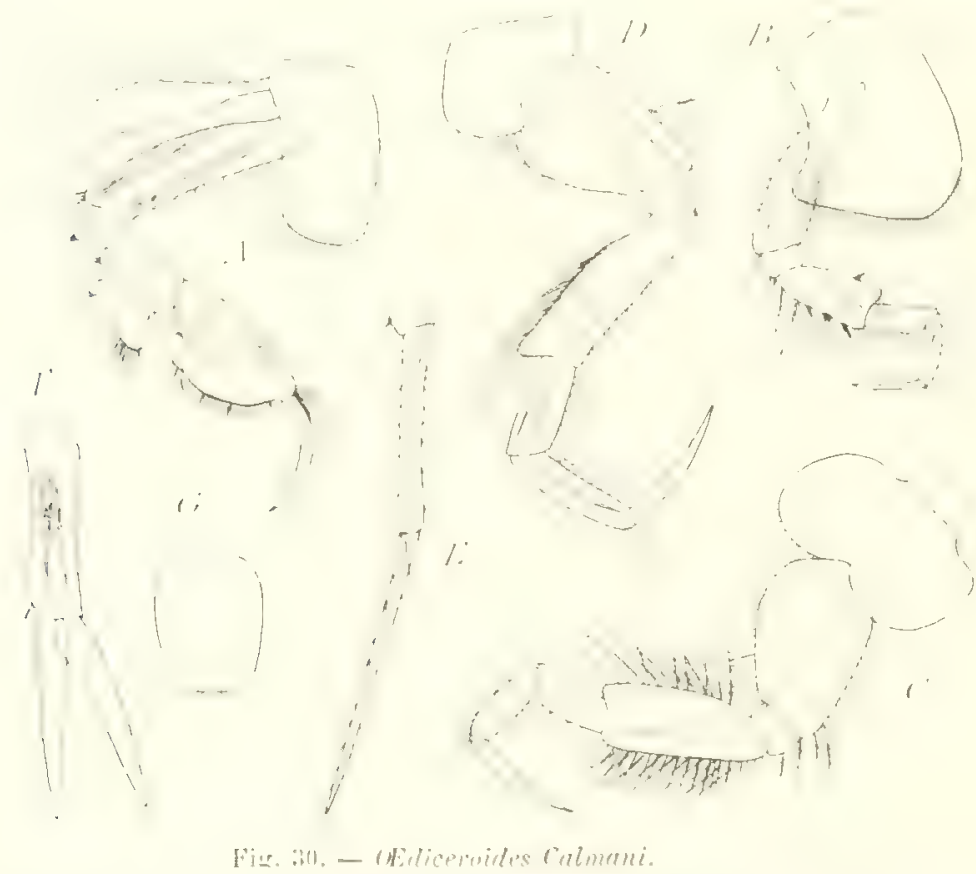

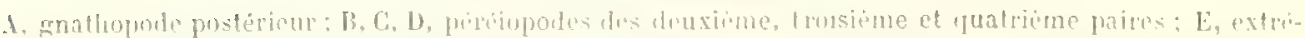

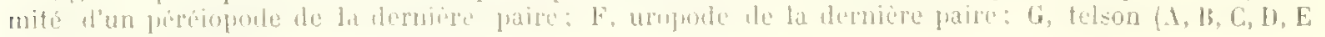
$\therefore 10 ; \mathrm{r},(\mathrm{i}: \times 20)$.

bords, dre longues soies ciliérs, entremêlées de soies simples. Le propode, phus long que le earpe, est beancoup plus court que le dactyle.

Larticle basal des péréiopodes de la quatrieme paire porte, au bord antériour, une grosse soie ciliée. Liarticle mépal, tris déreloppé, aussi long que l'ensemble des denx articles précédents, no porte de longnes soles quatu bord postérieur.

Lartich basal des pérópodes de la derniere paire est piriforme. Lu mape ast pus long que l'article méral et que le propode. Le dactyle, beancoup plus long que le propode, styliforme, porte de nombreuses petites soies.

Las branches des mopodes des denx premieres parres, subégales, soul phus courtes que lo predoncule. Les mopodes de la derniere paire nattri- 


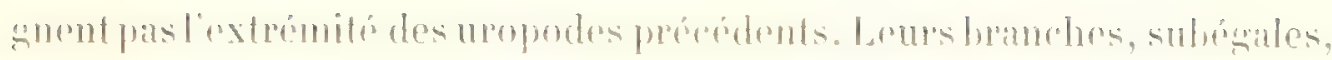

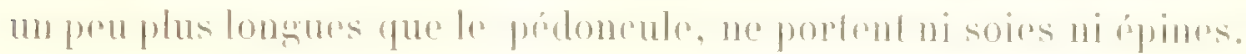

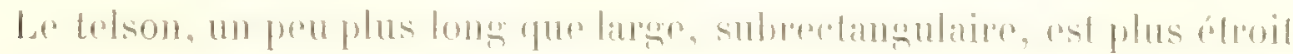

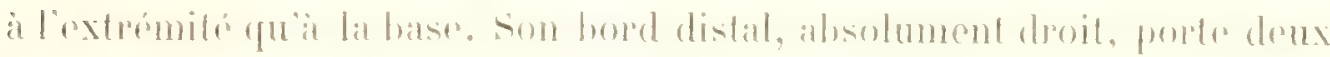
paimes do spimules.

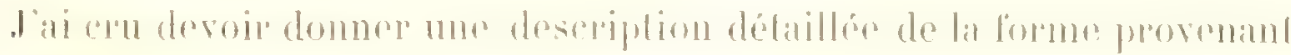

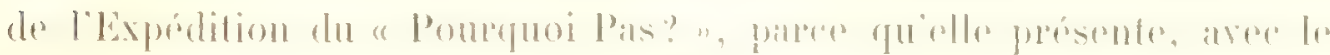

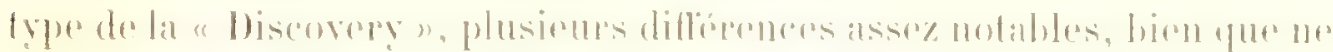

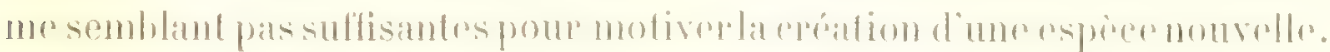

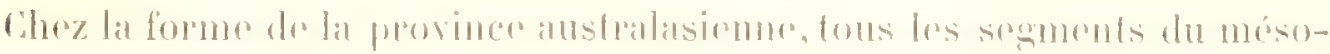

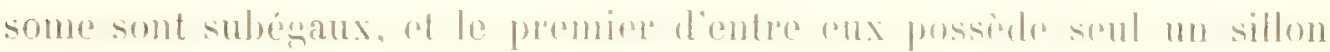

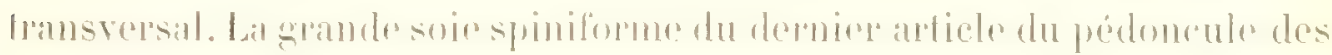

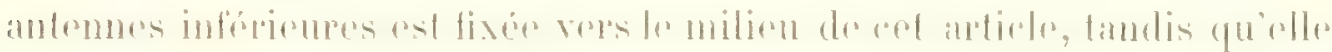

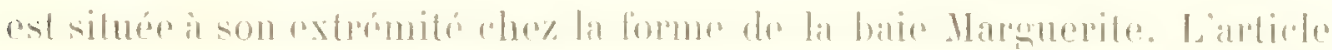

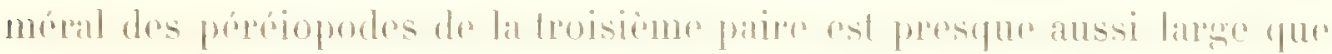

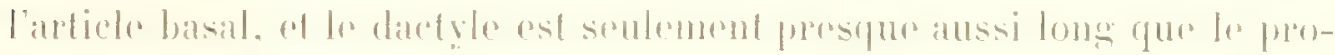

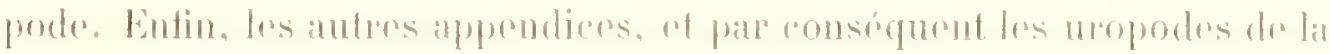

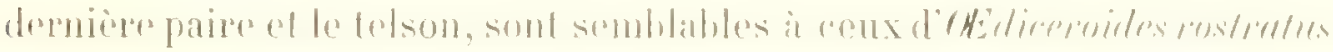

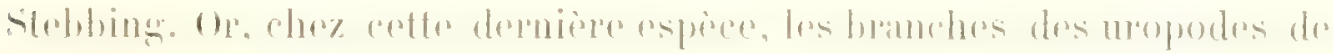

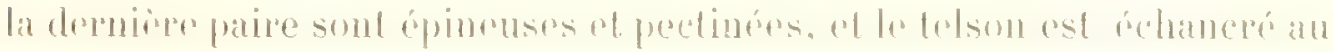
bord distal. ce qui ne se reteouve pas chez la lonmo décrite ci-dessus.

\section{Tlil). 1111.6}

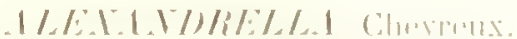

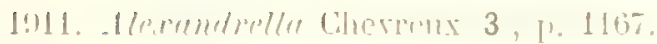

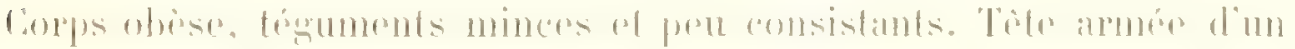

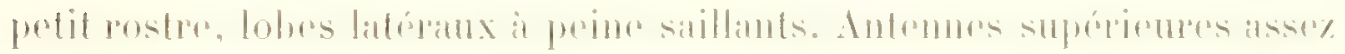

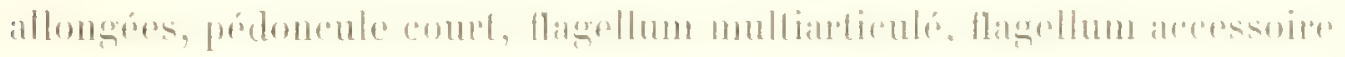

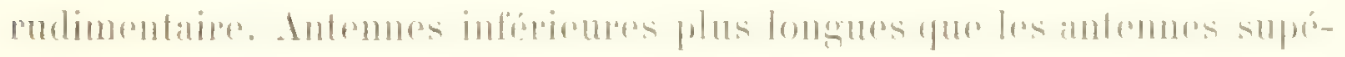

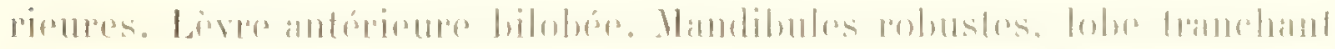

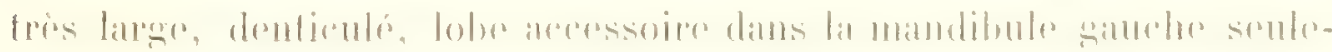

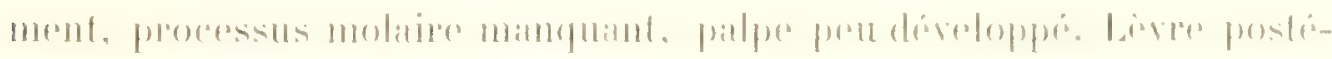

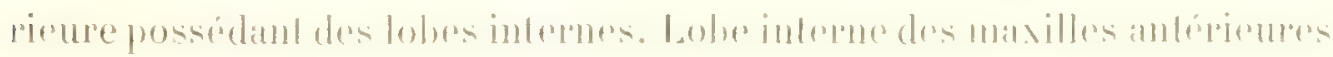


trins large, bordé de nombrenses soies ciliées, lobe externe armé de dixsept epines, palpe remarquablement développé. Lohe interne des maxilles posterieures beatucoup plus large que le lobe externe. Lobe externe des maxillipèdes tres développé, dépassant de beancoup l'extrémité du palpe. Ginathopodes antérienrs et postérieurs semblables entre eux, propode non subehrafiforme. Péréiopodes des deux derniores paires subéganx, plus longs que ceux de la troisieme paire. Branches des uropodes de la premirere paire subégales. Branche axtrune des uropodes de la deuxieme pare beaucoup plus courte que ha branche interme. Branches des uropodes de la dernìre paire trés allongées, étroitement lancéolées; lranche externe un peu plus courte que la branche interne. Telson quadrangulaire, echanceré au bord distal.

Alexandrella dentata Cheveux.

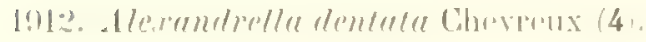

Dragage $X, 22$ janvier 1909 , pres la terre Alexandere 1 er profondent.

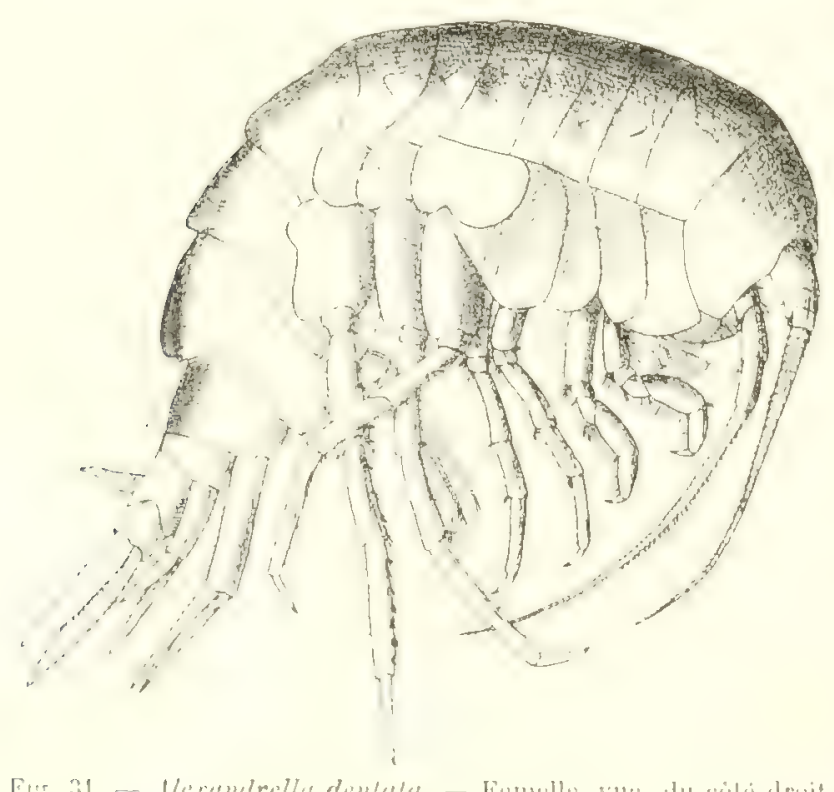

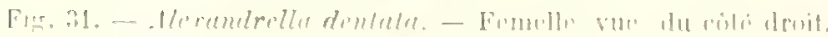

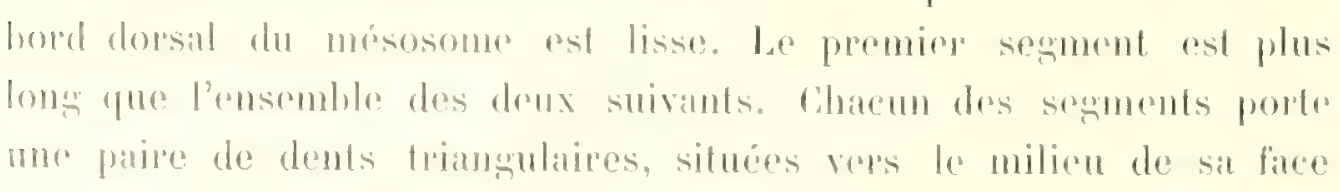

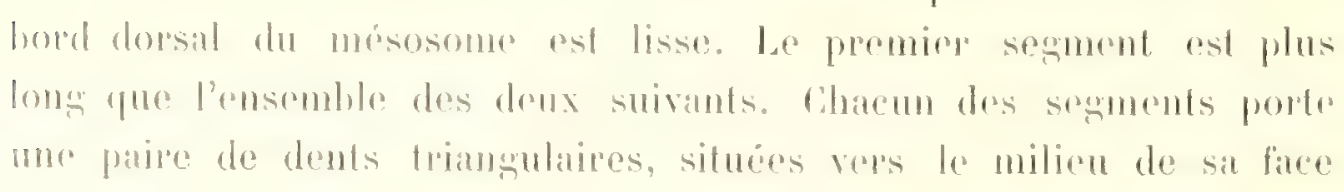

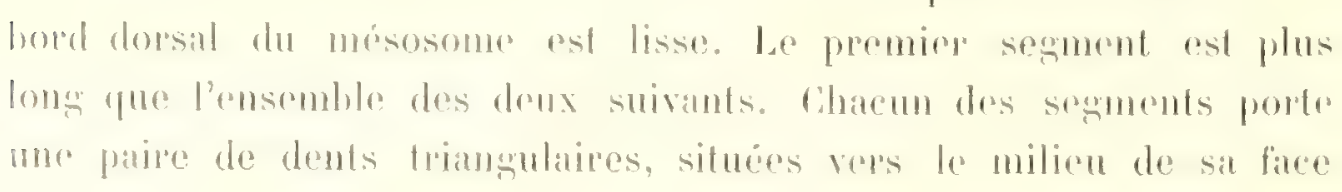
rienr d'une éponge. Une lemelle ovigien, coloré en jaune orangé.

Gette fomelle mesmait Is millimetros do longueur dans la posilion on clle est figuroe ici; elle poptait vingt-neuf ands dans sa poche incubatlide?.

Le corps, remarquablement obise, prósente des tromments fres minces of peu consistants. Lo 297 metres: dans linté- 


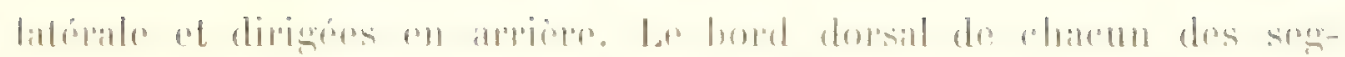

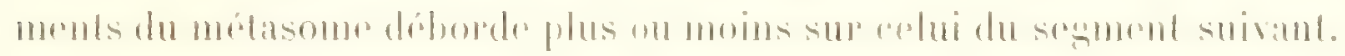

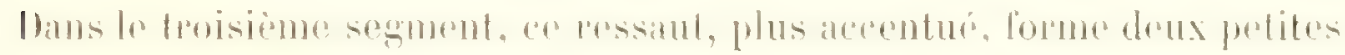

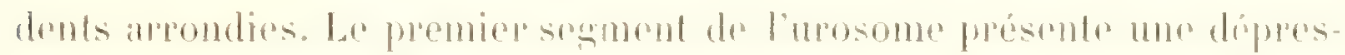

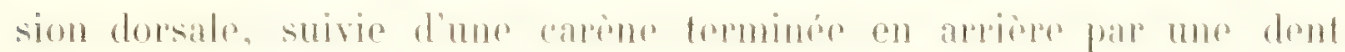
aing

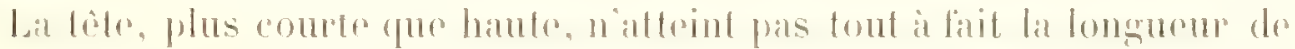
l'ansemble des deux premiers somments dumésosome. Ello porte un pretil

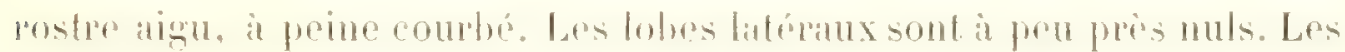

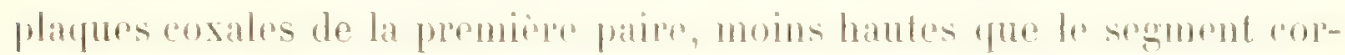
respondant du mésosome, dilaties dans tour partie distale, prósentont un

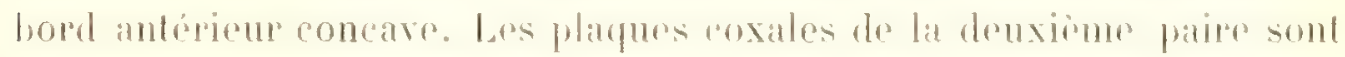
fortoment rétrécies dans leur partio distale. Les plapues coxalos do la quatriome pare ne présentent qu une lablo échancure au bord postéloreur. Les plaques éprmórales du demier segment da médasome ne se

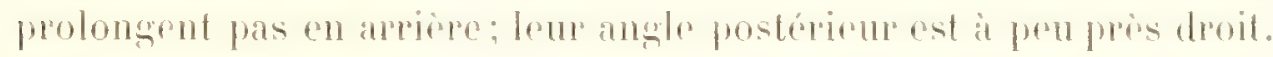

1111 ya pas traces dorantes de vision.

Les antennes superiempes attrignent lin longuene de l'ansemble de la têto al des cing foremiers segments du mósosome. Le pédonente est trós

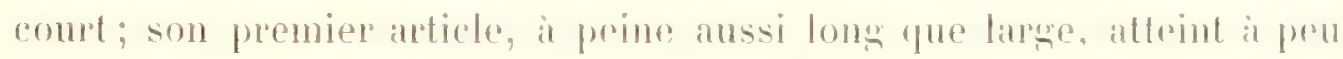

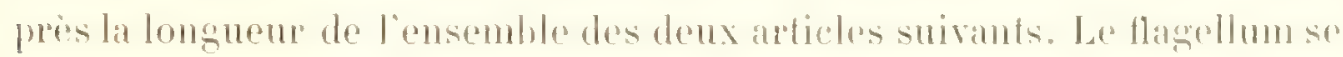

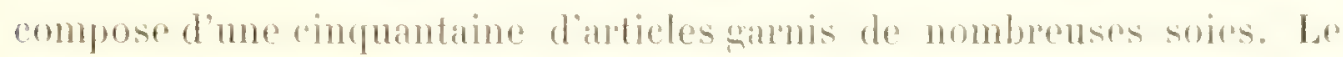
llagellum aceessoire, uniarticule, natheint pas la moitié de ha longurar

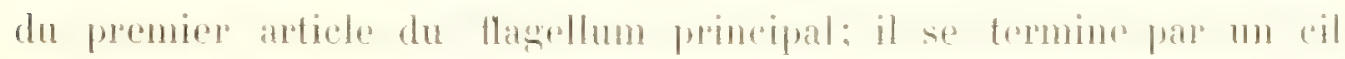
boracoup plus lonerge gue lui.

Les antennes inforicures somt an pen plus longues quo los antemmes

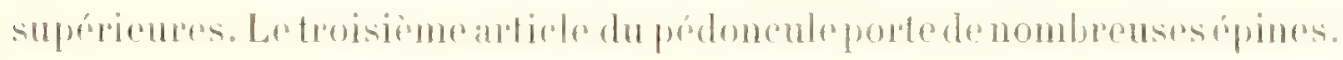

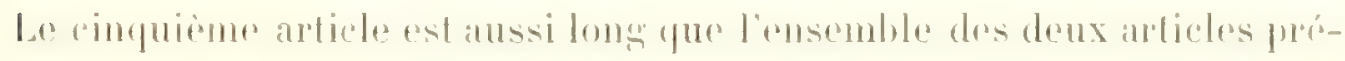
codents. Le flagellum comprend mo cinquantaine diaticles cilies an forded antringur.

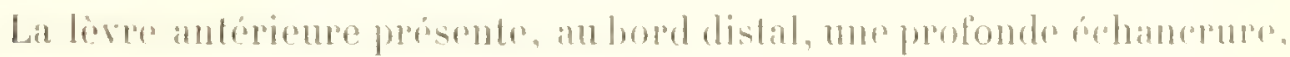
qui former deux lobes dinrogale laillo.

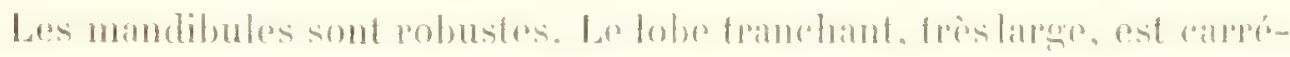

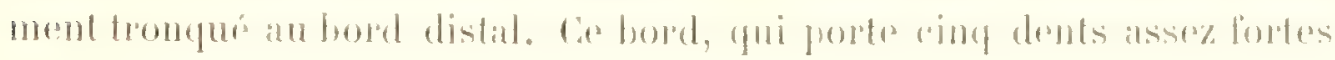




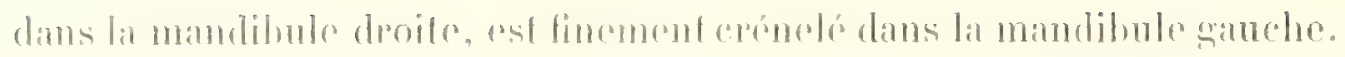

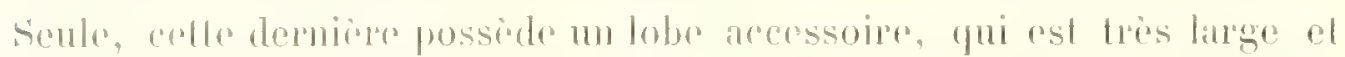

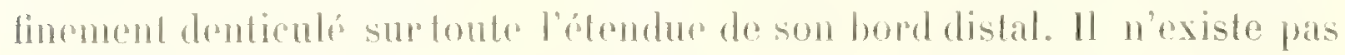
le processus molaire. Le palpe est compt; son troisieme article, moins

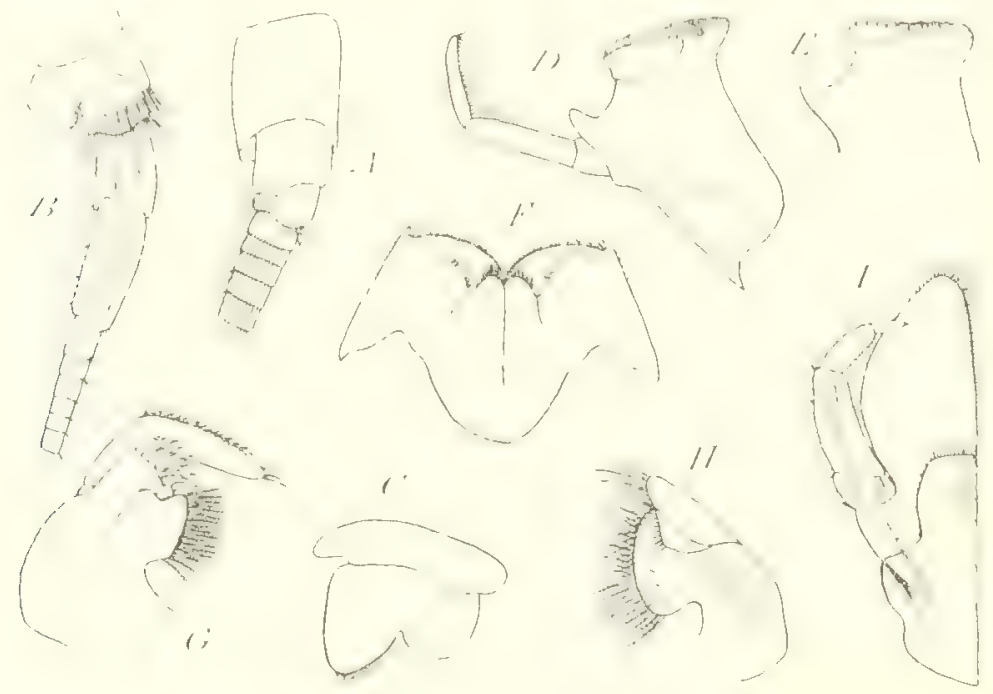

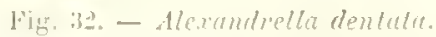

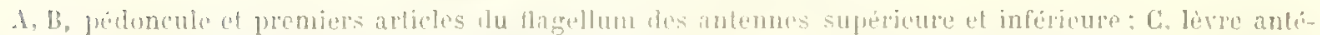

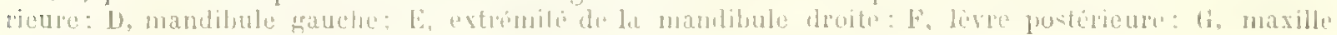

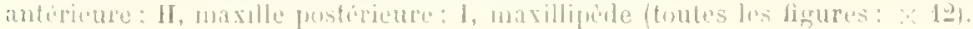

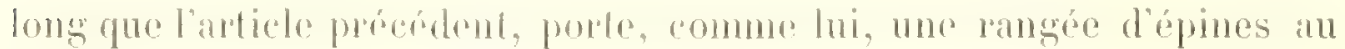
hord interme.

La linere posteriome, mombraneuse, posside des lobes internes peu

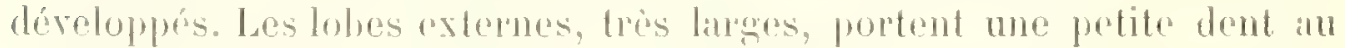
bord distak. Les prolongenonts postérien's, peu allongés, sont aigus.

Le lobe interme des maxilles anterieneres, frins large an bord distal, porte mo rangée do vingt soics ciliés. Lu lobe extene, carément tron-

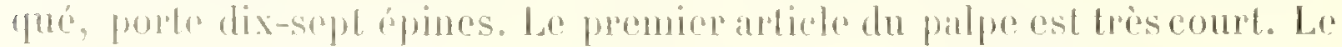

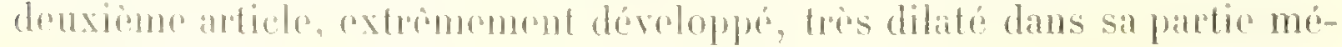

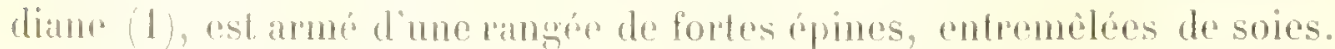

La lobe inforne des maxilles postérienes est heaucoup plus large

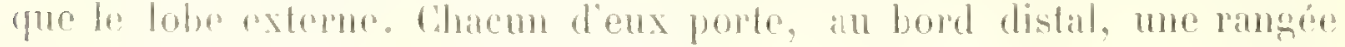

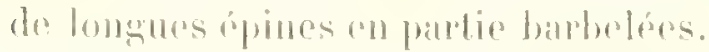

Lo lobe indormo des maxillipedes est carrément trompué au bord dis-

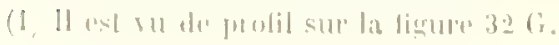


lal, qui portedo nombreuses pretites fophos. Le lonecxterne, extremement devolopper, porte des epines atu bord distal el an bord interne. Le palpe est loin d'alleindro l'extrénité du lobe oxterne: son quatriemo article est tris court.

Lartiche basal des gunthopodes antérieurs est légèrement counbé. Les deux articles suivants, trés courts, portent, au bord postérieur, de nom-

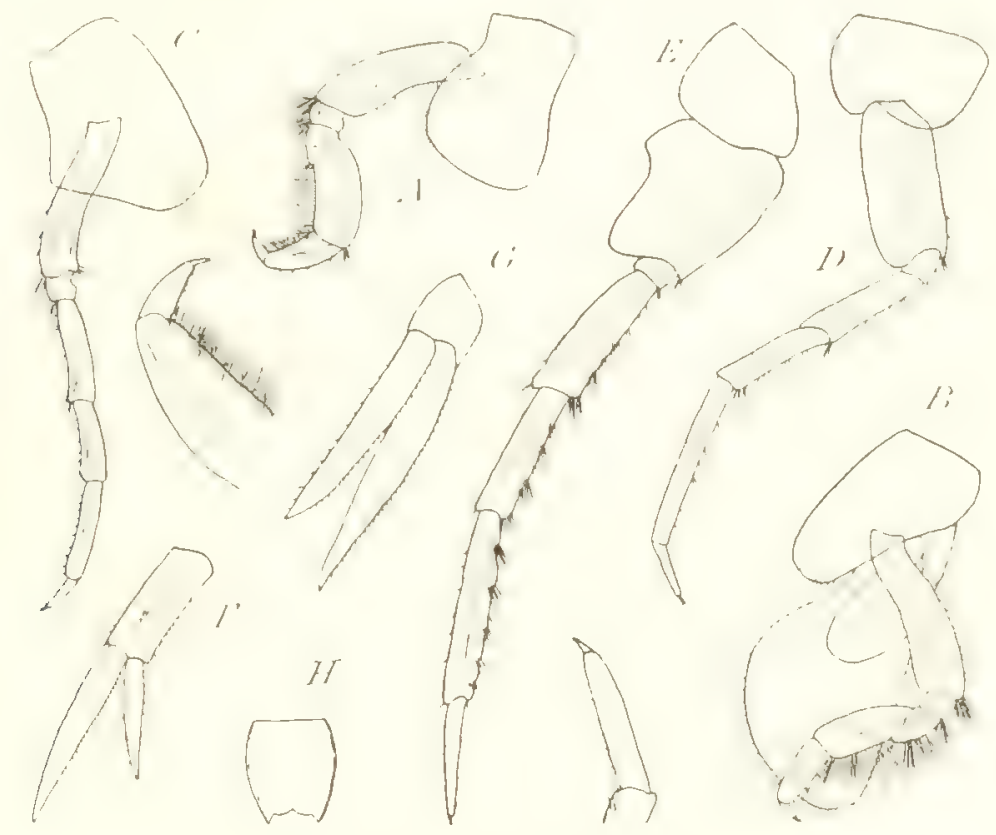

Hig. 33. - Alerentrellu dentata.

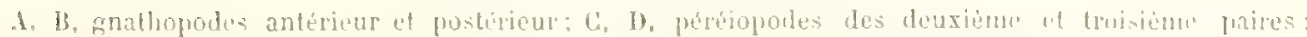

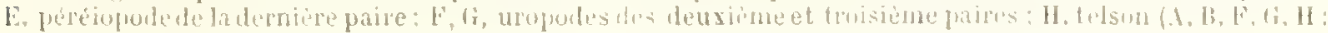
$\{y ; C, 1), E: \times 6)$.

breuses soies spinilormos. Le carpe est tris développé. Le propode, beaucoup phus court yue le carpe, n'est pas subchrififorme. Le dactyle porte me rangée de spinules au bord interne.

Les gnathopodes posteriemes diflient it peine dos gnathopodes antérieurs; neanmoins, le carpe et le propodr sont un peu plus étroils. Les lamelles ineubatriees sont remarguablement développées.

Lespéréiopodes des deux premieres paires sont longs el griotes. Lin'licle mépal et le propode, d'ígale taille, sont plus longess que lo cappe.

Dans les prériopodes des troisième el quatriome paires, l'article basil,

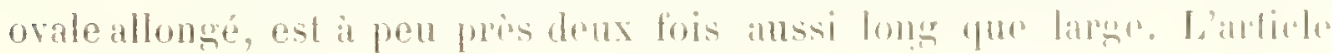

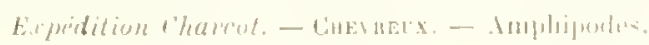


móral et le carpe, d'ésale taille, sont loin d'alteindre la longueur du propode. Le dactyle est presque droil.

L'article basal des péréiopodes de la dernière paire, plus large que celui des péréiopodes précédents, présente une forme inusitée, son bord postérieur portant une profonde échancrure arrondie. Le bord antérieur des articles suivants porte d'épaisses toulfes d'épines.

Le pédoncule des uropodes des deux premières paires porte une rangée d'épines au bord postérieur. Dans les uropodes de la première paire, les branches, d'égale taille, sont à peine plus courtes que le pédoncule. La framche externe desuropodes de la deuxième paire est beaucoap plus courte que la branche interne. Les uropodes de la dernière paire dépassent de beaucoup les uropodes précédents. Le pédoncule est très court. Les branches, étroitement lancéolées, sont bordées de petites épines. La branche externe est un peu plus courte que la branche interne.

Le telson, à peu près aussi longr que large, présente des bords latéraux convexus; son bord distal porte une petite échancrure médiane et deux échancrures latérales. Il ne possède ni soies ni épines.

Le nom spécifique fait allusion aux dents situées sur les cotés du minsosthur.

LIOUVILLISA Chevreux.

1911. Lionillea chevreux (3), P. 1167.

Corps obèse, portant des dents dorsales. Tète armée d'un rostre. Yeux proéminents. Pédoncule des antennes supérieures court, flagellum multianlicule, llagellum acessoire rudimentaire. Antemnes inférieures, che\% la lomelle, phus longues que les antennes supérieures. Eistome proéninent. Bord libre de la lexre antérieure arrondi. Mandibules robustes, lobe aceessoire présent dans les drux mandibules, processus molaire roluminenx; dernicr article du palpe beanconp plus court que l'article précédent. Livre postérienre possédant des lobes internes. Lobe interne des maxilles antérieures très large, garni de plusieurs soies; lobe externe et palpe normaux. Lobes des maxilles postérieures subégaux, bord interne du lobe interne garni dr soies. Lobe externe des maxillipides alteignant au dela 
du milien du deuxime article du palpe ; troisieme article prolongé le long du quatrième. Gmathopodes faibles chez la femelle, subchéliformes. presque d'égale grosseur. Pépéiopodes normaux. Branche externe des uropodes des deux premieres paires beaucoup plus eourte gue la branche interne. Telson subovale, lindu dans sa parlie distale.

Jai dédié en nouveau genre à M. Io D' Liouville, naturaliste attaché à l'expédition du "Pourpuoi Pas?"

\section{Liouvillea oculata Cherreux.}

191:3. Livuilled oculala (ihevreux (4).

Ile Petermamn, f octobre 1909. Dans une foulle do Desmorestiu ramenée de 3 mitres de profondeur. Lne femelle ovigire.

Dragage XTV, is novembre 1909, le long de la coile nst de l'ilo Petepmann ; profondeur, 60 à 40 métres. Une femelle, dont le corps étail brun, ponetué de blane. Les yeux étaient d'un rouge-brique.

Lat femelle du dragage XIV mesurait 9 millimistres de longueur, dins

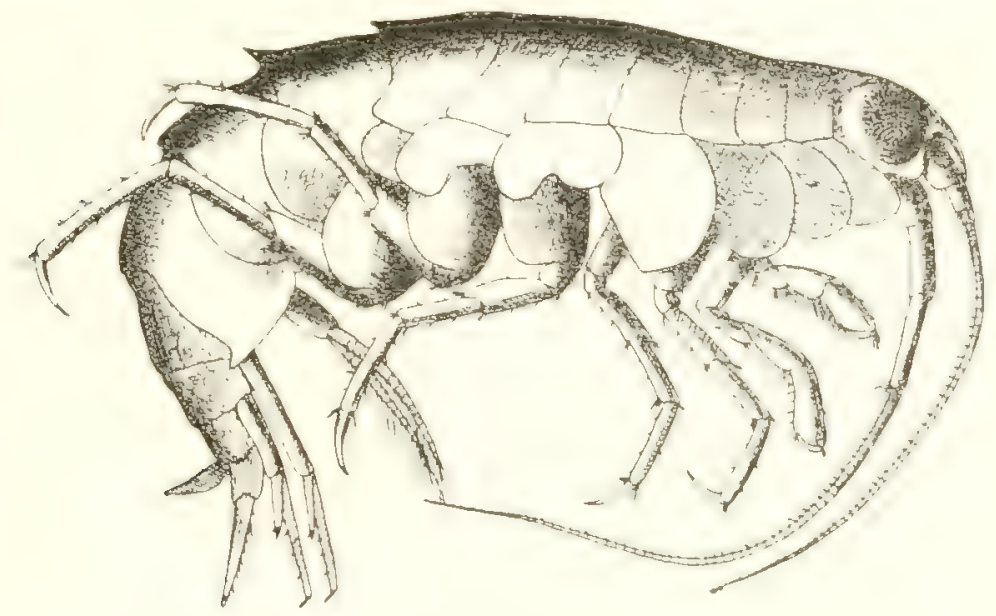

Fig. 3i. - Limerillea oculuta. - Fennillo rue du cité droit.

la posilion ou elle est figuré ici. Sa poche inculatrice contenail quatre mothryms.

Le corps, assez obese, présente des léguments cipais et durs. Le depnier segment du mésosome, beaucoup phus long quechacun des segments précédents, porte une dent dorsale modérément aigüu. Le premier seg- 
ment du métasome se prolonge en arriore pour former une dent dorsale plus longue et phus aignë que la dent précédente. Le deuxième segment du métasome porte unc petite dent dorsale arrondie.

La tête, trìs volumineuse, est plus longue que l'ensemble des trois premier's segments du mésosome. Le rostre, aigu ef courbé, atteint l'ex. trémité du premier article du pédoncule des antennes supérieures. Les lobes latérax présentent un hord distal arrondi. Les plaques coxales des quatre premieres paires sont un peu plus haules que les segments correspondants du mésosome, les plaques de la premièe paire se prolongeant fortement en avant. Le lobe postérieur des plaques coxales de la cinquieme paire est plus haut et plus étroit que le lobe antérieur. L'angle postérieur des plarques épimérales du dernier segment du métasome se tormine par une dent aigue.

Les yeux, tris grands, proéminents, presque aussi hauts que larges, présentent un bord antéricur droit, tandis que leur bord postérieur est fortement convexe.

L'épistome, anguleux, se prolonge pour former une dent aiguë, qui déborde sur la lère antérieure; cette dernière est régulièrement arrondie au bord distal.

Les mandibules présentent un lobe tranchant long el aigu, celui de lat mandibule gauche portant quatre dents, tandis que celui de la mandibule droite n'en possède que trois. Les deux mandibules portent chacune un lobe accessoire tridenté. Une rangée de dix épines se trouve entre le lobe tranchant et le processus molaire, qui est robuste et très proéminent. Le dernier article du palpe n'atteint pas les deux tiers de la longueur de l'article précédent.

La lieve postérieure possède des lobes internes. Les lohes latéraux sont largement arrondis au bord distal. Les prolongements postérieurs sont issez courts.

Dans la maxille antérieure gauche, le lobe interne, très développé, plus liarge que le lobe externe, porte sept grosses soies cilices. Le lobe exteme est armé de onze épines. Le palpe porte une rangée d'épines au hord distal. Dans la maxille antérieure droite de l'exemplaire disséqué, lo lobe interne, plus étroit, ne porte que cinq soies ciliées. 


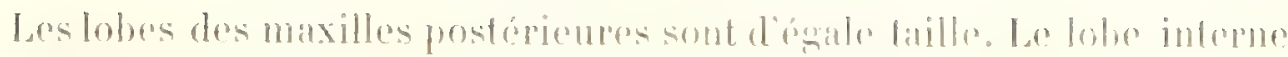

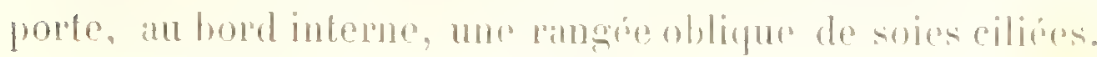

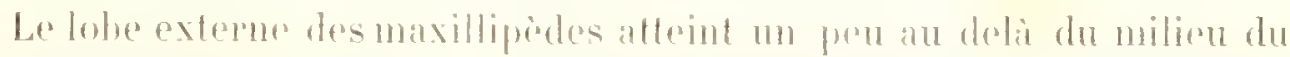

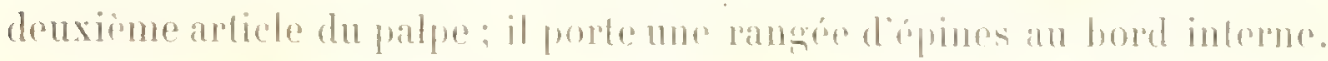

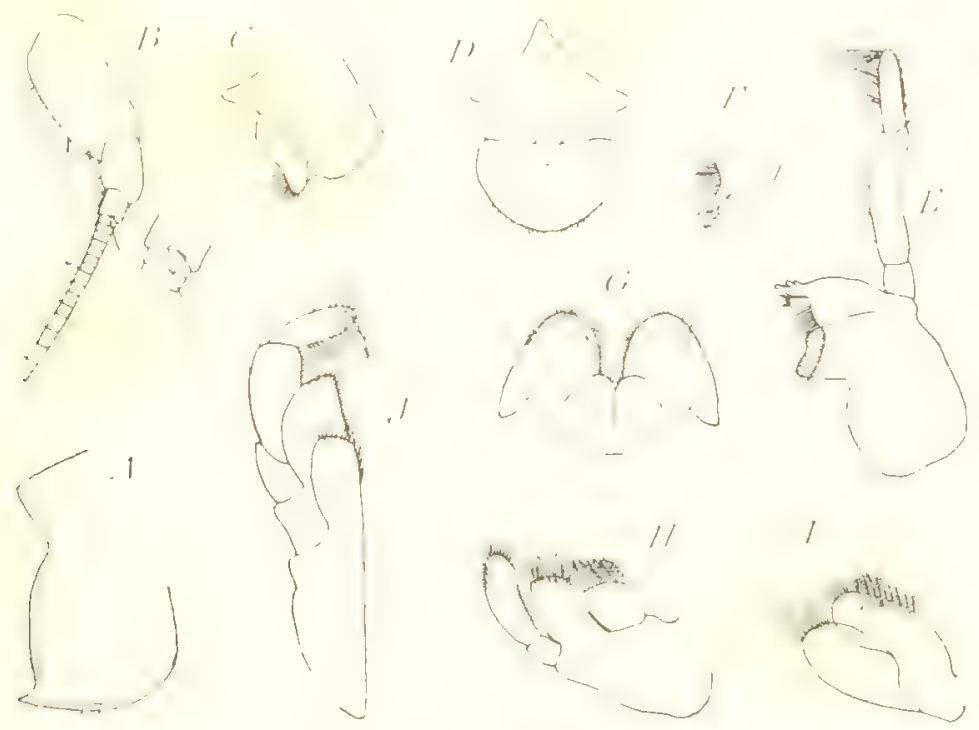

Fir. 30. - Limmrillore ncululn.

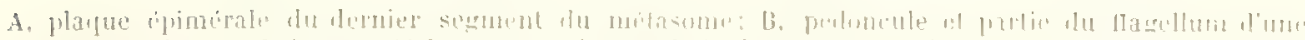

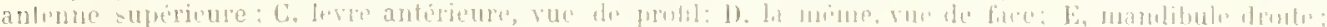

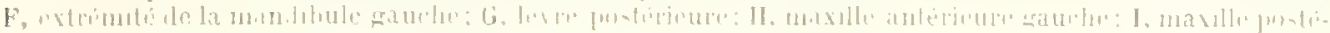

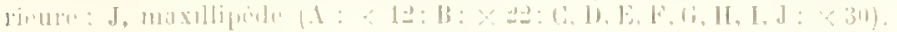

Le froisione anticle du palpe prosente un probongenent andondi qui déborde sur lo qualriéme anticle.

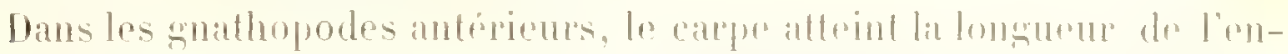

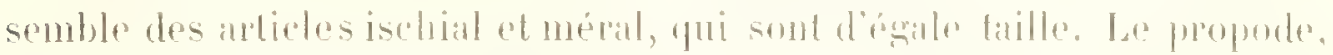

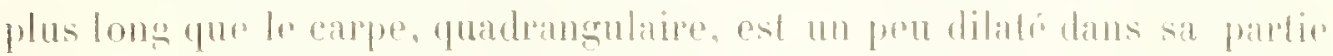

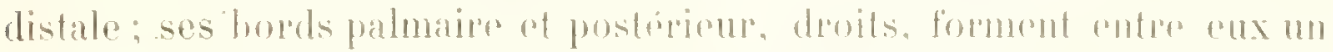

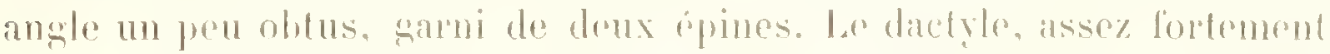

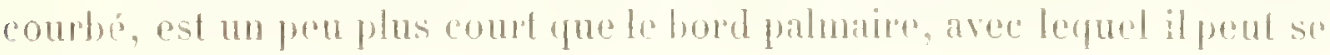
croiser.

Les gnathopodes posterienes, de meme fomme, mais plus longs que les guathopodes anterienure, ne sont pas plus pobustos.

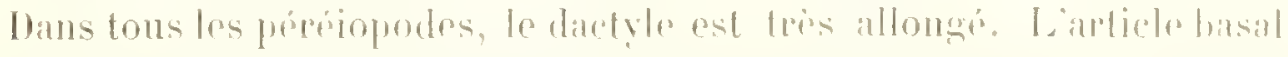

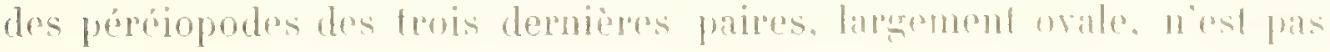


crénelé au hord postérieur. L'article méral, un peu dilaté en arrière, atteint la longueur du carpe. Le propode est plus allongé.

La branche externe des uropodes des deux premières paires n'atteint que la moitié de la longueur de la branche interne. Le bord distal du pédoncule des uropodes de la dernière paire est armé d'une dent longue

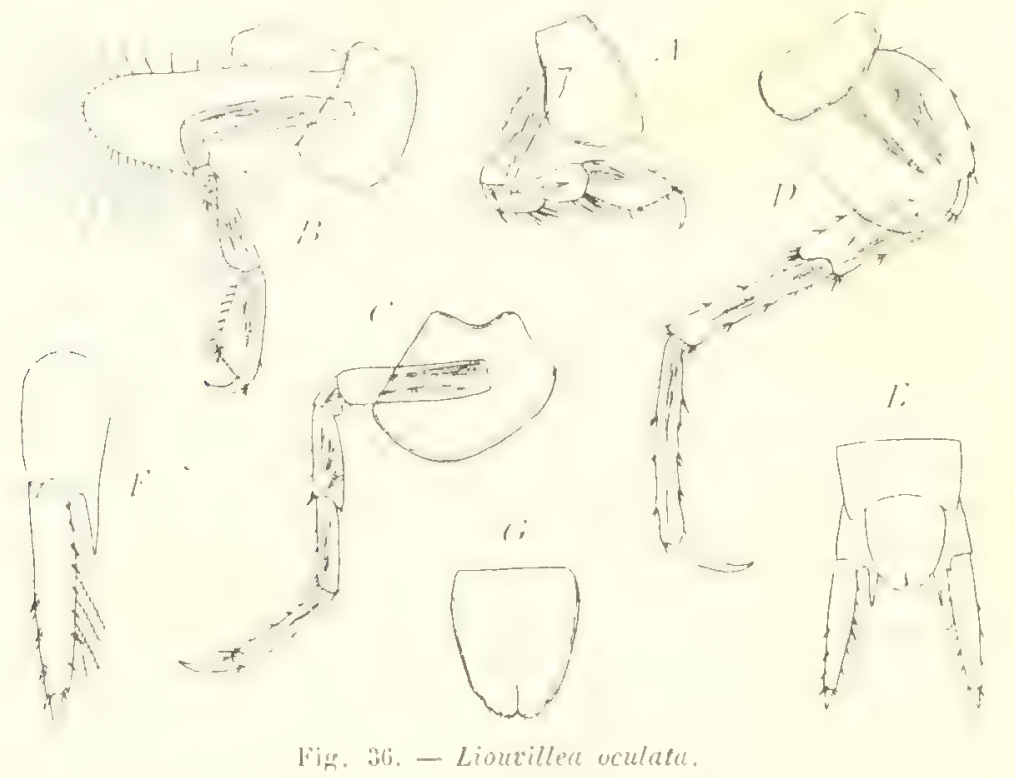

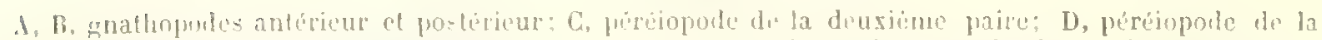

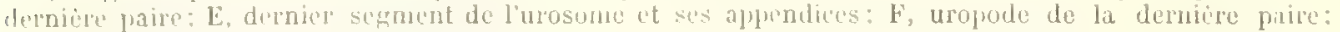

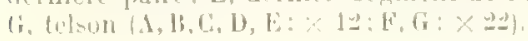

et aiguï, accompagnée de denx petites dents. La branche externe, beaucoup plus longue que le pédoncule, très robuste, posiède un petit arlicle terminal; elle porte quelques épines au bord externe, et son bord interne est garni de nombreuses épines, aceompagnées de soies ciliées. La branche interne manque, de chanue coté, chez les deux exemplaires preneillis, ce qui pourrait faire supposer que sa fragilité est due à sa srande longueur.

Le telson, un peu plus long que large, est arrondi an hord distal, qui présente de petites crénclures garnies d'un cil. Il est étroitement fendu sur te quart de sit longueur. 


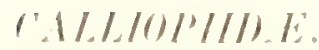

Leptamphopus Novæ-Zealandiæ (G. M. Thomsun).

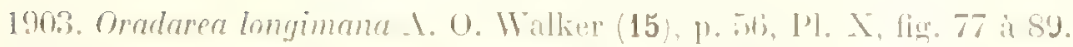

1900. Leptamphopus Tora-Zealandie? Strul,ing (11), p. ogl.

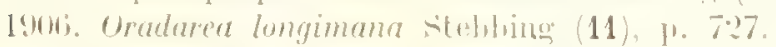

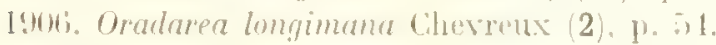

1907. Oratarea longimana 1. 0. Walker (17), 1, :3:.

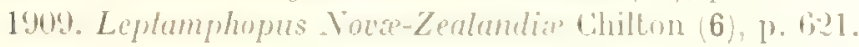

Tle Petermann, Port-Cireoncision, 3 october 1909, sur une Aluge brune (Dexmarestion. Ln exemplaire de conleur marron.

Ile l'etermann, Port-Circoncision, 10 oetober 1909, sur une touffe

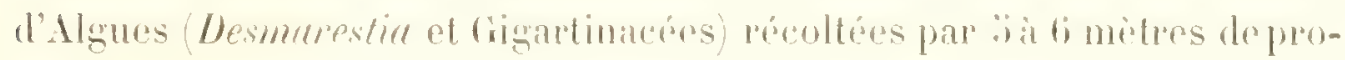
fondenr. Quatre exemplaires, dont une grande femelle de 12 millimetres de longueur.

Iragage XWe, 18 nowmbre ly09, le long de la còte nord-est de l'ile Petermann, dans le chenal de Lemaire profondenr 60 ì 40 meitres. Quatre exemplaires, dont le corps était ponctué de points bruns el hanes, et un exemplate coloré en blane d'allumine, ponctué de brun violacé et de brun jaunitre. Les yeux de cetexmplaire étaient d'un rougrbrigue.

Le nombre el la forme des druts dorsales, la longueur des antemes. sont tris variables chez cette espece. La siande femelle de 12 miltimitres de longueur, de l'ile P'etemann, ne porte de dents qu'aux denx premiers segments du métasome: les antennes, subégales, sont de la longueur du rorps. Chez dautres femellos, plus petites, le dernier segment du mésosome porte une dent courte ef ohtuse. landis que les dents des denx premiers segments dumétasome sont aiguës, ces segments étant dislinctement caténés. Les antemnes des femelles sont quelquefois beatuenp phu longues que le corps. Entin une femelle ovigèe, mesurant b millimitres de longueur, ne prósente pas traces do dents dorsales. Gihoz lous les exmulatres examines, les antemnes supérieures possident un petit Hagellum aceessoire mintarticulé. 


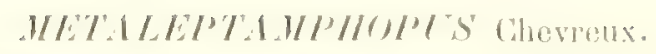

1911. Melaleplamphopes Ghevrenx (3), 1. 116 .

Corps modépenent comprimé, lisse. Thete amme d'un rostre allongé. placues coxales do la quatriome paire ne présentant pas d'échancrure au bord postórieur. Pédoncule des antennes court, fligellum multianticulé. Antennes suprideures plus longues que les antennes inférieures et ne possedant pas do Hagellum aceessoipe. Bord libre de la levre antérienre arrondi. Mandibules robustes, processusmolabe bien développé, dernier article du palpe plus long que l'atticlo prócédent. Livre poslérieure no possedant pas de lobos internes. Lobe interne des maxilles antérieures ganni de nombrenses suirs, lobe externe armé do onze épines, palpe bien développé. Lobes des maxilles posterienres d'egale laille. Lobe interue des maxillipedes tres langr, obliquenunt lonepuí; lobe externe court, n'atteignant pas le milieu du denxieme artich du palpe. Gnathopodes antérieurs et postérieurstemòme forme, courts et faibles chez la femelle, plus développés chez le mile. Péréiopodes grêtes et counts. Lropodes de la derniore pairo tries robustes et teros allonges, depassant de beaucoup l'extrémité des uropodes précédents, branches subéguales. Teelson arrondi atr bord distal.

\section{Metaleptamphopus pectinatus Chevreux.}

1912. Melaleplamphopus peclinulus (hevreux: (4).

Ile Petermann, 10 octubro 1909, Port-Cipconcision, dans des toufles

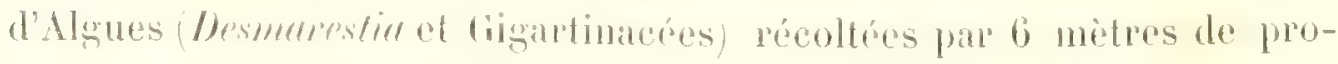
fondent. Un male et quinze fimelles, presque loutes ovigènes.

Frmelle. - L'exemplaine mestuat i millimetres de longueur dans la position ou il rest ligurá ici.

Lacorps, modérement romprimé, ast lisso. Lat tète porte un rostre aigu, legerement courbé, qui atteint presque l'extrémité du premier arlicle du pédoncule des antemes supérioures. Les lobes latéraux, trós

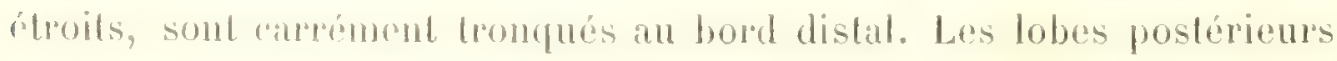
présentent un contour antromdi. Les plirpues coxales des quatre premieres 
paires n’alteignent pas la hauleur des segments correspondants du mésosome. Lesplaques coxales de la troisieme paire présentent un bord inférieur quelque peu concave. Les plaques coxales de la quatrieme paire ne sont pas b́chancrées au bord postérieur. Le lobe antérieur des plaques coxales de la cinquieme pare est un pert plus haut que le lobe postérieur. Les

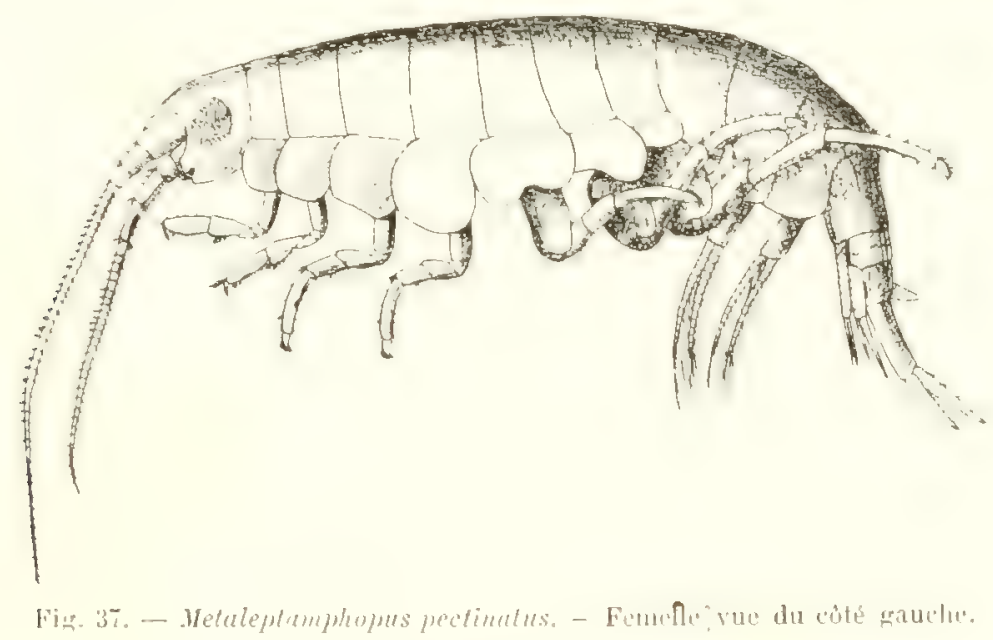

plaques épimérales du dernier segment du métasome, un peu prolongées en arriere, sont régulierement anrondies.

Les yeux, tris grands, arrondis, comprennent de nombreux ocelles.

Les antemnes supérieures afteignent à peu près la longueur de l'ensemble de la tète et du mésosome. Le pédoncule est très court; son premier anticle égale en longueur l'ensemble des deux articles suivants. Le flagellum se compose de trente-einy articles garnis de courtes soies. Il n'existe pas de llagellum aecessoire.

Les antennes inférieures n'atteignent pas tout it fait la longueur des antemes supérieures. Le dernier article du pédoncule est un peu plus long, maisbeaucoup moins large, que l'article précédent. Le flagellum, qui comprend trente articles, atteint pres du double de la longueur du pédoncule.

Le bord libre de la leve antérieure, rónuliobement arrondi, ne présente pis d'échancrure.

Les mandibules, assez polustes, prisentent un lobe tranchant aigu, finement denticulé, suivi d'un rang de trois épines barbelées. Le pro-

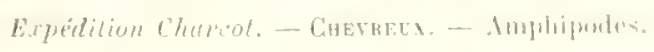


cessus molaire est trìs saillant et tris volumineux. Le palpe dépasse un peru en longueur le corps de la mandibule; son dernier article est plus long que l'article précédent. Tous deux portent des soies au bord interne.

La livre postérieure ne possède pas de lobes internes. Les prolongements postérieurs sont modérément développrés.

Le lobe interne des maxilles antérieures, très large, est bordé de neuf

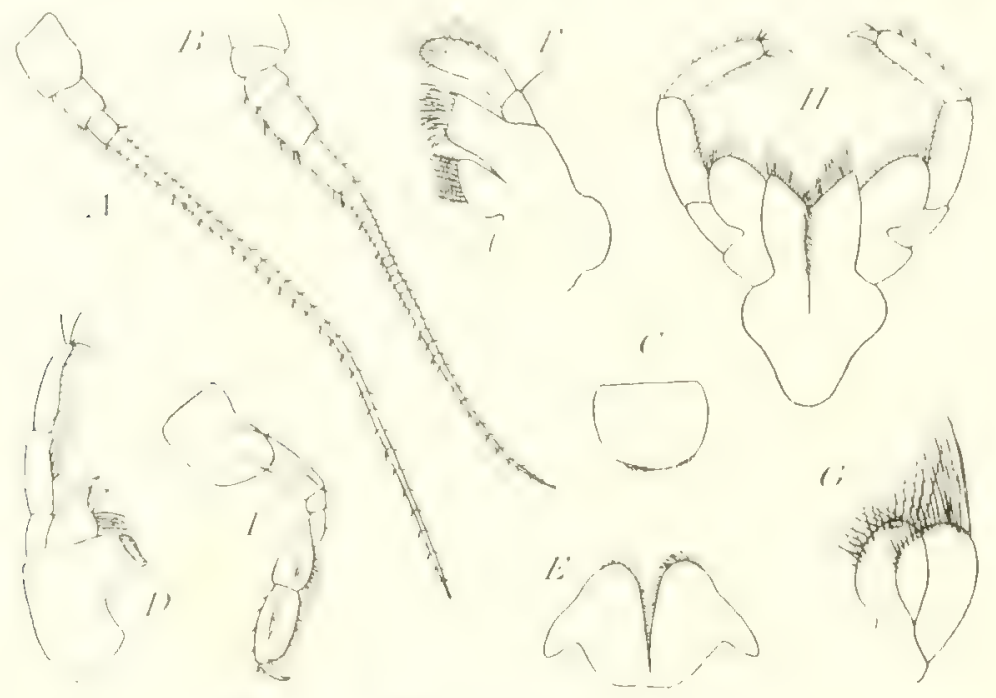

Fig. 3i. - Metuleptampleopus pectinntus.

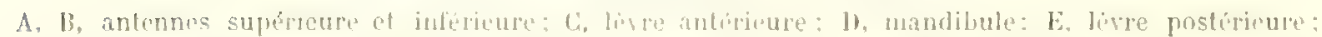

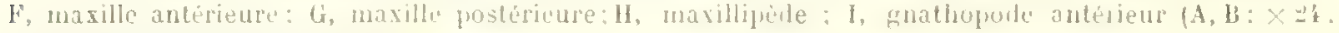
Li, I) $\mathrm{F}, \mathrm{F}, \mathrm{G}, \mathrm{H}: \times 56:$ I : $\times 3 H$.

soies ciliées. Le lobe externe porte onze épines. Lepalpe, bien développé, dépasse l'extrémité du lobe externe; son dernior article, un peu courbé, porte de longues et nombreuses épines.

Les lobes des maxilles postérieures, d'ŕgale taille, sont bordés de nombreuses apines, plus longues dans le lobe extorne que dans le lobe interne.

Le lobe inteme des maxillipèdes, très développé, est obliquement tronqué dans sa partie distale. Le lobe externe, assez court, n'atteint pas le milieu du deuxième article du palpe; il porte une rangée d'épines au bord distal et an bord interne. Les deuxième of troisième articles du palpe, très allongés, sont d'égale taille. Le quatrième article, très court, cest dactyliforme.

Les grathopodes sont peu développés. Dans les gnathopodesantérieurs, 
le propode, ovale allongí, est un peu pis long que le carpe; son bord palmaire se confond avec le bord posterieur el fous deux sont garnis d'une rangéc de soies. Le dactyle, court et faible, natteint guère plus du tiers de la longueur du propode.

Les gnathopodes postéricurs, de mème forme que les gnathopodes

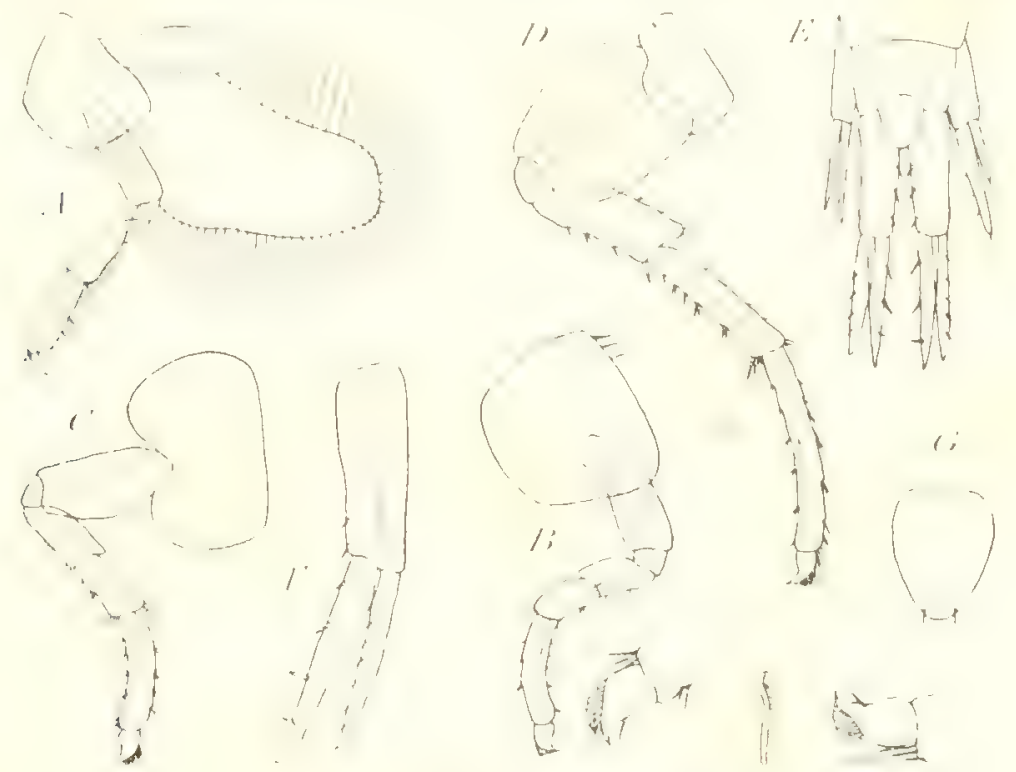

Fies. 3\%. - Metuleptimphomus pectinnlus.

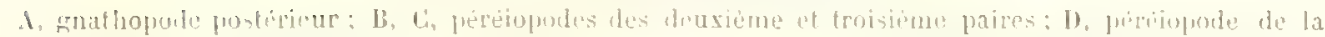

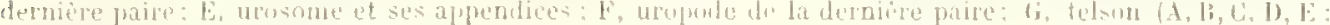

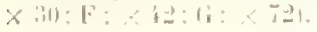

anterieurs, sont à peine plus longs. Le carpe et le propode sont relativement plus gretes.

Tous les periópodes sont courts al laibles. Dans les perriopodes des deux premieres paires, l'articte méral et le carpe sont d'égale longueur. Le propode, assez fortement courlé, est aussi long que l'ensemble des deux articles précédents. Le dactyle, très gros à la base et terminé en pointe aigü el courbée, porte, dans la moitié distale de son bord externe, une épaisse langée d'íphes pectinéres.

L'articto hasal des péróiopodes de la troisième pare est peu dilaté en arrière. Le carpe n'atteint pas tout à fait la longueur de l'article méral, qui est, lui-mème, beaucoup plus court que le propode. Les péréiopodes de la quatrieme pare, plus longs que les péréiopodes précédents, onl l'article basal plus large. Mans les péréiopodes de la dernière paire, qui 
dépassent en longueur les péréiopodes précédents, l'article basal, presque aussi large que long, présente un bord postérieur à peu près droit et ne portant pas de crénclures. Ces péréiopodes, comme ceux des deux paires précédentes, sont bordés de nombreuses épines et leur dactyle est semblable à celui des péréiopodes des deux premières paires.

Les uropodes des deux premières parres sont grêles et courts. Les branches des uropodes de la première paire, subégales, atteignent presque la longueur du pédoncule. Dans les uropodes de la deuxieme paire, la branche externe est beaucoup plus courte que la branche interne, qui atteint à peine l'extrémité du pédoncule des uropodes suivants. Cés derniers, très robustes, sont presque aussi longs que les gnathopodes antérieurs. Leurs branches, subégales, atteignent la longueur du pédoncule.

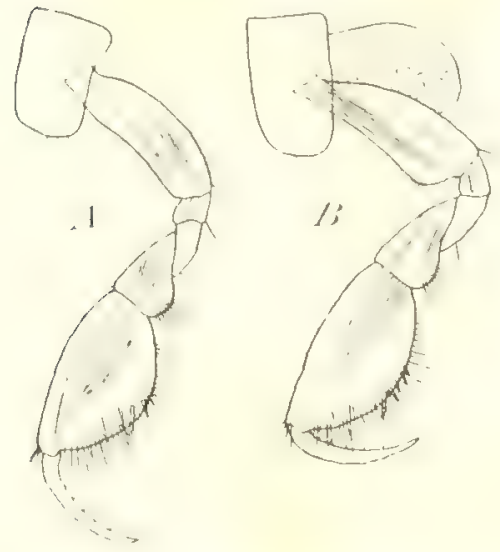

Fin. 40. - Melaleplamphopus jectinalus.

1. gnalhopode antrivieun; $B$, gmatho porle postérieur $(>50)$.

Le telson, un peu plus long que large, est arrondi au bord distal, qui porte deux petites épines.

Mrile. - L'unique màle recueilli ne mesurait que 3 millimetres de longueur. Ses antennes étaient mutilées. Les yeux, arrondis, sont un peu plus grands que ceux des femelles. Les gnathopodes, trìs robustes, aflectent à peu près la mème forme et la mème longueur dans les deux paires. Le carpe, subtriangulaire, n'alteint que la moitié de la longueur du propode, qui est largement ovale, le bord palmaire n’étant délimité du bord postérieur que par un sroupe d'épines. Le dactyle, long ef grêle, atteint plus des trois quarts de la longueur dupropode; il porte quelques petites épines au bord interne. Les péréiopodes, les uropodes et le telson ne different pas des appendices correspondants de la femelle.

\section{PALAWPIITIIOIDE.}

Epimeria macrodonta A. O. Walker.

1906. Epimeria macrodonla A. O. Walker (16), p. 16.

1907. Epimeria macrodonla A. O. Walker (17), p. 24, PI. VIII, fig. 14. 
Dragage VIII. 20 janvier 190!, baie Naryuerite; profondeur, 200 metres. Trois exemplaires, dont le plus grand mesurait lis millimetres de longueur. Les yeux de cos exemplaires étaient d'un ronge vil; deux dentre eux avaient te copps banc el orangé le corps du troisieme élat gris et rouge.

Dragage XT, 26 novembre 1909, devant Port-Lockroy, chenal de Roosen, profondeur 60 i 70 motres. Trois exemplaires, de 22 millimètres de longueur. Lecorps de ces excmplaires etait teinté de blanc rosé, avee de très nombreuses taches d'un rouge vif; les yeux étaient rouges.

\section{Epimeria similis Chevreux.}

191:. Epimeria similis Cihevreux (4).

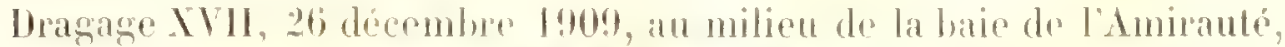

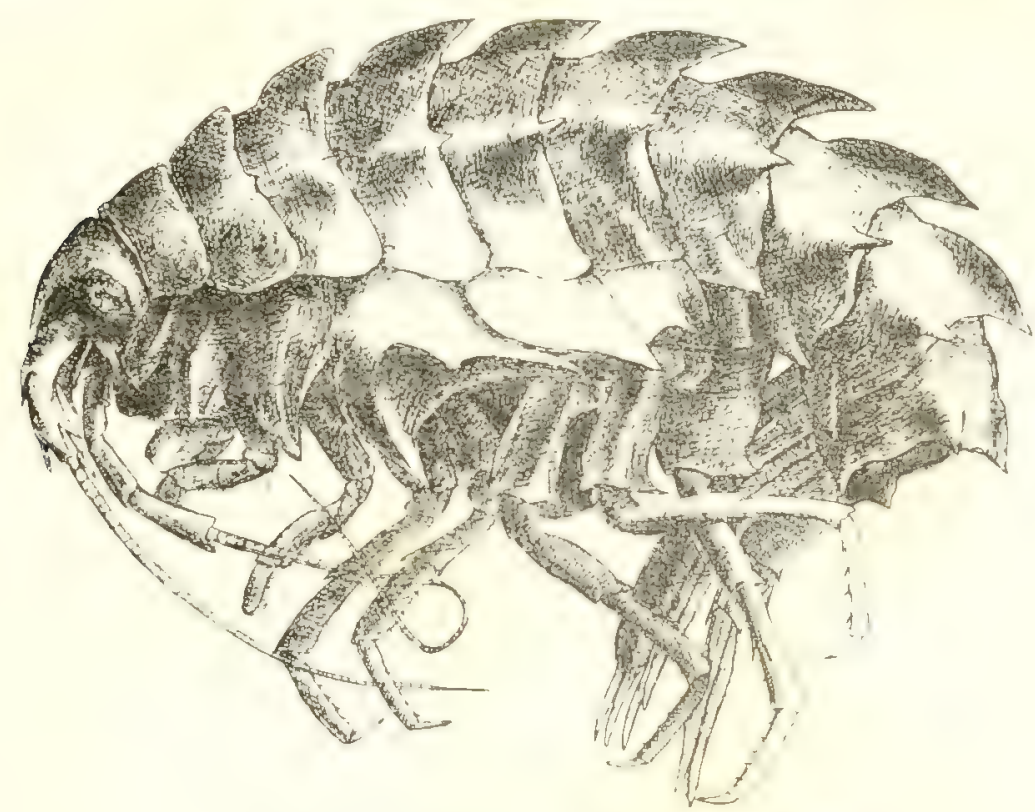

Fir. 11. - Epimeria similis. - Fonselle vue lu citi gauche.

ile du Iobi-ficorge, shetlands du Sud; protondeur, 120 mères. Deux femellesovigeres, dont le corps citait grisitre, avec fuelques laches d'un rouge vif. Les yeux étairnt d'un rouge vil.

Ces deux femelles, de mome taille, mesuraient 30 millimiotres de longueur dans la position où l'une d'elles est figure ici. La poche incubatrice de chacune d'elles contenait plus de cent ants. 
Le corps, trìs obise, présente des téguments épais et consistants. Les deux premiers segments du mésosome sont d'égale longueur. Chacun des cinc segments suivants ef chacun des segments du métasome porte une forte dent dor'sale, large à la base, aiguë à l'extrémité el dirigne en arrière, et une paire de petites dents latérales. Ces dents sont légirement indiquées dans le deuxieme segment du mésosome. Le pre-

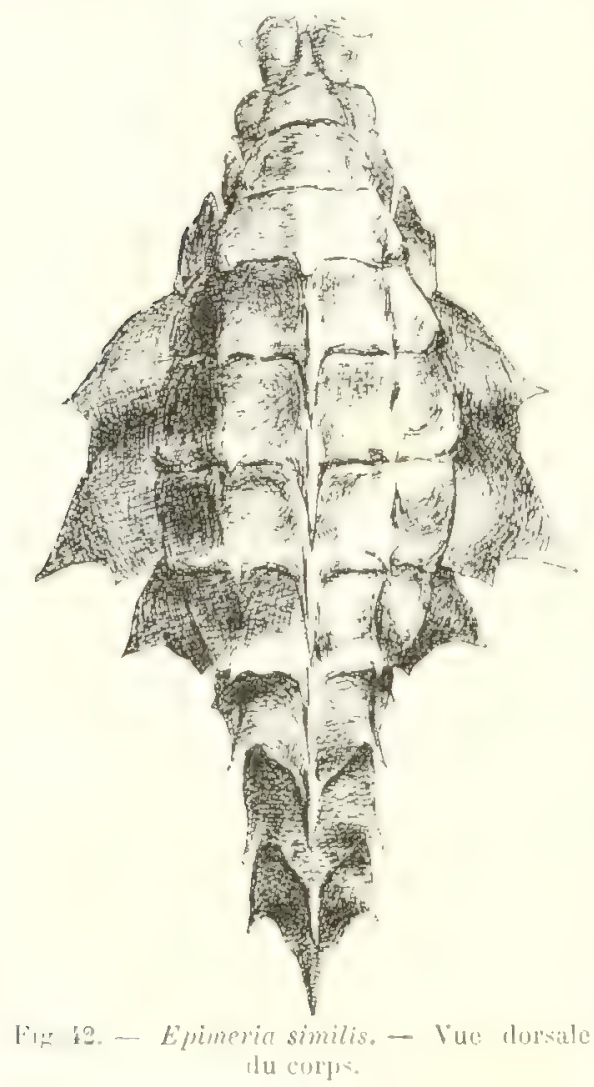
mier segment de l'urosome porte aussi une deut dorsale el une paire de dents latérales. Le deuxième segment est lisse. Le bord dorsal du troisiemo segment se termine par une petite dent aiguë. Les angles postérieurs des segments du mésosome, arrondis dans les cing premiers segments, sont atigus dans les deux serments suivants.

Lat tète, non compris le rostre, est it peu pris aussi longue que le premier segment du mésosome. Le rostre, un peu courbé, atteint l'extrémité du premier article du pédoncule des antennes supérieures. Les angles inférieurs, fortement prolongés en avant, sont aigus. Les plaques coxales des trois premicres paires, relativement larges, se terminent inférieurement par une dent aiguï. Los plaques coxales de la quatrième paire, très épaisses, présentent deux dents latérales et une dent médiane. Les plaques coxales des cinquiène et sixième pares se terminent en arrière par une dent aiguä. L'angle postérieur des plagues coxales de la dernière paire est aigu. Les plaques épimérales des trois segments du métasome se terminent en arriere par une dent longue el aiguë.

Les yeux, grands et de forme ovale, sont proéminents.

Les antennes superieures sont aussi longues que l'ensemble de la tête et des einq premiers segments du mésosome. Le premier article du 
peidonculo porte trois dents tominales, pelativoment rourtes. Lo

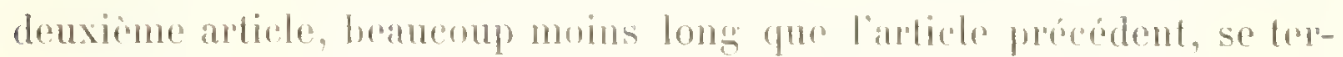
mine par deux dents qui atteignent à peu pros au nivean de l'extremité du troisiome anticle. Ce dronior, do moitié moins long que le druxième,

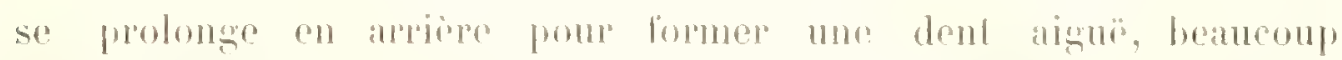
plus longue que collos des andirles précédents. Lo llagellum se compose d'une cinquantaine d'articles garnis de nombremses pelites soies.

Les antemnes inferioures sont brauroup phus longues que les antemmes smperieures. Le deuxieme artiche du pédoncule se prolonge pour former une dent antérieure, qui dépasse l'extrómité de l'article suivant, et une dent postérieme un peu plus conde. Le quatriome anticle, qui porte mon petite dent distale, est un pen plus long que lo vinquiemo articte. Le flat gellum comprend de nomberens atlicles, faiblement ciliés.

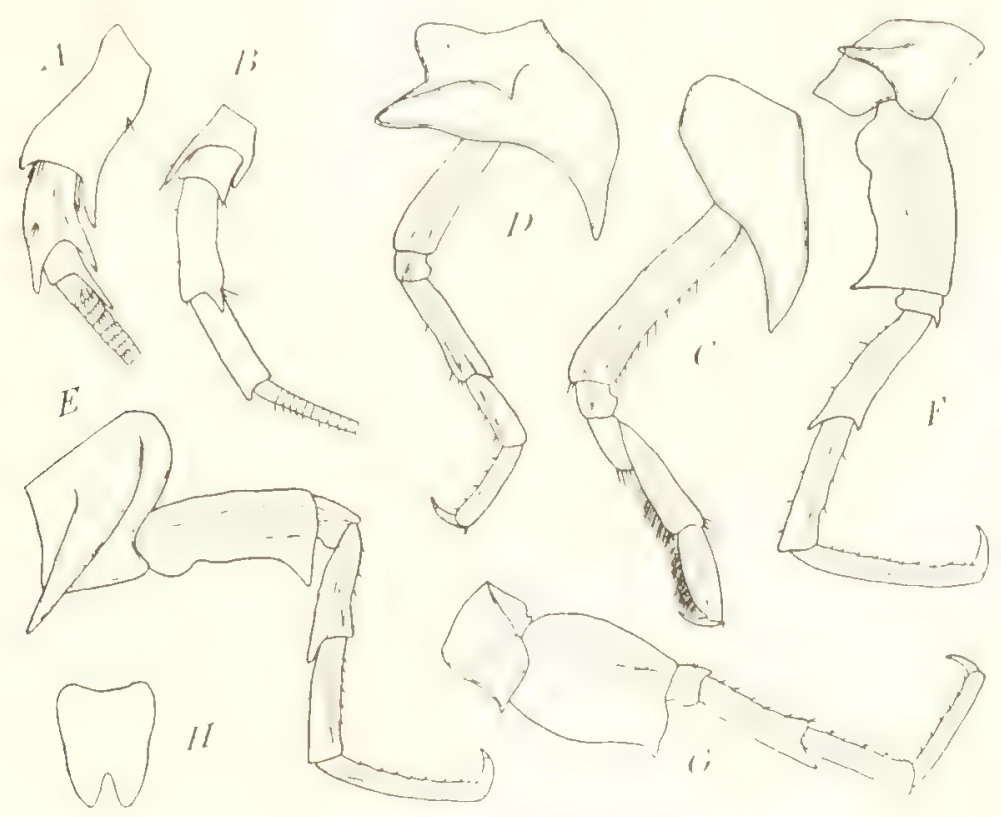

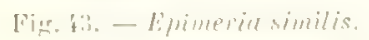

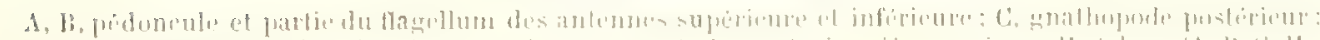

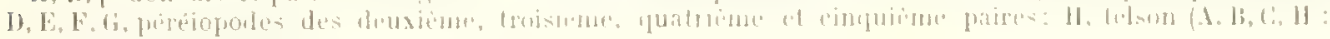
(i): $11, k, k,\left(\frac{1}{2}: \cdots\right.$ i)

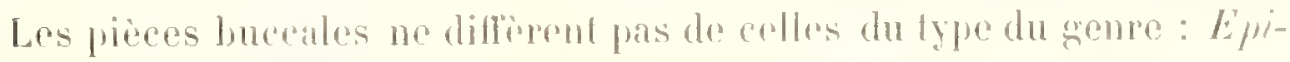
merial comigera liabl'.

Les guathopodes, semblables contere oux, diflionent quelque pen de cenx des autres especes du gente Evimeria, leur propode elant it peine sub- 
chéliforme. L'article méral est plus long que l'article ischial. Le propode est loin d'atteindre la longueur du carpe. Tous deux portent une épaisse rangée de soies au bord postérieur.

Dans les péréiopodes des deux premieres paires, l'article basal est beancoup plus long que l'article méral, et le carpe n'atteint pas tout à fait la longueur du propode.

L'article basal des péréiopodes de la troisième paire, assez étroit, présente un bord antérieur à peine convexe. Le bord postérieur, d'abord fortement convexe, puis droit dans sa partie médiane, se termine par une dent aiguë, dirigée en arrière. L'article méral et le carpe sont à peu près d'égale taille. Le propode est beaucoup plus allongé.

Les péréiopodes de la quatrième paire sont les plus longs de tous. Ils dillèrent à peine des péréiopodes précédents.

Les péréiopodes de la dernière paire sont un peu plus courts que ceux des deux paires précédentes. L’article basal, notablement plus large que dans les péréiopodes des troisième et quatrième paires, présente des bords antérieur el postérieur convexes. Le carpe est presque aussi long que le propode.

Dans les uropodes de la deuxième paire, la branche externe est beancoup plus courte que la branche interne. Les branches des mropodes de la dernière paire, d'égale taille, atteignent quatre fois la longueur du pédoncule.

Lo telson est échancré sur environ le lier's de sa longueur.

Cette nouvelle espèce est tellement voisine d'Epimeria macrodonta A. O. Walker qu’il y a lieu de rappeler ici les principaux caracteres qui différencient les deux formes. Ghez E. marmotomta :

Les dents dorsales sont très longues et très etroiles.

Le premier segment du mésosome atteint le double de la longueur du second segment.

Le deuxieme segment de l'urosome porte une dent dorsale.

Les plaques coxales des trois premieres paires sont tres etroites.

Les plaques coxales do la demiere pare sont arrondies au bord postórieur.

Le rostre est beancoup plus long quo lo reste de la lite. 
Les deux premiers apticles du pédoncule des antennes supérieures sont d'égale taille, et les dents du deuxime article atteignent lextrémité du deuxieme article du flagellum. La dent du troisiome article est très courte.

Le propode des gnathopodis ast aussi long que le carpe.

Larticle méral des péréiopodes des deux premieres paires est aussi long que l'article basal.

Le bord antérieur de l'arlicle hasal des pépéiopodes de la troisiome paire est concave.

Le pédoncule des uropodes postérieurs atteint le tiers de la longueur des branches.

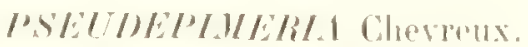

1911. I'sendepimeria Chevreux (3), 1, 1167.

Corps portant des dents dorsales et des tubercules, tíguments épais of durs. Tète armée d'm rostre allongé, lobes lateraux nuls, lobes postérieurs spinilormes. Plaques coxales des trois premières paires carémés, triangulaires. Plarques coxales de la quatrieme pare trés développées. portant denx échancrures au bord postérieur. Plaques coxales des cinquieme el sixiène paires très épaisses, mais ne présentant pas de prolongements aigus. Paques coxales de la derniere paire normales. Antemnes supérieures pluscourtes que les antemnes inférieures of possédant un petit llagellum accessoire. Mandibules courtes, processus molaire tres développé, palpe peu allongé Lever postérieure possédant des lobes internes. Lobe interne des maxilles anterienres bordí do nombreuses soles, palpe wrêle. Lobe interne des maxilles postérieures plus grand que le lobe exterme ol ne portant pas de soies an hord interne. Troisiome article du palpe des maxillipides tries grede, prolonge au-dessus du quatrieme article. Cinathopodes faibles, non subehéliformes. Péréiopodes courts, larticle basal de ceux des trois demires paires portant une dent à l'angle inféro-postérieur. Branches des uropodes do la derniere parere lancéolées, subézales. Telson fendu. 
Pseudepimeria grandirostris Chevreux.

1912. I'sendepimeria grandirostris Chevreux (4).

Dragage VI, I: janvier 1909, entrée de la baie Varguerite; profondenr, zit metres. Lne femelle.

Cette femelle mesurait 10 millimètres de longueur dans la position où clle est figurée ici. Elle était colorée en hrun orangé.

Le corps, assez obèse, présente des téguments durs et épais. Le pre-

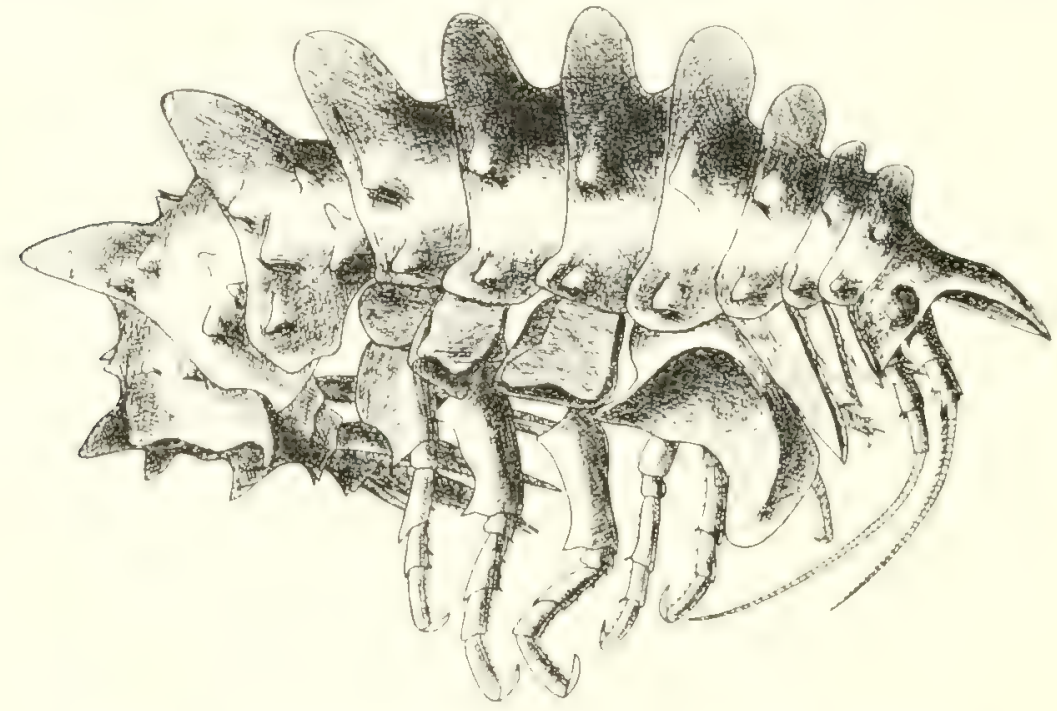

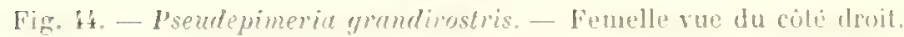

mier segment du mésosome, beaucoup pluslong que le segment suivant, atteint presque la longueur du troisieme segment. Tous les segments du mésosome sont surmontés d'uno forte dent, largement arrondie dans sa partie distale, la dent du dernier segment élant seule un peu dirigée en arrière. Le mésosome porte aussi deux langées latérales de tubercules coniques, dont le sommet est quelque peu dirigé en arrière.

Le premier segment du métasome est surmonté d'une énorme dent, étroitement arrondie an bord distal, et porte six paires de tubercules coniques, dirigés dans des sens divers. Le deuxième segment porte, au bord dorsal, une paire de petites dents aignës, suivies d'une grande dent subaigü, dirigée en arrière. Les cotés de ce segment portent chacun ciny tubercules. Le bord dorsal du dernier segment du métasome porte 
des dents semblables à colles du sergment précódent; chacun des cotes

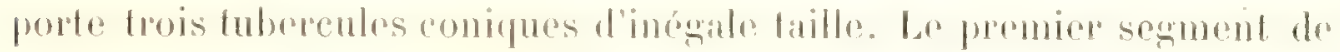
l'mosome porte, an hord dorsil, une dont stubaigur, suivio d'une dent un peu phus longue ef phos aiguë. Chacun des drux segments suivants porte une paire de pelitesdenls dorsales.

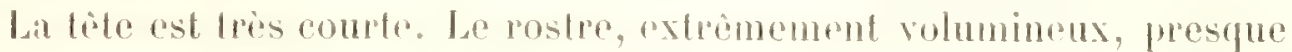
droit, inférieurement concare, attrint le double de la longurar de la tete el dépasse de beancoup lo pédoncule dres antemues supérieures. Il n'existe pas de lobes latéraux. Les andes inférieurs sont spiniformes.

Les plaques coxales dos trois premiomes paibes, etroitement frian-

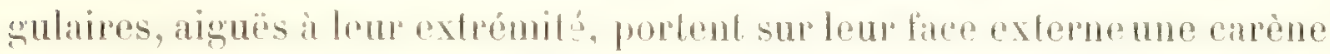
tranchante, située au voisinage du bord anteriour. Les plaques coxales de la quatrième paire, tries développées, se protongent en arrièe pour former deux lobes. Io lobe inlónene bant arondi au bond distal, tandis que le lobe supériour se prolonge en pointe subaigü̈. The careno ablevé, partant de l'extremité du lobe supérieur, aboutit au lobe inferécu apres

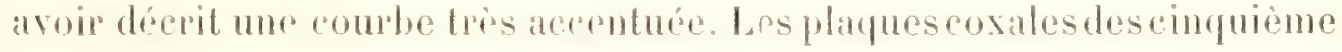
et sixieme paires aflectent une forme prismatique absolument inusitie chez les Amphipodes, lour epaisseur btant presque byale à leur longueur. Elles sont à peu pres aussi haules que larges et ne se prolongent pas ron

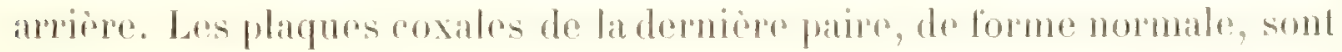

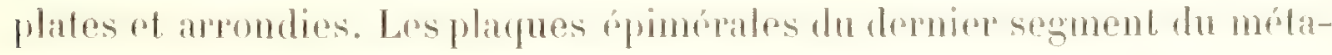

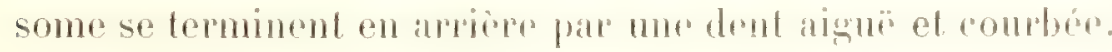

Les yeux. assez grands, do lome ovalr, sont prociniments.

Les antennes supérioures atteignent a peu pros la longurur de lonsemble de la tate et des trois premiers segments du mesosome. La premier article du pédoncule est aussi long que l'ensemble des deux anticles suivants. Le bord anteriene du deuxiome artiole se prolonge justua an

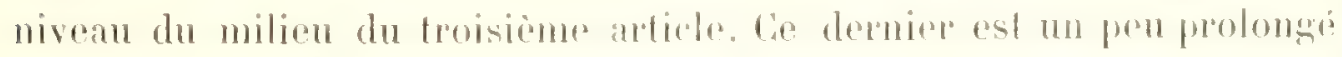
en arriore. Le flagellum comprend vingt-huit andioles lontement ciliós an bord postérienr. Le flagollum areessoire, uniartioula, n’alleint que lo tiers de la longueur du premier artiele du flagellum principal.

Les antennes inférieures sont un peu plus longangs que les antenmes

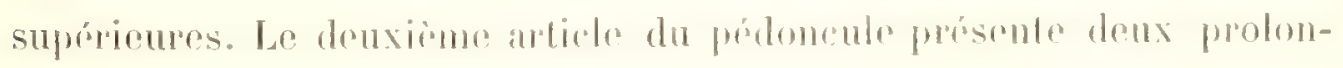


gements dentiformes. Le bord antérieur du troisième arlicle se termine par une forte dent. Ic cinquième article est un peu plus long que le quatribme. Le flagellum comprend trente-huit arlicles absolument glabres.

La live antérieme est légèrement tronguée an bord distal.

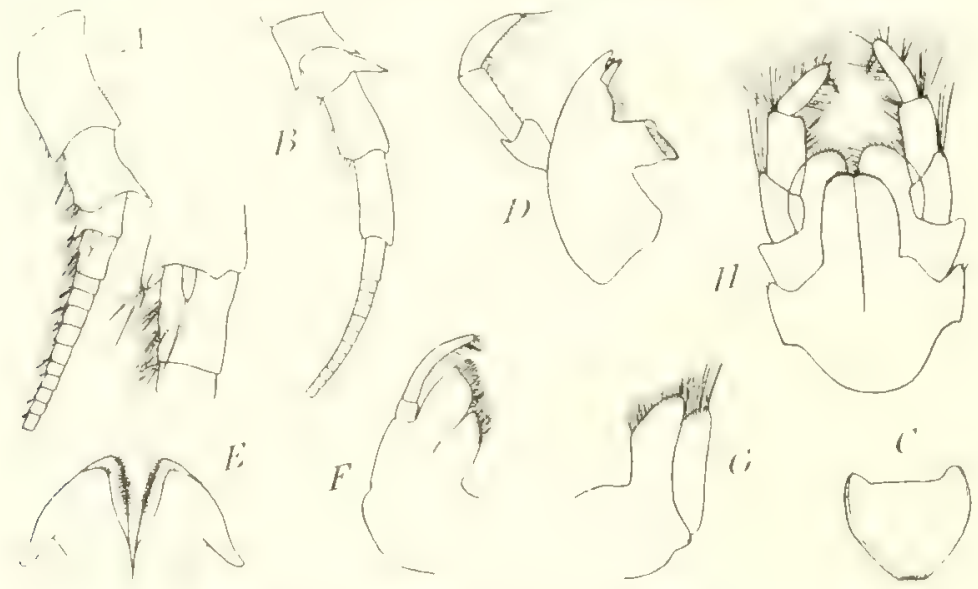

Fig. 4.0 - Pseudepimeria grundirostris.

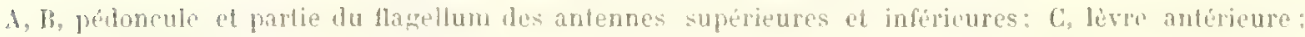
1), mandibule gaurh: E, levre postérienre: F, maxille antérieure: G. masilfe posterieure; H, maxilli-

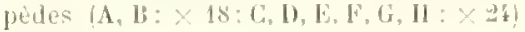

Les mandibules, assez courtes, présentent un lobe tranchant aigu, tridenté. Ie lobe accessoire est bidenté dans la mandibule droite, tandis que celui de la mandibule gauche porte cing dents. Les ćpines sont au nombre de seize. Le processus molaire est tris robuste et très saillant. Le palpe, plus court que le corps do la mandibule, se compose d'un premier article rolativement longe el robuste, dont le bord externe se prolonge pour former une dent aiguë, suivi de deux articles d'égale taille.

La live postérieure possede des lobes internes soudés aux lobes externes par leur bord externe. Ixs prolongements postériemrs sont étroits et divergents.

Le lobe interne des maxilles antérieures porte onze soies ciliées. Le lobe externe, carrement tronqué, est ammé de dix ćpines. Le palpe, tres grêle, porte sept épines au bord distal.

Lo lobe interne des maxilles postérieures, un peu plus long et plus large que le lobe externe, ne porte de soies qu'au bord distal.

Le lobe externe des maxillipedes, assez. court, atteint le milieu du douxieme andicle du palpe. Le troisibue article du palpe, plus court ot 
beaucoup plus ábroit que l'article précedent, so prolonge an dela de l'arlieulation du dactyle, qui est trés petit.

Dans les gnathopodes antérieurs, l'article basal est aussi long que l'ensemble du carpe et du propode. Les articles ischial ot méral sont très courts. Le propode, un peu moins long que le earpe, n’est pas subchéliforme; ces deux articles portent de nombrenses toufles de soirs. Le

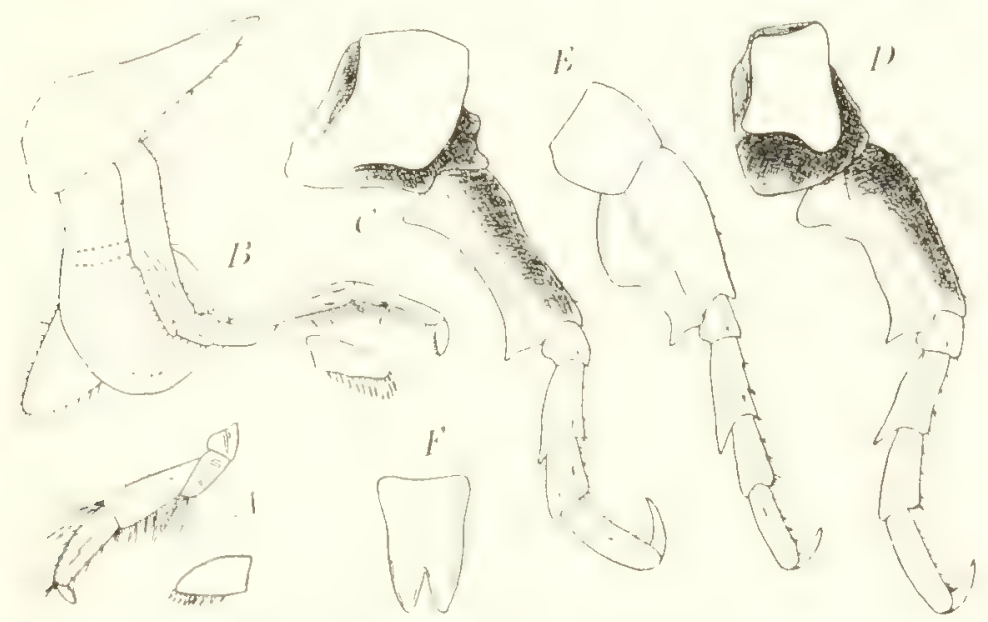

Fig. 40. - I'sendepimerit amudimstris.

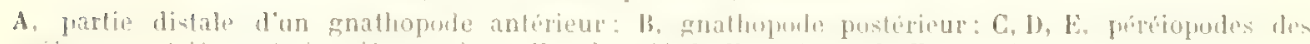

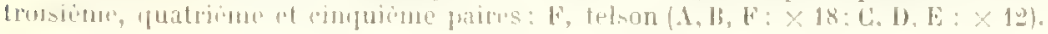

dactyle, très robuste, porte une rangée de neuf fipines au bord interne.

Les grnathopodes postrieur's, un peu plus longs que les gnathopodes antérieurs, affectent la même forme, mais le carper et le propode sont notablement plus grêles. Le bord interne du dactyle porte une rangée de douze épines.

Tous les péréiopodes sont courts et rolustes; ceux des troisiome of quatrième paires dépassent un peu les autres en longueur. Dans ces deux paires de péréiopodes, l'article basal, un peu concave, est limité, en haut et en bas, par une dent dirigée en arriere, la dent supérieure étanl phus ou moins obtuse, tandis que la dent inférieure est aiguë. Dans les péréiopodes de la derniere paire, le bord postérieur de l'article hasal, d'abord assez fortement convexe, devient concave dans sa partie distale. qui forme une dent aiguë avec le bord inférieur. Une carène fongitudinate assez élevée existe sur la face externe de l'article basal des péréiopodes des trois dernieses paires. L'arlich móral, un peu plus long qur le carpe, 
est beancoup plus court que le propode. Le bord antérieur de ces trois articles est garni d'épines. Le dactyle est robuste el courbé.

Les hranches des uropodes de lit premiere paire sont subégales. Dans les uropodes de la deuxieme paire, la branche externe est beaucoup plus courte que la branche interne. Les branches des uropodes de la dernière paire, étroitement lancéolées, d'égalo taille, atteignent le double de la longueur du pédoncule.

Le telson est subtriangulaire, sa plus grande largeur égalant les deux tiers de sa longueur. Son extrémité présente une fente très ouverte, s'étendant sur le tiers de sa longueur. Les lobes ainsi formés, étroitement arrondis au bord distal, ne portent ni soies ni épines.

\section{PAREPIMERIA Chevrens.}

1911. Parepimeria Chevreux (3), P. 1168.

Corps comprimé, portant des dents dorsales. Tête armée d'un long rostre. Plaques coxales des deux premières pares terminées inférienrement par un angle aigu. Plaques coxales des cinq paires suivantes de lorme normale. Antennes supérieures plus courtes que les antemnes inférieures, pédoncule allongé dans les deux paires, flagellum accessoire rudimentaire. Bord libre de la levre antérieure echancré. Processus molaire des mandibules bien développé, palpe très long et très robuste. Levere postérieure possédant des lobes internes. Lobe interne des maxilles anterreures bordé de plusieurs soies. Lobes des maxilles postérieures itroits, arrondis au bord distal. Lobe externe des maxillipedes faleiforme, tronqué dans sa partie distale; palpe très robuste et très allongé, mais ne possédant que trois articles. Gnathopodes non subchéliformes, carpe très développé, propode étroit, dactyle grête. Article basal des péréiopodes des trois dernières paires de mème forme. Branche exteme des uropodes des deux dernimes paires plus courte que la branche interme. Trolson entier, arrondi an bord distal.

\section{Parepimeria crenulata Cherreux.}

1!91․) I'apepimeria erenula'a Chevreux (4). 
Dragage III, 26 décombere 1908, ehenal do Roosen; profondeur, l:9 mives. line fermella.

Cette femelle nesurat $10^{\text {mm }}, ;$ de longrour, dans la position ou alle est figurécici.

Le corps, tres comprimé, présente des tegmments durs ef epais. Chacun des ciny derniers segments du mésosono porte me dent dorsale et une paire de dents subdorsales; cos dents ausmontont graduclloment

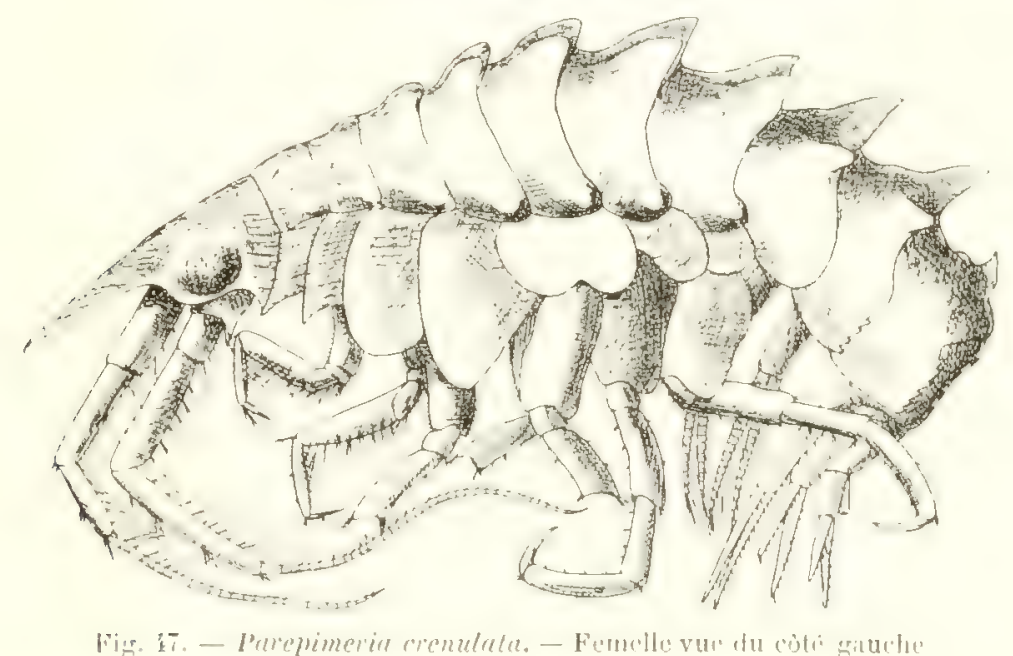

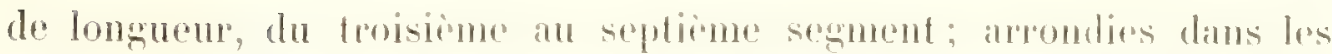
froisiome ef quatriome sogments, alles sont plus ou moins aiguës dans les segments suivants. Tous les segmonts du mesosome portent, an bord

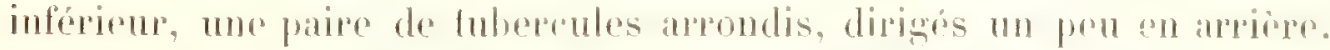
Chacun des deux premiers segments do metasomo porle une dent dorsale, longue of aigui, areompagnée d'ume paite de pelites dents subdorsales, arrondies. Le troisiome segment ne porte qu'un petite dent dorsale, recourbée on avant. La hord dorsal de l'urosome est lisso.

La tète dépasse en longueur l'ensemble des qualeo premiers sogments du mésosome. Le postre, à peu pres deoit, est anssi long que le reste de

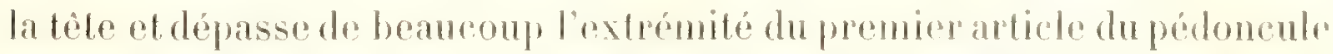
des antenmes superienres. La tete ot le rostre portont une potite carene dorsale. Les lobes lateraux, peu prononcés, sont larement arrondis. Les angles postérieurs sont aigus.

Les platpes coxales des deux premieres paires, subtriangulaires, se 
terminent inférieurement par un angle aigu. Les plaques coxales des cing pares suivantes sont de forme normale. Les plaques coxales des trois premieres pares et celles do la derniere paire portent quelques petites cénelures au bord postérieur. Dans les plaques épimérales des deux derniers segments du métasome, le bord postérieur présente une partic droite, armée de quatre dents aiguës dans les plarpues de la deuxieme paire, tandis que celles de la troisieme paire en portent six.

Les yeux, assez grands, ovales, sont proéminents.

Les antemes supérieures dépassent un peu en longueur l'ensemble
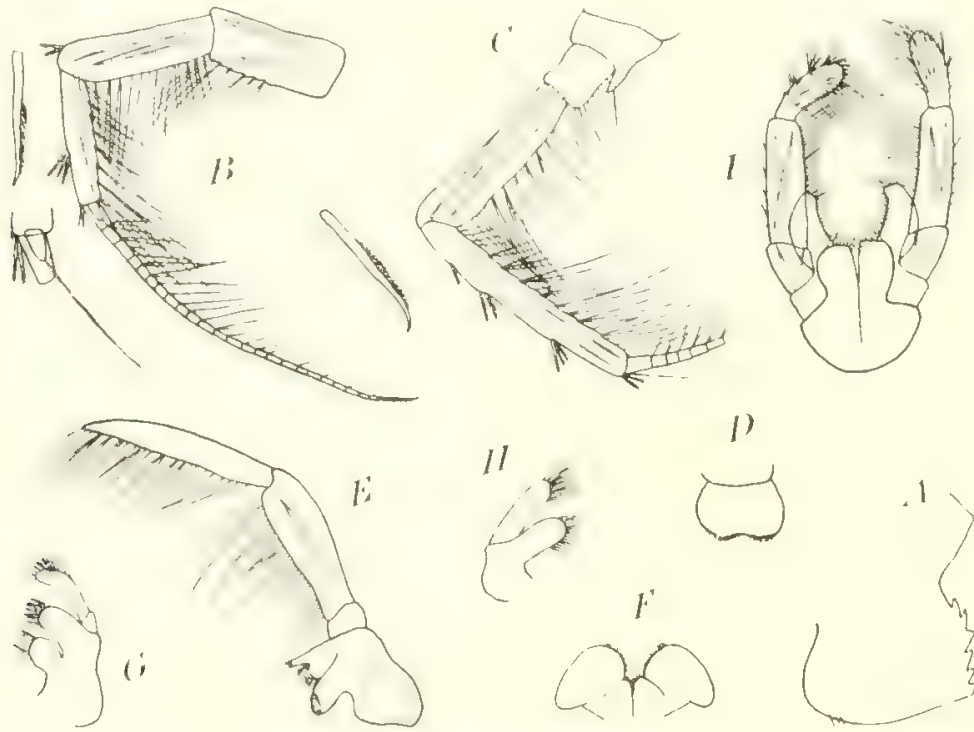

\section{()}

Fig. 48. - I'arepimeria crenulula.

1. plaptue épmérale du dernier segnent du metasone: B. C, antennes superieure et inferieure 1) Jive antericure; $\mathbf{E}$, mandibule droite: F, levre posterieure: G, maxille antérieure droite: 11 , maxilh

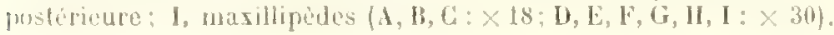

de la tête et des (puatre premiers segments du mésosome. Le pédoncule est trios long et tres robuste; ses premier et troisieme articles, d'égale taille, sont un peu plus courts que le second article. Le bord antripieur du pédoncule porte quelques épines barbelées, tandis que son bord postérieur est garni de touftes de longues soies. Le flagellum, à peine aussi long que le pédoncule, porte de longues soies au bord postérieur; il comprend vingt-six articles. Le flagellum accessoire, uniarticulé, plus cout que le premier article du flagellum principal, se termine par une longue soie. 
Les antennes inferieures sont beaucoup plus longues que les antennes supérieures. Le pédoncule porte de longues soies au hord postérieur. Son demier article, beancoup plus long que l'article précédent, porte, au bord antérieur, quelques épines bathelées. Le flagellum, ì peu près aussi longr que le pédoncule, se compose de trente-cinq articles.

Le bord libre de la livre anterienre est un peu échancré.

Le lobe tranchant des mandibules, étroit et peu développé, est accompagné, dans les deux mandibules, d'un lobe accessoire bidente. Les épines sont au nombre de treize. Le processus molaire est tres saillant. Le palpe, remarquablement grand, atteint à peu près trois fois la longueur de la mandibule. Son deuxieme article, très robuste, porte une rangée de longues soies au bord interne. Le troisieme article, également bordé de longues soies, est plus étroit et plus allongé que l'article précédent.

La levre postérieure posside des lobes internes. Les angles postórieurs. pen saillants, sont largement arrondis.

Le lobe interne des maxilles antérieures porte cinc soies ciliées. Le lobe externe est armé de onze épines. Le palpe porte, an bord distal, six épines dans la maxille ganche et quatre épines dans la maxille droite.

Les lobes des maxilles postériemes sont arrondis au bord distal. Le lobe externe est un peu plus long et plus atroit que le lobe interne.

Le lobe interne des maxillipèdes est carrément tronqué au hord dislal. Le lobe externe, falciforme, tronquéa son extrémité, n'atteint pas tout à fait le milieu du deuxième article du palpe. Le troisiome anticle du palpe, beaucoup plus count que l'article précédent, est abondamment garni de longues soies. Le palpe ne possede que trois articles.

Les gnathopodes aflectent la mème forme, cenx de la pare postérieure étant seulement un peu plus longs que les précédents. Liarticlo basal est a peu près de la longueur du carpe. Larticle ischial se prolonge inferieurement en arrière pour former un lobe armé de quatre épines crochues. Le carpe, très développé, se rétrécit dans sa partie distale: son bord postérieur porte des touffes de longues soies. Le propode, beaucoup plus court et plus étroit que le carpe, porte de longues soies au bord posteriem. 
Le dactyle, grêle et droit, alteint près de la moitié de la longueur du propode.

L'article basal des péríiopodes des deux premières paires, très robuste, dilaté dans sa partie distale, se prolonge inférieurement en arrière pour former un lobe aigu, présentant quelques crénelures garnies de soies. Ces péréiopodes étaient brisés dans l'unique exemplaire recueilli, et leurs trois demiers articles avaient disparu.

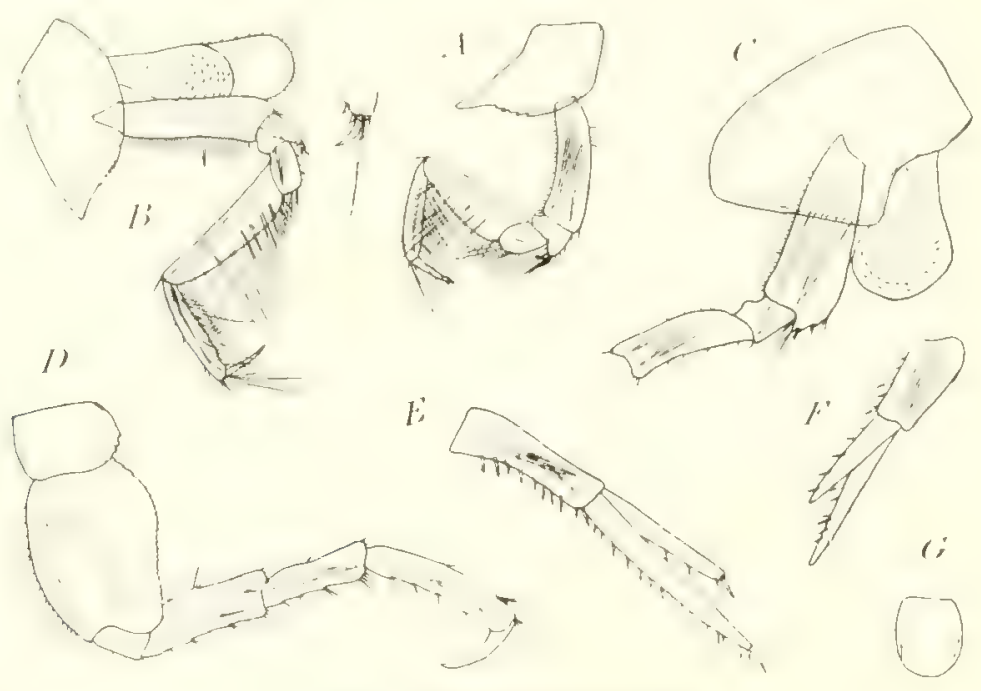

Fir. 49. - l'arepimeria crenulata.

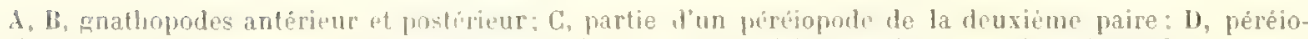

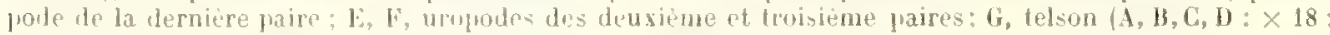
Li, F, G: $\times 9$ a

L'article basal des péréiopodes des troisième el quatrième paires, modérément dilaté, présente un bord postérieur presque droit, légèrement crénelé dans les péréiopodes de la quatrième paire. L'article basal des péréiopodes de la dernière paire est plus dilaté. Son bord postérieur, bien nettement crénelé, offre une courbure d'abord convexe, puis légèrement concave dans sa moitié distale. L'article méral, un peu plus long que le carpe, est beaucoup plus court que le propode. Le dactyle, robuste el courbé, atteint plus de la moilié de la longueur du propode.

Les branches des uropodes de la première paire, subégales, sont plus courtes que le pédoncule. Dans les uropodes de la deuxième paire, la branche externe, aussi longue que le pédoncule, est beaucoup plus courte que la branche interne. La branche externe des uropodes de la 
dernière paire, un peu plus longue que le pédoncule, atteint à peine les deux tiers de la longueur de la branche interne. Toutes deux portent une rangée d'épines au bord postérieur.

Le telson, subovale, largement arromdi dans sa partie distale, porte une paire d'épines marginales.

Le nom spécilique fait allusion aux crénelures des plarques épimérales des deux dernières paires.

\section{EUSIIIIDE.}

Eusirus perdentatus Cherrenx.

1912. Ensirus perdentalus Chevreux (4).

Dragage $X V$, 26 novembre 1900 , devint Port-Lockroy, chenal de Roosen: profondeur, 60 à 70 mètres. Une femelle dont le corps était blanchàtre, tigré de rouge. Les yeux étaient d'un brun foncé.

Le corps, assez fortement comprimé, mesurait 33 millimètres de

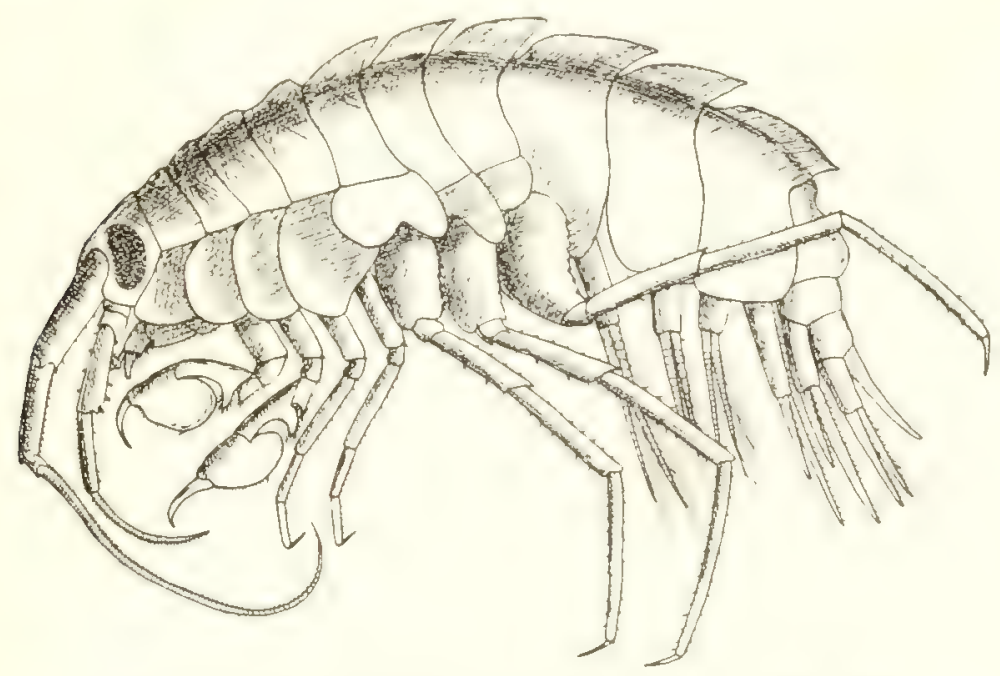

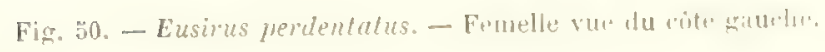

longueur dans la position où il est figuré iri. Les téguments sont ápatis et durs. Les trois derniers segments du mésosome et tous les segments du métasome portent une carène dorsale qui forme, dans chacun de ces segments, une forte dent aiguë, dirigée rn arriere. Le bord dorsal du 
premier segment de l'urosome présente une dépression suivie d'une carène arrondie.

La tête, un peu plus longue que l'ensemble des deux premiers segments du mésosome, porte un rostre légèrement courbé, aigu à l'extrémité. Les lobes latéraux, assez saillants, sont très larges au bord distal. Les angles postérieurs sont arrondis. Les plaques coxales des quatre premières paires atteignent à peu près la hauteur des segments correspondants du mésosome. Cés plaques sont irrégulièrement denticulées au bord distal. Le lobe postérieur des plaques coxales de la cinquième paire est plus étroit et plus haut que le lobe antérieur. Dans les plaques coxales de la sixième paire, le lobe postérieur est beaucoup plus haut que le lobe antérieur. Les plaques épimérales du dernier segment du métasome, à peine arrondies en arrière, presque rectangulaires, sont peu distinctement crénelées au bord postérieur.

Les yeux, très grands, réniformes, sont proéminents.

Les antennes supérieures atteignent à peu près la longueur de l'ensemble de la tète et du mésosome. Le premier article du pédoncule porte une dent aiguë au bord distal. Le deuxième article, presque aussi long que l'article précédent, est denticulé au bord distal. Le troisième article, très court, porte deux dents distales. Le flagellum, composé d'un très grand nombre d'articles extrêmement courts, est beaucoup plus long que le pédoncule. Le flagellum accessoire, uniarticulé, est rudimentaire. Le deuxième article du pédoncule et le flagellum portent, au bord postérieur, une rangée de calcéoles accompagnées de tigelles sensitives.

Les antennes inférieures sont beaucoup plus courtes que les antennes supérieures. L'avant-dernier article du pédoncule, très robuste, est denticulé au bord distal. Le dernier article est un peu plus court et beaucoup plus étroit que l'article précédent. Le flagellum, composé de nombreux articles extrèmement courts, dépasse à peine en longueur le dernier article du pédoncule; son bord antérieur est garni de calcéoles.

Les mandibules, assez robustes, présentent un bord tranchant droit, armé d'une petite dent à chaque extrémité. Le lobe accessoire, bien développé et denticulé dans la mandibule gauche, est très réduit et bidenté dans la mandibule droite. Les épines sont au nombre dẻ huit. Le processus 
molaire, de forme conique, ne possède qu'une surface trifurante très réduite. Le palpe, remarquablement robuste, atteint le double de la longueur de la mandibule. Son deuxieme article est fortement dilaté dans sa partie médiane. Le troisieme article, falciforme, dépasse de beaucoup en longueur l'ensemble des deux articles précédents.

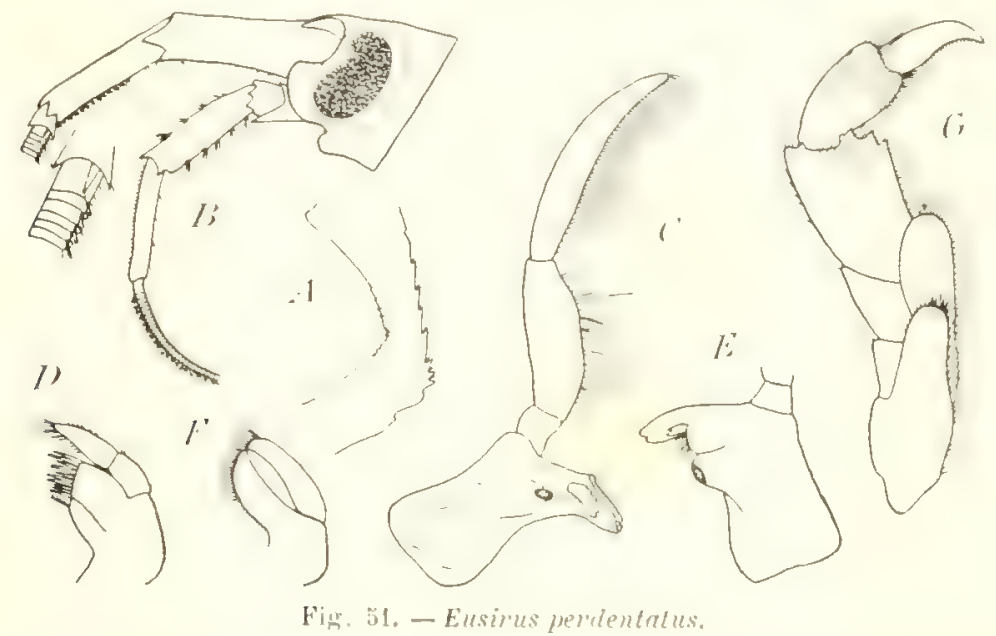

d. plaque épimérale du dernier segment du métasome; B, tite tet partie dis antennes: C. mandibule

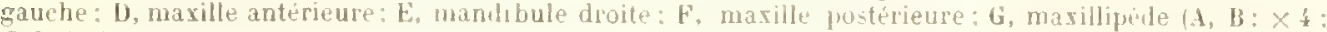
C. $\mathbf{1}, \mathrm{E}, \mathbf{F}, \mathrm{G}: \times 10)$.

Le lobe interne des maxilles antérieures porte, au bord distal, une seule soie ciliée. Le lobe externe est armé de onze épines. Le palpe est remarguable par la grande taille de son premier article, qui atteint les deux tiers de la longueur de l'article suivant.

Le lobe interne des maxilles postérieures, anssi long mais plus large que le lobe externe, porte des soies an bord interne.

Les lobes interne et externe des maxillipèdes sont modérément développés. Le lobe externe, bordé de longues soies, ne porte pas d'épines. Le palpe, extrêmement robuste, présente un deuxième article très dilaté, garni de nombreuses soirs ot dont le borrl distal est armé de dents aiguës. Le quatrieme article, dactyliforme, porte me rangée de petites épines au bord interne.

Les gnathopodes des deux paires affectent la mème forme, ceux de la paire postérieure étant, conme d'habitude, un peu plus longs que les précédents. Le propode, subquadrangulaire, est un peu plus large que long. Le bord palmaire, régulièrement convexe, porte une rangée de 
petites épines. Le bord postérieur est remarquable par sa forme un peu concave. Le dactyle est fortement courbé dans sa partie distale.

Les péréiopodes des deux premières paires, grêles et courts, dépassent à peine en longueur les gnathopodes postérieurs. Le propode, plus long que le carpe, est beaucoup plus court que l'article méral.

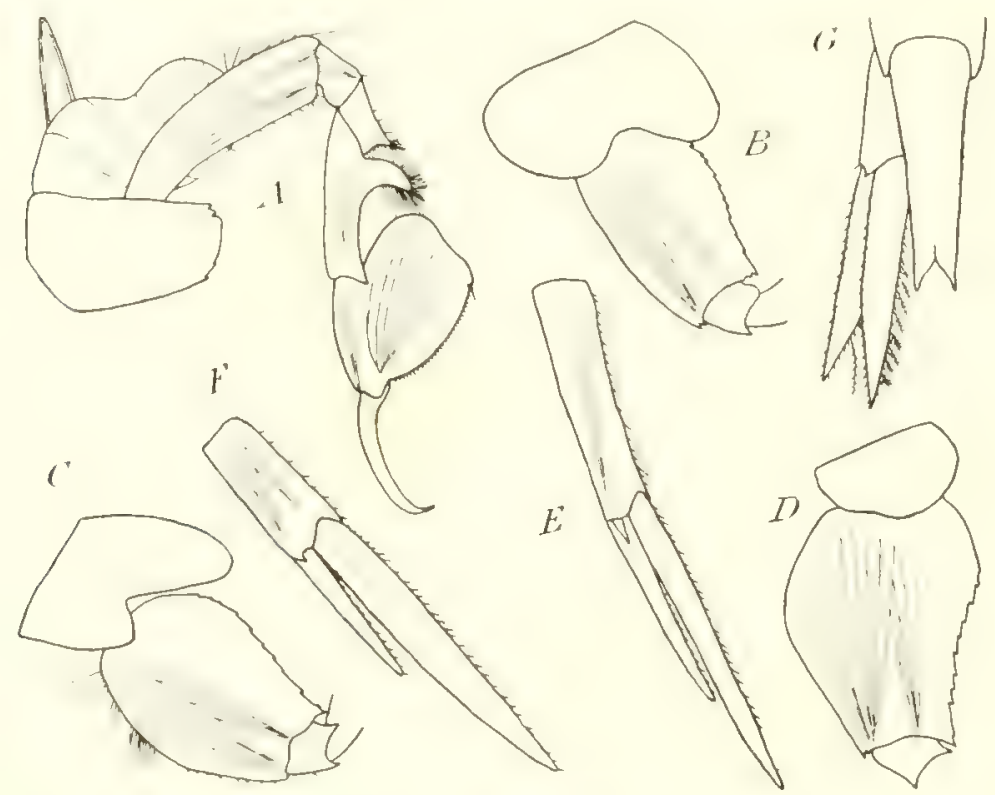

Fig. 52. - Eusimus perdentatus.

A, gnathopode postérieur; B, C, D, partie proximale des péréiopodes des troisième, quatricme et cinquieme paires; $\mathbf{E}, F$, uropodes des premiere et deuxième pares; G, uropode de la dernière paire et telson (toutes les figures: $\times 6$ ).

Les péréiopodes des trois dernieres paires, longs et grêles, sont subégaux. Le bord postérieur de l'article basal, nettement crénelé, est un peu concave dans sa partie distale, principalement dans les péréiopodes de la dernière paire. Le carpe, un peu plus long que l'article méral, est loin d'atteindre la longueur du propode. Le dactyle, grêle et court, est presque droit.

La branche externe des uropodes de la première paire n'atteint que les deux tiers de la longueur de la branche interne, qui est beaucoup plus longue que le pédoncule. Bans les uropodes de la deuxième paire, la branche externe, aussi longue que le pédoncule, n'atteint pas tout à fait la moitié de la longueur de la branche interne. Les branches des uropodes de la dernière paire, grêles et subégales, sont bordées de 
nombrenses épines; leur bord interne porte quelques soies ciliées.

Le telson n'atteint que le milieu des branches des uropodes de la dernière paire. Il est fendu sur le cinquième de sa longueur. Cette fente, d'abord tris étroite, s'élargit brusquement pour former deux lobos, aigus a leur extrémité. Le telson ne porte ni soies ni épines.

Eusirus microps A. O. Walker.

1906. Eusirus microps A. O. Walker (16), p. 15\%.

1907. Eusirus microps A. O. Walker (17), p. 31, Pl. XI, fig. 19.

Ile Petermann, 27 juillet 1909, dans l'estomac d'un Pygoscelis Adeliz. Deux exemplaires mesurant 37 millimètres de longueur.

Ln des exemplaires de la "Discovery " atteignait 48 millimètres de long.

\section{Eusirus laticarpus Chevreux.}

1906. Eusirus laticarpus Chevreux (2), p. 49, fig. 27 à 30 du texte.

Dragage VIII, 20 janvier 1909, baie 1 arguerite; profondeur, 200 mètres Un jeune exemplaire, de conleur blanchatre, long de 6 millimètres.

Dragage IX, 21 janvier 1909, au sud de l'ile Jenny; profondeur, 230 mètres. Trois exemplaires, colorés en rose, trourés dans une Éponge. Le plus grand de ces exemplaires mesurait 10 millimetres de longueur.

Dragage X, 22 janvier 1909 , prés de la Terre Alexande Jer; profondeur, 297 metres. Trois exemplaires, colorés en rose très pàte, trouvés dans une Eponge. Le plus grand de ces exemplaires mesurait a millimetres de longueur.

Les yeux ont été mal observés chez la femelle, en assez manvais état de conservation, draguée par le "français". En réalité, ils sont de mème forme que ceux du màle, bien qu'un peu moins grands.

\section{PONTOREVEIIIE.}

Eurymera monticulosa Pfeffer.

1906. Eurymera monticulosa Stebbing (11), p. 357.

1906. Eurymera monticulosa Chevreux (2), P. 59, lig. 31 à 36 du texte. 
Ile Petermann, 6 novembre 1909. Une femelle de 15 millimètres de longueur, recueillie à marée basse par le $D^{\mathrm{r}}$ Liouville. Cette femelle, colorée en brun rougeàtre, portait des embryons dans sa poche incubatrice.

\section{Bovallia gigantea Pfetter.}

1906. Bovallia gigantea Stebbing (11), p. 357.

1906. Bovallia gigantea Chevreux (2), p. 54, fig. 31 a 33 du texte.

1909. Bovallia monoculoides Chilton (6), p. 622.

Ile Petermann, Port-Circoncision, 10 octobre 1909, dans une touffe de Desmarestin récoltée par 5 mètres de profondeur. Un exemplaire de 13 millimètres de longueur.

Ile Petermann, 30 octobre 1909, marée basse, dans le creux d'un rocher couvert d'Algues. Quatre exemplaires, de longueur variant entre 17 et 27 millimètres. Leur corps était d'un brun verdàtre; leurs yeux, d'un rouge-brique.

Shetlands du Sud, ile du Roi-George, baie de l'Amirauté, 26 décembre 1909. Trente-six exemplaires, de longueur variant entre 18 et 38 millimètres, mesurés du bord antérieur de la tête au bord postérieur du dernier segment du métasome, recueillis à marée basse par le $D^{\mathrm{r}}$ Liouville. Leur corps étail d'un brun verdàtre, tournant au brun rougeàtre dans la partie dorsale.

Je ne puis partager l'opinion de $\mathbf{M}$. Chilton $(6,1.622)$, qui considère Bocallia giganter conme synonyme d'Eusiroides monoculoides (Haswell) et de $\boldsymbol{E}$. Crassi Stebbing et réunit les trois formes sous le nom de Bocallia momoruloides (Haswell). Le tableau suivant montre les principales diflérences qui séparent les deux premières de ces espèces. D'autre part, Eusirnides Crassi me semble suflisamment caractérisé par la forme fuadrangulaire du propode de ses gnathopodes.

Eusiroides monoculoides.

Chacun des deux premiers segments du métasome prolongé dorsalement pour former une petite dent aiguë. Troisieme segment sans carène dorsale.
Bovallia gigantea.

Demier segment du mésosome et chacun des deux premiers segments du métasome prolongés dorsalement pour former une robuste dent, modérément aiguë. Troisième segment portant une carène dorsale, arrondie en arrière. 
Plaques épimérales du métasome carrées dans les deux premiers segments, très convexes et gamies de 10 a 18 dents recourbées dans le troisieme segment.

Yeux très grands, réniformes.

Antennes supérieures possédant un petit flagellum accessoire.

'Troisième article du palpe des mandibules beaucoup plus long que le second article.

Lobe interne des maxilles antérieures portant deux soies; premier article du palpe atteignant plus de la moitié de la longueur du second article.

Extrémité des lobes du telson bidentée.
Plaques épimérales des trois secments du métasome semblables entre elles, bord postérieur légèrement convexe, portant une seule petite dent à l'angle inférieur.

Yeuxhauts etétroits, en formede croissants. Antennes supérieures ne possédant pas de tlagellum accessoire.

Deuxiène et troisième articles du palpe des mandibules d'égale taille.

Lole interne des maxilles antérieures portant sept soies; premier article du palpe n'atteignant que le tiers de la longueur du speond article.

Extrémitẻ des lobes du telson arrondie.

11. Chilton attribue la plupart des différences existant entre Eusiroides monoculoides et la description et les figures que j'ai données de Bovallia gigantea à la grande taille des exemplaires antaretiques. Pour supprimer cette cause d'erreur, j’ai comparé, dans le tableau qui précède, Eusiroides monoculoides $\lceil=E$. Ciesaris $+E$. Pompei t. Stebbing (11), p. $3 \% 3$ avec un jeune exemplaire de Bocallia giganten mesurant 13 millimètres de longueur, c'est-ì-dire à peu près la taille des Eusiroides du "Challenger" ". Du reste, cet exemplaire ne diftère des adultes que par le nombre des soies (sept au lieu de douze) du lobe interne des maxilles antérieures.

Les caractères exposés dans ce tableau ne sont évidemment pas tous de valeur égale, et il est bien certain qu'un seul d'entre eux ne suffirait pas à l'établissement d'une espèce nouvelle, mais la réunion de sept caractères différents me semble amplement suffisante pour séparer, tout au moins spécifiquement, les deux formes.

\section{Bovallia Walkeri (Stebbing).}

1903. Alylus anlarclicus A. O. Walker (15), p. 58, P. XI, fig. 91-97.

1906. Alylus Walkeri Stebbing (11), p. 7:3.

1907. Alylus Walkeri A. O. Walker (17), p. 3.1.

1909. Alylus Walkeri Chilton (6), 1). 62:1.

Ile Déception, Pendulum Cove, 23 décembre 1908, le long du rivage. Trois exemplaires.

Expedition Charcot. - Chevreus. - Amphipodes 
Cet Amplipode a été décrit par A. O. Walker sous le nom d'Alylus antareticus. Stebbing l'a nommé Atylus Walkeri, le nom d'A. antarcticus ayant été donné, en 1878, à un Amphipode que Della Valle a classé, en 1893, dans le genre Polycheria. II ne me semble pas possible de laisser cette espèce dans le genre Atylus, ni même dans la famille des Atylida, puisqu'elle ne présente pas deux des principaux caractères

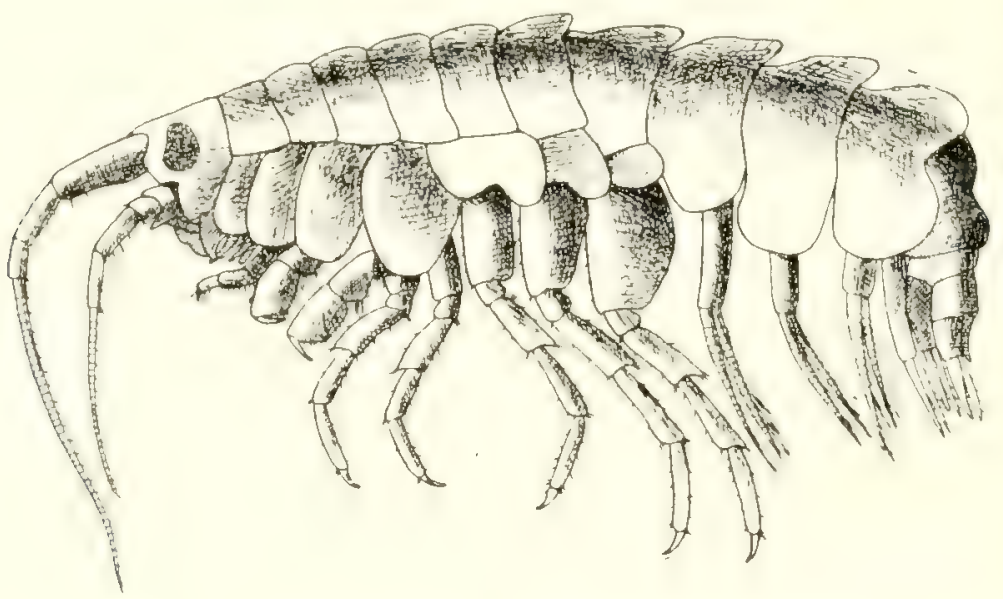

T̃ìn. 53. - Bocallia Walkeri. - Femelle vue du côté gauche.

de cette famille: la soudure des deux premiers segments de l'urosome et la position retournée du dactyle des péréiopodes de la dernière paire. Elle possède, au contraire, tous les caractères du genre Bocallia et doit prendre place à côté de Bocallia gigantea, dont elle est très voisine. Cette ressemblance a déjà été signalée par Walker (15, p. 60).

Les trois exemplaires recueillis à l'île Déception sont des femelles probablement non adultes, puisqu'elles ne mesurent que 10 millimètres de longueur, tandis que le type décrit par Walker atteignait 13 millimètres. Le corps est assez fortement comprimé. Le mésosome et le métasome portent une carène dorsale. Cette carène, arrondie dans les quatre ou dans les cinq premiers segments du mésosome, se prolonge dans les segments suivants et dans les deux premiers segments du métasome, pour former une dent subaiguë. La carène du troisième segment du métasome est arrondie en arrière. Le premier segment de l'urosome présente une légère dépression dorsale.

La tête, aussi longue que l'ensemble des deux premiers segments 
du mésosome, porte un petit rostre aigu. Les lobes latéraux, assez. grands, sont largement tronqués au bord distal. Les plaques coxales des quatre premieres paires dépassent un peu en hauteur les segments correspondants du mésosome. Le lobe postérieur des plaques coxales de la cinquieme paire est un peu plus haut que le lobe anterieur. Les playues épimérales du dernier segment du métasome, largement arrondies en arrière, sont faiblement crénelóes au bord postérieur.

Les yeux, assez grands, réniformes, comprennent un très grand nombre d'ocelles.

Les antennes supérieures atteignent la longueur de l'ensemble de la

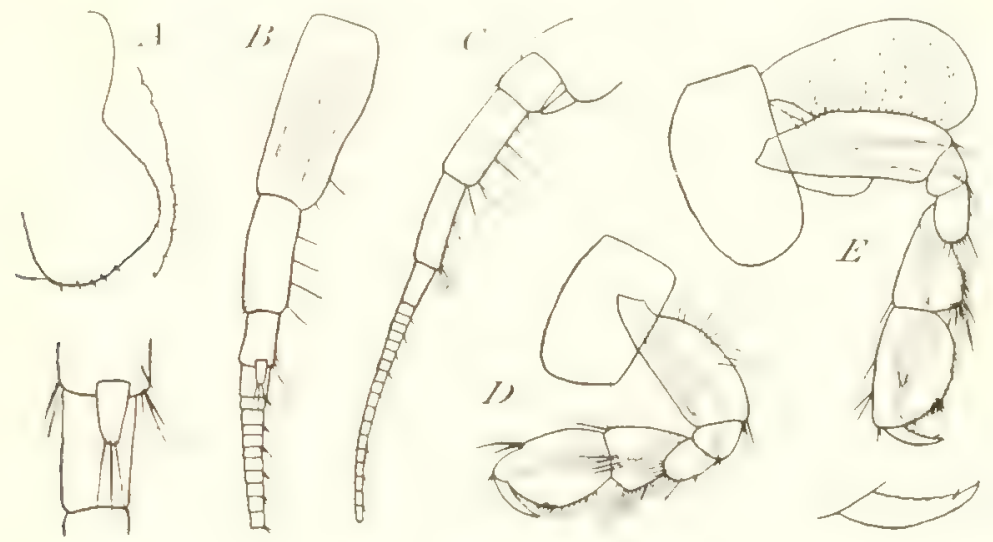

Fig. 5s. - Bocallia Wolkeri.

A, plaque épimérale du dernier segment du métasome: $B, C$, partie des antennes supérieuresetinférieures: D, gnathopode antérieur: E, gnathopode postéricur $(\mathrm{A}: \times 1 \mathrm{D}: \mathrm{B}, \mathrm{C}, \mathbf{0}, \mathrm{E}: \times 16)$.

tête et du mésosome. Le premier article du pédoncule est un peu plus long que l'ensemble des deux articles suivants. Le troisieme article atteint la moitié de la longueur du second. Le flagellum comprend trente-trois articles portant, de deux en deux, une petite toutle de soies au bord postérieur, mais ne possédant pas de calcéoles. Le flagellum accessoire, uniarticulé, atteint la moitié de la longueur du prenier article du flagellum principal.

Les antennes inférieures sont beaucoup plus courtes que les antennes supérieures. Le dernier article du pédoneule n'atteint pas tout a fait la longueur de l'article précédent. Le flagellum, un peu plus long que le pédoncule, se compose de vingt-sept articles.

Les pièces buceales diffèrent à peine de celles de Barallia gigantea. 
Le dernier article du palpe des mandibules est plus court que l'article précédent. Le lobe interne des maxilles antérieures porte six soies ciliées; le lobe externe est armé de dix épines barbelées.

L'article basal des gnathopodes antérieurs est fortement dilaté en arrière. Le carpe atteint les deux tiers de la longueur du propode, qui est à peine quadrangulaire, le bord postérieur formant avec le bord palmaire un angle extrêmement obtus, armé d'un groupe d'épines. Le bord interne du dactyle est crénelé.

Les gnathopodes postérieur's ne diflèrent des gnathopodes antérieurs que par leur taille un peu plus grande et par les dimensions du carpe, qui est presque aussi long que le propode.

Dans les péréiopodes des deux premières paires, l'article basal

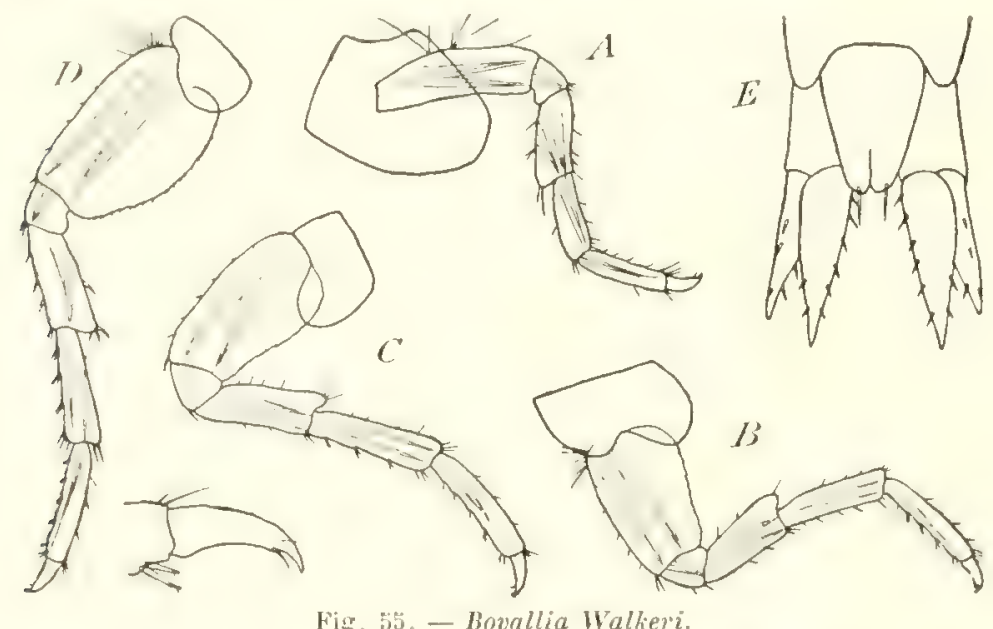

Fig. 55. - Bovallia Walkeri.

$A, B, C, b$, péréiopodes des deuriène, troisiẻme, quatrième et cinquiẻme paires; $E$, uropodes de la derniere paire et telson $(\mathbf{A}, \mathbf{B}, \mathrm{C}, \mathbf{I}): \times 12 ; \mathrm{E}: \times 26)$.

atteint la longueur de l'ensemble de l'article méral et du carpe, qui sont d'égale taille. Le propode est un peu plus allongé. Le dactyle, court et robuste, porte une petite soie au bord interne.

L'article basal des péréiopodes des trois dernières paires est faiblement crénelé au bord postérieur. Ce bord, à peu près droit dans les péréiopodes de la troisième paire, est légèrement concave dans sa moitié distale dans les péréiopodes de la quatrième paire et bien nettement convexe dans les péréiopodes de la dernière paire. Dans tous ces péréiopodes, le carpe et le propode, d'égale taille, sont plus longs que 
l'arficle méral. Le dactyle porte une petite soie an bord interne. Les branches des uropodes de la premirpe paire, d'égale taille, sont plus longues que te pédoncule. Dans les uropodes de la deuxième paire, la branche externe est batucoup plus courte que la branche interne, qui atteint la longueur du pédoncule. Les branches des uropodes de la dernière pare, assez larges, lancéolées, sont bordées de nombreuses épines. La branche externe est un peu plus courte que la branche interne.

Le telson, subtriangulaire, un peu phus long que large, est fendu sur le tiers de sa longueur. Ses lobes, obliquement tronqués au bord distal, sont armés chacun d'une assez longue épine.

Cette espece s'écarte de Borallia giganten par sa forme plus comprimée, par ses yeux beaucoup plus larges, par ses antenues non munies de calcéoles et dont la paire antérieure possède un flagellum accessoire, et par la forme assez differente du propode de ses smathopodes, de l'article basal de ses péréiopodes des trois dernieres paires et de son telson.

\section{Stebbingia gracilis Cheveux.}

1912. Slebbingia gracilis Cilıvreux (4).

Dragage VI, 13 janvier 1909, entrée de la baie Narguerite; profondeur. 2.̈. mètres. Lne lemelle, dont le corps était trinté do blanc et de rose.

He Petermann. Port-Cinconcision. A oetobre 1909. dans une toulle de Desmarestio ramenée de ä mètres de profondeur. Tombresux exemplaires.

Hême provenance, 10 octohre 1909. Treize exemplaires.

Dragage XITe, 18 november 1909, cote nord-est de l'ile Petermann, chenal de Lemaire; profondeur', 60 it 10 metres. Six exemplaires. Le corps de ces Amphipodes était d'un rouge-brique; les yeux étaient d'un pouge vif.

L'exemplaire dont la description suit était une femelle ovigere, dont la poche incubatrice contenait trente-quatre ceufs. Sa longueur atteignait 8 millimètres, dans la position oủ il est figuré ici. 
Le corps, grêle et comprimé, est lisse. Le mésosome dépasse un peu en longueur l'ensemble du métasome et de l'urosome. La tête, beaucoup plus longue que l'ensemble des deux premiers segments du mésosome, ne porte pas de rostre. Les lobes latéraux, peu saillants, sont tronqués dans leur partie distale. Les plaques coxales des quatre premieres paires

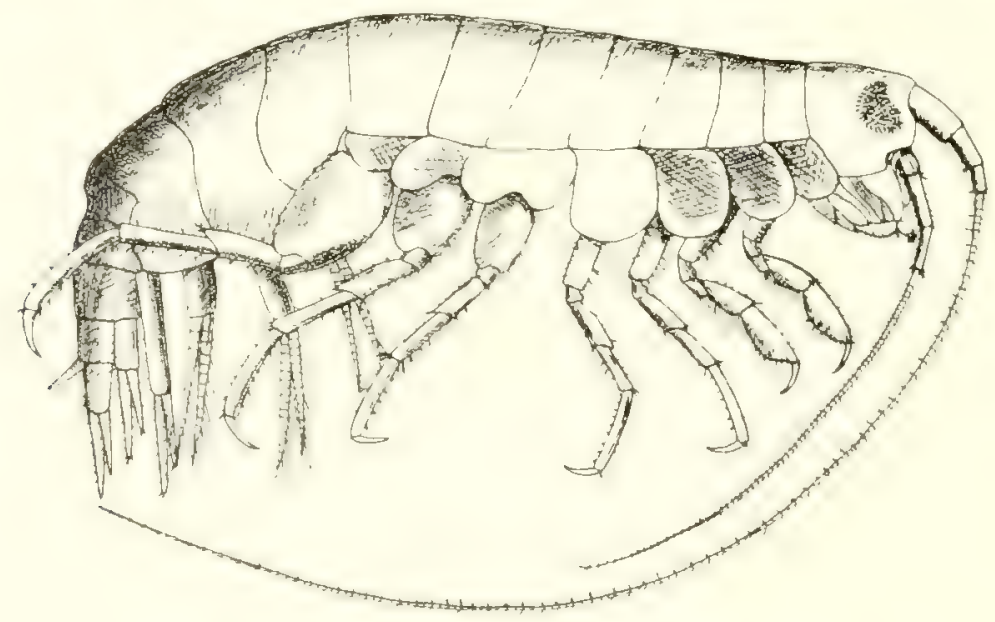

Fig. :50. - Stebbingia gracilis. - FemelJe vue du cỏté droit.

sont moins hautes que les segments correspondants du mésosome. Les plaques coxales de la quatrieme paire ne sont pas sensiblement échancrées au bord postéricur. Le lobe antérieur des plaques coxales de la cinquième paire est un peu plus grand que le lobe postérieur. Les plaques épimérales du dernier segment du métasome, un peu prolongées en arrière, portent, an bord postérieur, une petite échancrure garnie d'un cil; ce bord est séparé du bord inférieur par une petite dent obtuse.

Les yeux, assez grands, réniformes, comprennent de très nombreux ocelles.

Les antenmes supérieures atteignent à peu près la longueur du corps. Le pédoncule est très court. Son premier article dépasse un peu en longueur l'ensemble des deux articles suivants. Le flagellum comprend un grand nombre d'articles très courts. Il n'existe pas de flagellum accessoire.

Les antennes inférieures n'atteignent guère que la moitié de la longurur des antemnes supérieures. Tous les articles du pédoncule sont 
visibles en dehors de la tête. Le dernier article est un peu plus court que l'article précédent. Le flagellum comprend un srand nombre d'articles très courts.

La lève antérieure est régulièrement arrondie au bord distal.

Les mandibules présentent un lobe tranchant assez aigu, armé de ciny dents. Le lobe accessoire de la mandibule droite est tridenté, tandis

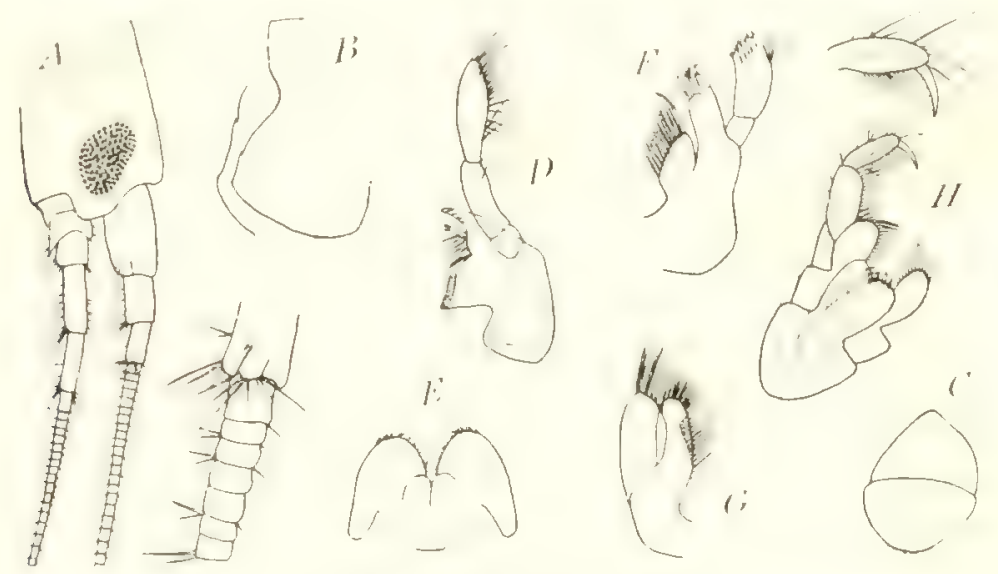

Fig. 57. - Slebbingia gracilis.

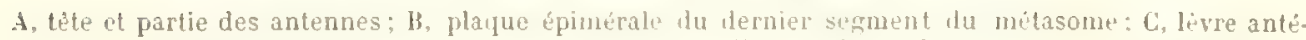
rieure: $D$, mandibule droite; $E$, levre posterieure; $F$. unaxille antérieure druite: $G$, maxille posterieure; $\mathrm{H}$, maxillipides $(\mathbf{A}, \mathrm{B}: \times 16: \mathrm{C}, \mathrm{U}, \mathrm{E}, \mathrm{F}, \mathrm{G}, \mathrm{II}: \times 30)$.

que celui de la mandibule zauche porte cinq petites dents. La rangée d'épines en comprend sept. Le processus molaire est très saillant et très développé. Le dernier article du palpe, garni l'une épaisse rangée de soies, est beaucoup plus long que l'article précédent.

La lère postérieure possède de petits lobes internes.

Le lobe interne des maxilles antérieures, très large, est bordé de quinze soies ciliées. Le lobe externe porte dix ćpines barbelées. Le palpe, très développé, porte une rangée de dents au bord distal.

Le lobe interne des maxilles postérieures, un peu moins long et moins large que le lobe externe, porte une rangée de soies au bord interne.

Le lobe interne des maxillipèdes, très développé, porte trois dents au bord distal. Le lobe externe, faible et court, n'atteint pas le milieu du deuxième article du palpe; il est bordé de longues épines. Le troisième article du palpe est un peu plus court et beancoup plus étroit que 
l'article précédent. Le quatrième article, dactyliforme, atteint la moitié de la longueur du troisième article.

Les gnathopodes, grèles et courts, sont ì peu près de même forme. Le propode, plus long que le carpe, ovalaire, est un peu plus large dans les gnathopodes antérieur's que dans les gnathopodes postérieurs. Le

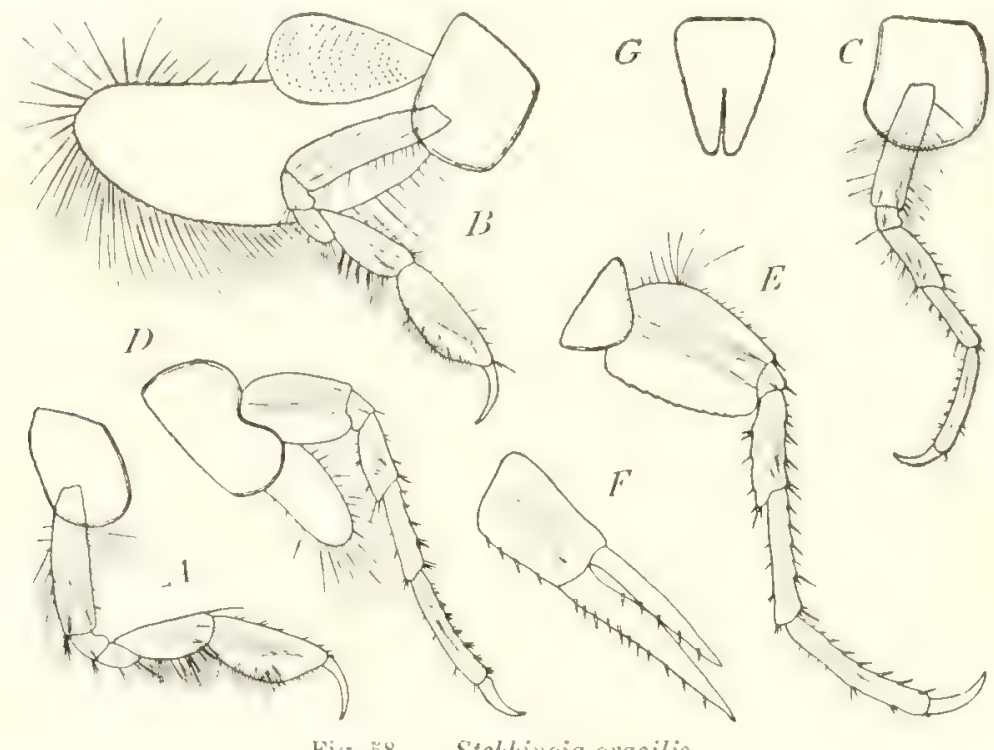

Fin. 5.. - Stebbingia gracilis.

A, B, gnathopodes antérieur ut postéricun: C, D, péréioportes des deuxième et troisième paires: Li, pé-

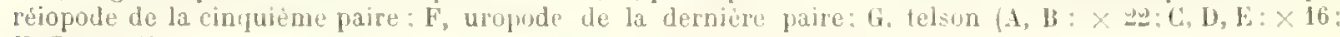
F, G: $\times 30\}$.

dactyle, grèle et courbé, atteint ì peu près la moitié de la longueur du propode.

Les péréiopodes, peu allongés, sont assez grèles. Dans les péréiopodes des trois dernières paires, l'article basal, beaucoup plus long que large, est faiblement crénelé au bord postérieur. Le carpe, un peu plus long que l'article méral, est beaucoup plus court que le propode. Tous ces articles sont garnis de nombreuses épines. Le dactyle, très robuste, est assez fortement courbé.

Dans les uropodes des deux premières paires, la branche interne dépasse de beaucoup la branche externe. Le pédoncule des uropodes de la demière paire, très volumineux, porte quelques épines au bord postérieur. Ia branche externe, étroitement lancéolée, est un peu plus longue que le pédoneule. La branche interne est plus laràe et notablement plus allongée que la branche externe. 


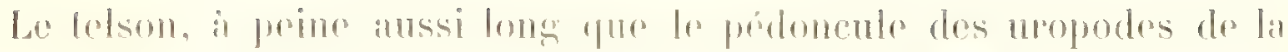
derniere parm, subliangulaire, est fendu sur ha moitie de sa longuenr. Ses lobes, itroitenent arrondis an bord distal, ne portent ni soies ni épines.

\section{Pontogeneia antarctica Cherreux.}

1906. Ponlogeneia antarclica Chevreux (2), p. 69, fig. 40 et 41 du texte. 1909. Pontogeneia antarctica Chilton (6), p. 6:4.

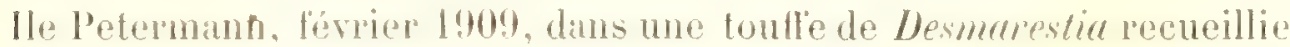
le long de la cote, par 6 metres de profondeur. Qunatorze exemplaires. -

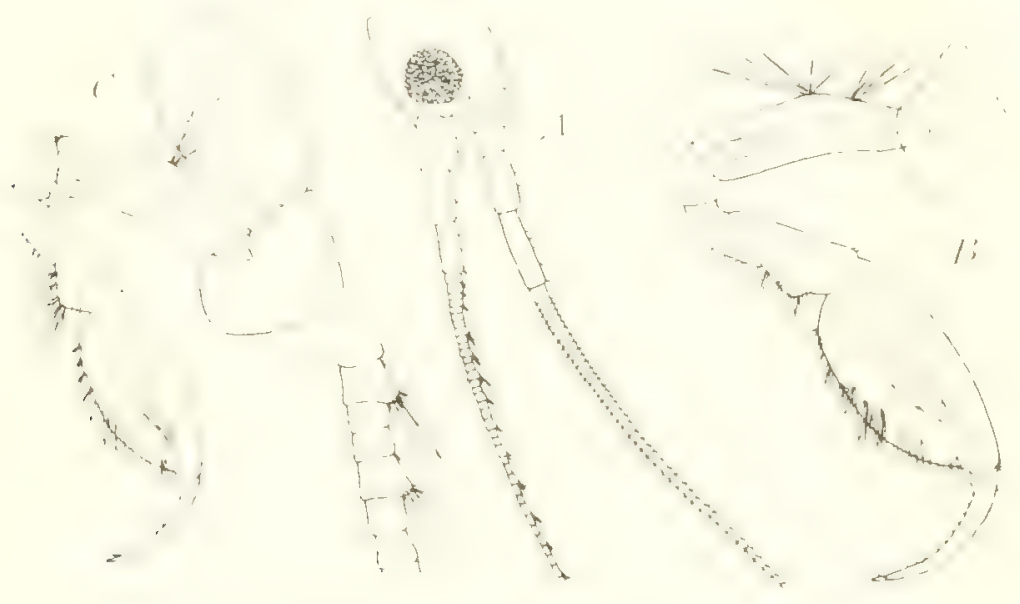

Fint.59. - Pontogeneirt antortict, mide.

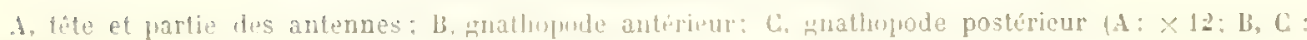
$x \div 6)$.

Mème provenance, 4 octobre 1909. Sept màles, douze femelles. Même provenance, 10 octobre 1909. Lne femelle ovigìre, un màle.

Ile Petermann, 16 novembre 1909. Quatre exemplaires, recueillis it marée basse par $\mathbf{M}$. le Ir Liouville. Cés exemplaires étaient colorés en brun verdâtre.

Shetlands du Sud, île du Roi-George, baie de l'Amirauté, 26 décembre 1909. Deux exemplaires, recueillis à marée hasse par M. Le D' Liouville.

Cette espèce, très voisine de Pontogeneia Danai G. M. Thomson, s'en distingue surtout par les articles du flagellum de ses antennes supérieures, qui sont renflés de trois en trois, tandis qu'ils le sont de quatre en quatre chez la forme de la Nouvelle-Zélande. I'autre part, chez P. Denai, 
les articles du pédoncule des antemues supérieures ont le bord infériemr armé de dents, les deux dermiers articles du pédoneule des antennes inférieures sont d'égale longueur, te telson est plus profondément féntu.

Un certain nombre de mâles de P'. antruetict ont été recueillis à l'île Petermann. Ils diflèrent des femelles par leurs yeux plus grands, leurs antennes plus allongées et par les propodes de leurs gnathopodes, qui sont plus développés et plus étroitement ovales.

\section{Atyloides magellanicus (stebbing).}

1906. Ponlogeneia magellanica Stebling (11), p. 360.

1906. I'onlogeneia magellanica Chevreux (2), p. 64, fig. 37 à 39 du texte. 1907. Pontogencia magellanica A. O. Walker (17), p. 33, Pl. XII, fig. 20. 1909. Alyloides magellanica Chilton (6), p. 627.

shetlands du Sud, ìle du Roi-George, baie de l'Amirauté, 26 décembre 1909 .

Nombreux exemplaires, recueillis it marée basse par M. Le Dr Liouville.

Je crois que M. Chilton est dans le vrai en classant cette espèce dans le genre Atyloides et en réservant le genre Pontogeneia pour les formes dont le flagellum des antennes supérieures porte, it intervalles égaux, des articles plus ou moins renllés et garnis de tigelles sensitives (1).

Chez tous les exemplaires du "Pourquoi Pas?" que j'ai examinés; les antennes supérieures possédaient un petit flagellum accessoire. Ce fragile appendice était probablement brisé chez l'exemplaire du "Francais " utilisé pour la deseription de l'espèce. Plusieurs des exemplaires du "Pourguoi Pas?" possindent trois petites dents au bord distal de chacun des lobes du telson, comme le type décrit par stebbing.

M. Walker a figuré un gnathopode antérieur de cette espéce, dont le propode, beanconp plus long que le carpe, est subpiriforme. Chez toutes les femelles que j’ai examinées, le propode, quadrangulaire et plus de deux fois aussi long que large, est de la longueur du carpe. Peut-ètre faut-il attribuer cefte différence au dimorphisme sexuel.

(1) Ces intervalles, de trois atticles chez Pontogeneia antarctica (Chevreux), sont de quatre articles chez I'. Danai (r. II. Thomson) de la Nouvelle-Zélande, el de deux articles chez le type du renre, P. inermis (Krijor), du nord de l'isurope et de l'Amérique, et chez P. minuta Chevreux, des iles du Cap-Vert. 


\section{Atyloides serraticauda siteh hinc:}

1906. Alyloides serraticauda Stelbing (11), p. 36:\%.

1906. 1lyloides serraticanda Chevreux (2), p. 87.

1907. Hyloides serralicauda A. O. Walker (17), p. :3:3.

1909. Alyloides serralicauda Chilton (6), p. 627.

Dragage 111, 26 décembre 1908, chenal de Roosen; profondemr, 129 meleres. Nombremx exemplaires.

Le nombre des dents des plarues épimérales du dernier segment du mótasome varie arec la taile de l'animal; j'en ai compté dix chez un grand exemplaire, long de I. millimètres.

\section{Atyloides longicornis Chevreux.}

1906. Atyloides longicornis Chevreux (2), p. 84 , fig. 48 a 50 du texte.

1909. Alyloides longicomis Chilton (6), p. 628.

Dragage III, 26 décembre 1908, chenal de lioosen; profondeur. 129 mitres. Ciny exemplaires.

Dragage XIT a 18 novembro 1909, lo long do la cote nord-est de l'ile Potermanu, chenal de Lemaire p profondeur, 60 à 40 midres. Deux complatres. La couleur sémérale du corps do ces exemplaires était d'un rouge paile, avee de nombreuses petites taches d'un rouge-brique. Les yeux étaient d'un brun rougeàtre.

\section{Djerboa furcipes Chevreux.}

1906. Djerboa furcipes Chevreux (2), p. 74, fig. 4 à 11 du texte.

1909. Djerboa furcipes Chilton (6), p. 622,2.

Ile Petermann, foctobre 1909. Dans une touffe do Desmarestin Pamenée de 3 mètres de profondeur. Deux màles.

Ile Petermann, Port-Cireoncision, 10 actobere 1909. Dans une toulle de Desmarestin ramente de $\ddot{i}$ motres de profondeur. Cinc màles, dixsopt femelles et jeunes exmmlatres. Le plus grand des males mesurait Il millimetres de longueur; la laille de la plus grande femelle était de 19 millimètres.

La récolte de nombreux exemplaires do cette cispere dans les Mlantes del'île Petermann me permet de rectifier une cereur qui s'est glissée dans 
la description du type, trouvé dans l'estomac d"un Pygascelis anteretirn au cours de la première Expédition du D' Charcot. Les spécimens de cotte provenance ne possédaient, à eux deux, qu'un seul uropode

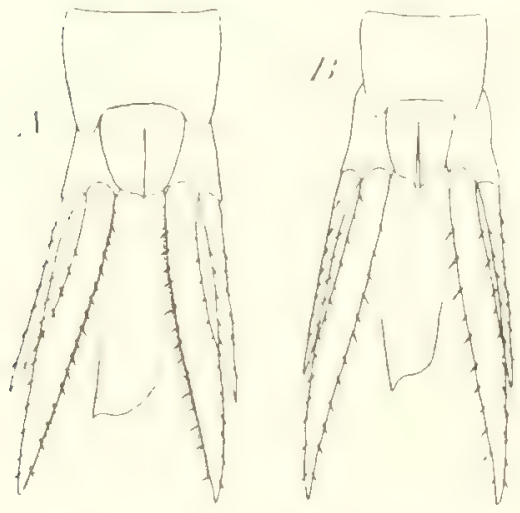

Fig. 60. - lljerbon furcipes.

Uropodes de la derniére paire et telson: A. de la fomelle: 13 , du måle $(\times 12)$. postérieur complet, et cet uropode, dont P'articulation avec le dernier segment de l'urosome était probablement un peu mutilée, a été lignuré à l'envers. En réalité, la branche externe des uropodes de la demière paire est plus courte que la branche interne, comme dans les uropodes précédents.

Le dimorphisme sexuel est peu accentué. Cependant, chez le mâle, les yeux. un peu plus grands, sont réniformes; les antennes supérieures, de taille inusitée, atteignent à peu près le double de la longueur du corps; les antennes inférieures sont aussi longues que le corps; les mopodes de la derniere paire sont plus allongés, leurs branches sont plus étroites; le telson est notablement plus long que large et l'angle interne de ses lobes est plus aigu. Les gnathopodes ne diflerent pas de ceux de la femelle.

\section{VIMUAKIDIS. \\ Paraceradocus Miersi (Pfeffer).}

1906. Paraceradocus Miersi Stebbing (11), p. 429.

1906. Paraceradocus Miersi Chevreux (2), p. 93.

Ile Petermann, 30 octobre 1909, marée basse, dans le creux d'une roche couverte d'Algues (Gigartinacées). Une femelle, dont le corps etait d'un brun rougeàtre et les yeux d'un gris noiratre.

Ile Petermann, Ier novembre 1909, marée basse, sous les pierres. Un mìle, une femelle. Leur corps était d'un rouge brun.

Ile l'etermann, 16 novembre 1909 , marée basse, dans les petites mares. Une femelle, trouvée par $\mathbf{M}$. le $\mathbf{W}^{\mathrm{r}}$ Liouville. Le corps était d'un brun rougeâtre. 
Dragage $1 \mathrm{~T}, 26$ novembe 1909, chenal de Roosen, devant loortLockroy: profondeur, bo it 70 mirtres. Une femelle, dont le corps, diu frun rougeitre, prosontait, sur toute sa longueur, uno ligne marrinale blanchatre, haissant au centre une bande d"un brun rougeattre.

shellands du sud, île du Roi-Grorge, baie de l'Amiranté, zfi décombe lo0!. Une fomello recueillie inare basse par M. lo Dr Liouville. Lecorps, d'un hrun rougrater, portait, au bond dorsal, deus lignes longitudimales banchitres. Ciettr femello atteignait 46 millimetres de longueur.

$$
\text { DEIAW/WHE. }
$$

\section{Paradexamine fissicauda Chevreux.}

1906. Paraderamine fissicnuda Chevreux (2), P. 88 , fig. in à 53 du texte. 1909. I'aradexamine fissicaula Chilton (6), p. 6i32.

Dragage III, 26 décombre l!08, chenal de Roosen; profondeur, 129 medres. Trois exemplaires, dont le plus grand mesumit 1. millimètres de longueur.

Dragage XII a, 1 7 novembro l!0!, lo long de la cote nord-est de l'île Petermann; profondemr, 70 a 90 mietres. Un exemplaire d'un très beau rouge, longde 6 millimètres.

Dragage XIY r, Is novembre 1909, chenal de Lemaire; profondent, 60 à 10 metres. In exemplaime, long de 11 millimetres el dont le corps était d’un beau rouge et les yeux brums.

Dragage XV, 26 novembre 1909, chenal de Roosen; profondenr, 60 à 70 mètres. Un exemplaire de 8 millimbles de lombrueur, de couleur générale rosée, avec des taches rouges de place en place et les yeux rougges.

Cette espece s'ócarte de toutes les antres formes commes de la famille des Deraminila par ses maxilles postericures, dont le lobe interne porto une rangée d'épines au bord interne.

$$
\begin{gathered}
\text { JAST/ll. } E \\
\text { Jassa Wandeli Cheveux. }
\end{gathered}
$$

1906. Jassa Wandeli cihevreux (2), p. 94, fig. 54 à 56 du texte. 
Ile Petermann. Port-Circoncision, 10 octobre 1909, dams des toufles d'Algues récoltées par 6 mètres de profondeur. Un jeune exemplare.

Ile Petermann, fer novembre 1909, marée basse, sous les pierres. Un mile adulte, long de 11 millinètres, une femelle ovigere. Leur corps étail d'un brun assez foncé.

Ile Petermann, 16 novembre 1909, marée basse, dans de petites mares. Sir males et quatre femelles, de couleur brune, trouvés par II. le Dr Lionville.

Les mailes recueillis par l'Expédition du "Francais" n'étaient pas
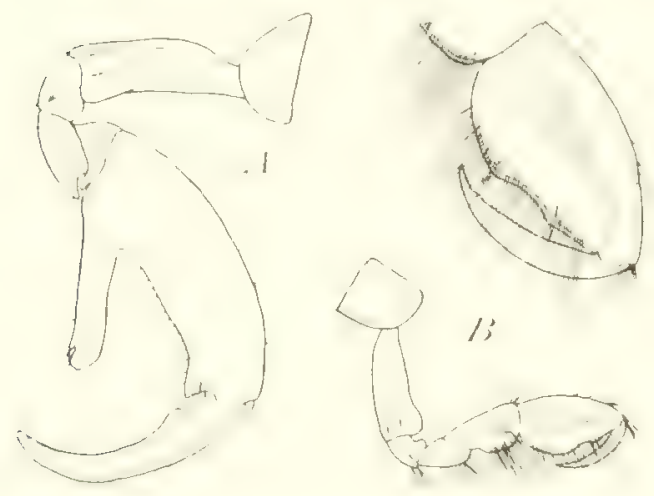

Fig. 61. - Jassa Mandeli, màle adulte.

A. gnathopode postérieur: B, gnathopode antirieur $(\times 10)$. completement adultes, ainsi que jai pu m'en assurer en leur comparant l'exemplaire trouvé le ler novembre 1909. Choz ce denier, les gnathopodes postérieurs ont pris, a peu de chose pres, la forme de cenx du vieux male de Iresse falcata (Montagu) (1). Wautre part, Jassa Wrameli s'en distingue par les caracteres suivants:

Les plaques coxales de la pro-

mière paire sont arrondies antérieurement.

Le carpe des gnathopodes antérieurs est plus allongé. Le propode, piriforme, présente, chez les exemplaires bicn adultes, une légére cehancrure au bord palmaire.

Le bord antérieur de l'article basal des péréiopodes des deux premières paires se prolonge infériemrement el forme un angle aigu avee le bord inferieur.

L'article basal des péréiopodes des deux dernières paires, relativement bitroit, présente un bord postérieur presque droit.

Labranche externedes uropodes de ladernierepaireneportepasdedents.

Le telson est moins aigu que chez. fulenta.

11 Jassa pulchella (Leach). Le lype de Montagu, conservé au Liritish Museum, a élé examiné pal. Mr's. Sexton, yui le déclare incontestahlement identique à Jassic pulchella Voir A. (). Warer (18), 1). 68, et E. W. SExtox (9 bis), p. 213]. 


\title{
1.1.1/ I I.1.
}

\author{
CYALIII.E. \\ Cyamus erraticus Roussel de Vauzème.
}

187:. Cyamus erralicus Lïtlien (7), p. 260, 1'. III, fig. 5.

1910. Cyamus erraticus stebling (13), p. 47\%。

Shetlands du Sud, ile Dreeption, 11 décembre 1909. Phusieur's exemplaires, des deux sexes, trouvés par $\mathbf{~ I}$. le lor Liouville sur une femelle adulte de Vegraptera Inmgimana.

Shetlands du Sud, ile Déception, Yankee IIarbour, 20 décembre 1909.

Nombreux exemplaires, des deux sexes, trouvés par $\mathbf{~ I I . ~ l e ~ l o r ~ l i o u v i l l e ~}$ sur un mâle adulte de Hegaptera longimana.

Paul llayer (8, p. 1.46, Pl. HT, lig. 40 à 42) a montré que le palpe des maxillipèdes, trìs développéchez l'embryon de C'yamus melosus contenu dans la poche incubatrice de la femelle, etrait rudimentaire chez retto femelle. L'examen d'un eertin nombere d'embryons el de jemes axemplaires, de différentes tailles, de Cyames erraticus m'a permis de constater que ce palpe ítait en-
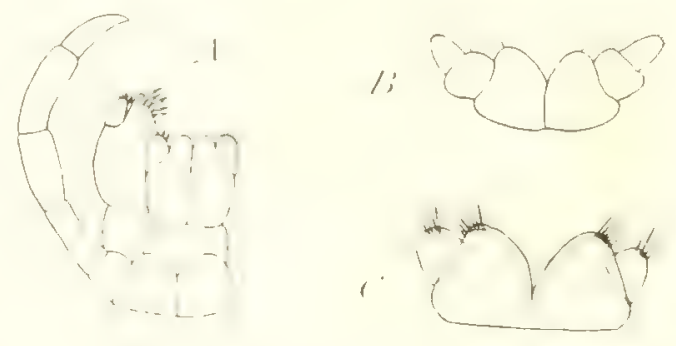

Fig. 6ะ. - Cymmus erraticus.

A. maxille antérieure, maxilles posterieures ef maxillipède, in siln, d'un jeune exemplaire de 3 millimetres de longueur: $B$, maxillipides d'un jeune exemplaint de \& millinetres: C. maxillipedes diun

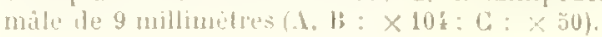
core completement développé chez des exemplaires de 3 millimètres de longueur. Il commence à satrophier et ne possede plus que deux arlicles chez un spécimen long de 4 millimètres, pour en arriver à ètre très count ef mianticulé che\% les adultes.

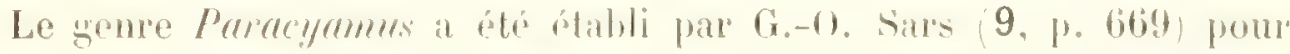
contenir des Cyames dont les gnathopodes sont contormés comme cenx des Cyamus, tandis que les maxillipedes sont mdimentaires, comme chez les Platycyamus. Le type du genre est l'aracyammes hropis Lïlken). 
184 AMPHINODES.

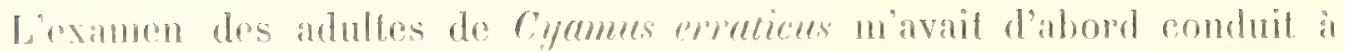

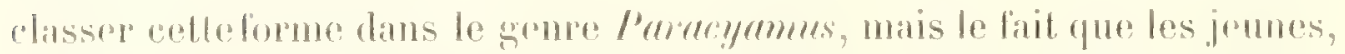
mome arpives ì mo certaine taille, possedent encore aux maxillipèdes un palpe bien constitué me semble suffisant poü la maintenir dans le genre cyomus. 


\section{INDEX BIBLIOGRAPHIQUE}

1. Chevreux (ED.). - Diagnoses d'Amphipodes nouveaux provenant de l'Expédition antarctique du "Français " (Bull. Soc. zool. de France, XXX, 1905, p. 159, et XXXI, 1906, p. 37, 76, 82 et 87$)$.

2. Chevreux (Ed.). - Crustacés Amphipodes [Expéd. Anlarcl. Française (1903-1905). Sciences nat, Doc. scientifiques, Paris, 1906].

3. Chevreux (Ev.). - Sur les Amphipodes des Expéditions antarctiques françaises (Comples rendus Acad. des Sciences, t. CLIII, 4 décembre 1911).

4. Chevreux (ED.). - Deuxième Expédition dans l'Antarctique, dirigée par le Dr Charcot, 1908-1910. Diagnoses d'Amphipodes nouveaux (Bull. Mus. d' Hist. Nat., 1912, no 4).

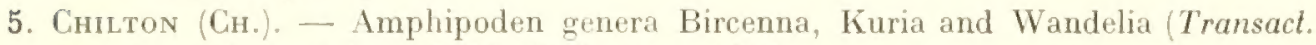
New-Zealand Inst., XLI, Wellington, 1909).

6. Chilton (CH.). - The Crustacea of the subantaretic Islands of New-Zealand (Subanlartic Islands of New-Zealand, art. XXVI, Wellington, 1909).

7. Lutken (Fr.). - Bidrag til Kundskah om Arterne af Slægten Cyamus Latr. [Vidensk. Selsk. Skr. (5), X, Copenhague, 1873].

8. MAyer (P.). - Die Caprelliden des golfes von Neapel und der angrenzenden MeeresAbschnitte. Nachtrag zur Monographie derselben Fauna und Flora des Golfes von Neapel, XVII, Berlin, 1890.

9. SARS (G. O.). - An account of the Crustacea of Norway. I. Amphipoda. Christiania, 1891-1895.

9 bis. Sexton (E. W.). - The Amphipoda collected by the "Huxley " from the North Side of the Bay of Biscay in August 1906 (Journ. of the Marine Biol. Associalion, vol. IX, $\mathrm{n}^{\circ}$ 2, octobre 1911 ).

10. Stebing (Th. R. R.). - Report on the scientific resuits of the voyage of H. M. S.. "Challenger " during the years 1873-1876. Zoology, vol. XXIX. Report on the Amphipoda. L dinburg, 1888.

11. Stebbing (Th. R. R.). - Amphipoda. I. Gammaridea (Das Tierreich, XXI, Berlin, 1906).

12. Stebbing (TH. R. R.). - Scientific results of the trawling Expedition of H. M. C. S. "Thetis ». Crustacea, V. Amphipoda (Mem. Australian Museum, IV, part 12, juillet 1910).

13. Stebing (Th. R. R.). - General Catalogue of South African Crustacea (Ann. South African Museum, VI, Londres, 15 décembre 1910).

14. Strauss (Erich). - Das Gammaridenauge. Studien über ausgebildete und rückgebildete Gammaridenaugen (Deutsche Tiefsee-Expedition, 1898-1899. XX. 1er fascicule, Iéna, 1909).

15. Walker (Alfr. 0.). - Amphipoda of the "Southern Cross » Antarctic Expedition (Linn. Soc. Journal, Zool., XXIX, 1903).

Expédition Chareot. - Chevreux. - Amphipodes. 
16. Walker (Alfr. O.). - Preliminary description of new species of Amphipoda from the "Discovery" Antarctic Expedition, 1902-1904 [Ann. and Mag. of Nat. Hislory (7), XVII, mai, juillet et août 1906).

17. Walker (Alfr. O.). - Amphipoda (Nat. Anlarcl. Expedition. Nalur. Hislory, III, Arthropoda. 1907).

18. Walker (Alfr. O.). - Notes on Jassa falcata (Mont.) (Transact. Liverpool Biol. Sociely, XXV, Liverpool, 1911). 
